Universidad de Lima

Escuela de Posgrado

Maestría en Administración y Dirección de Negocios

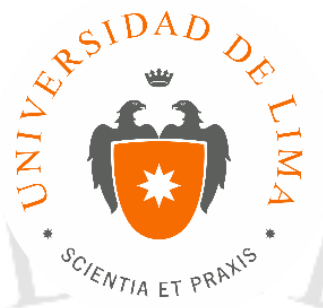

\title{
PROYECTO DE EMPRESA PARA IMPLEMENTAR UN BAR CON
}

\section{AUTOSERVICIO}

Trabajo de Investigación para Optar el Grado Académico de Maestro en

Administración y Dirección de Negocios

\section{Alexandro Najib Chahud Rivera \\ Código 20090225 \\ Gustavo Arnaldo Figueroa García \\ Código 19883210}

Asesor

Carlos Ricardo Chirinos Cuadros

Lima - Perú

Diciembre de 2018 


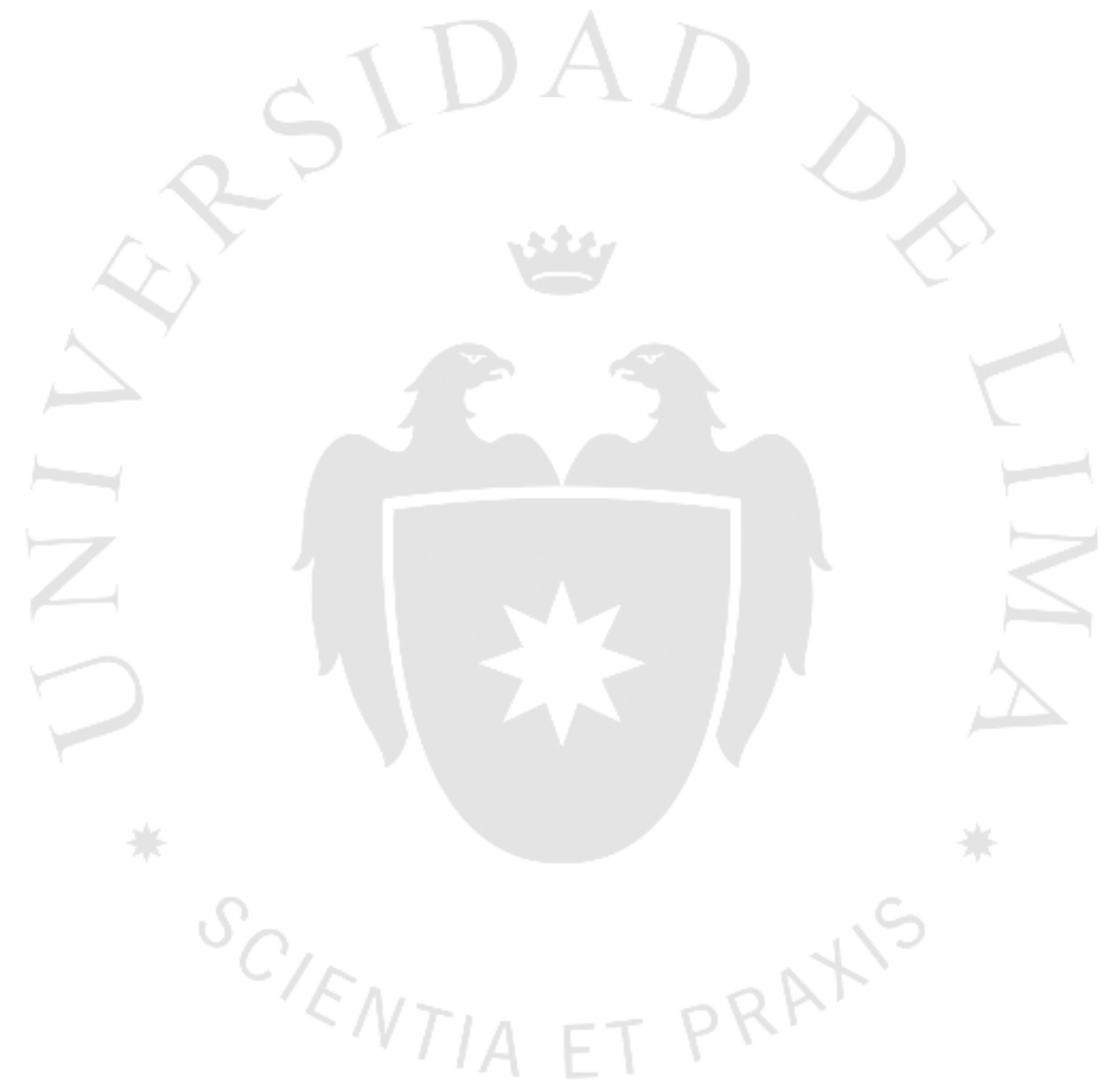




\section{INDICE GENERAL}

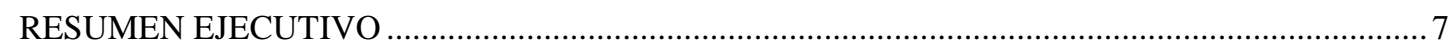

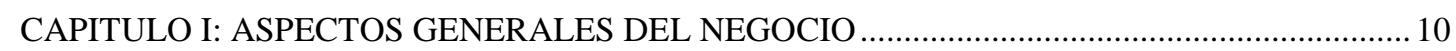

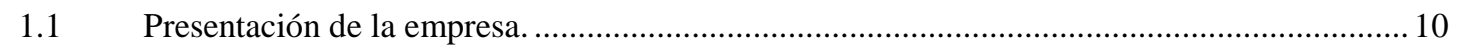

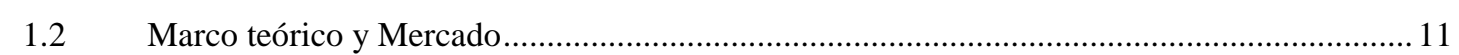

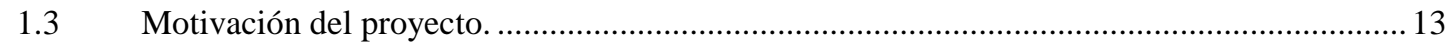

1.4 Percepción de la necesidad: análisis problema-solución. .......................................................... 14

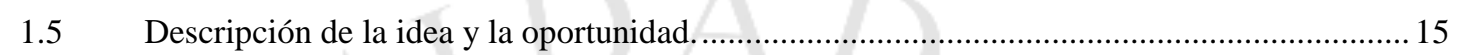

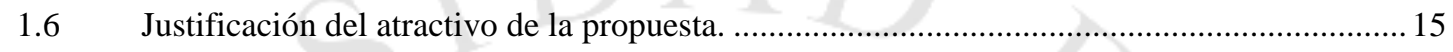

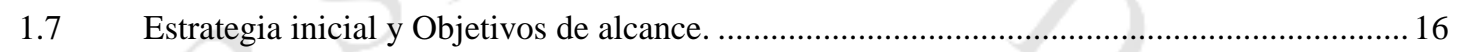

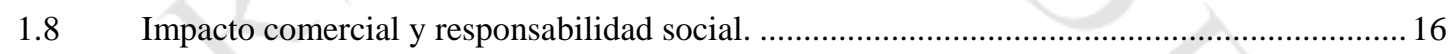

CAPITULO II: IDEA, INVESTIGACIÓN Y VALIDACIÓN DE SOLUCIÓN ..................................... 18

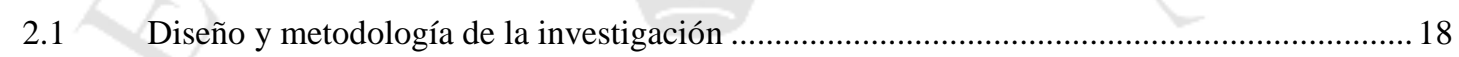

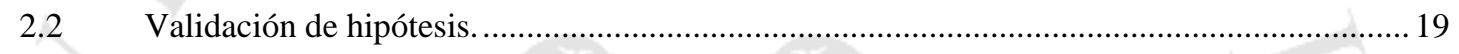

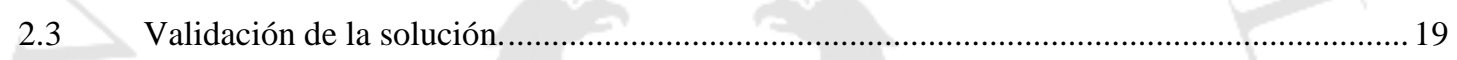

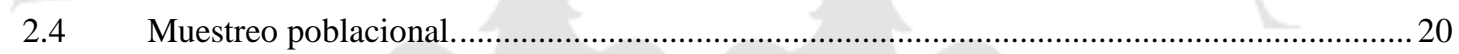

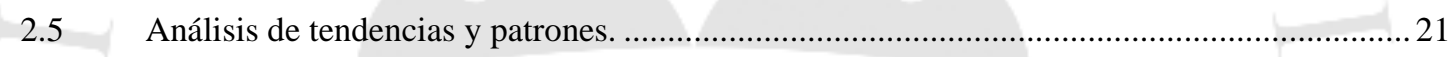

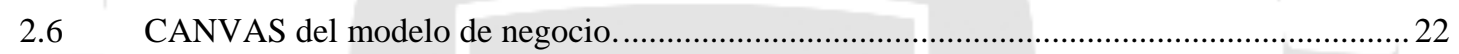

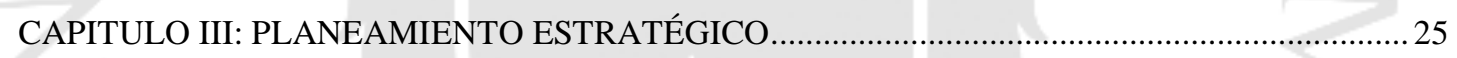

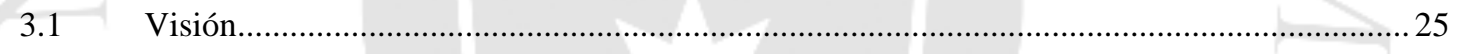

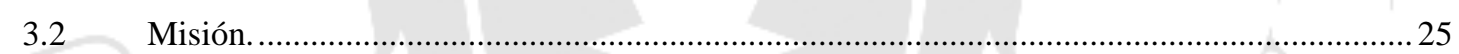

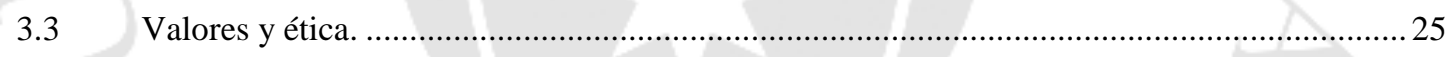

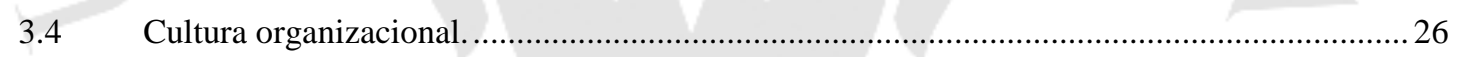

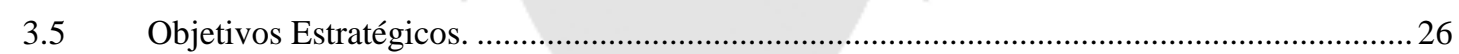

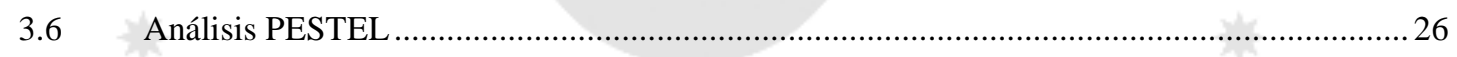

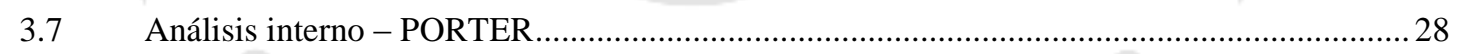

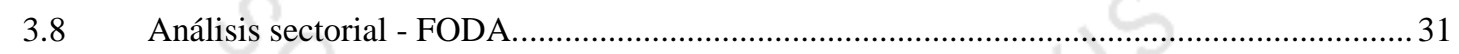

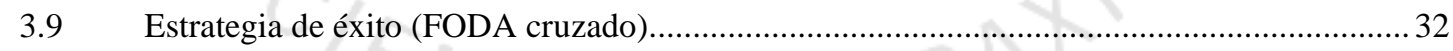

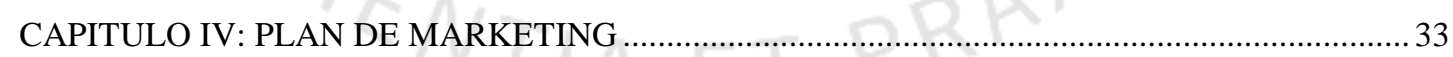

4.1 Planeamiento de Objetivos generales de Marketing ……………….................................... 33

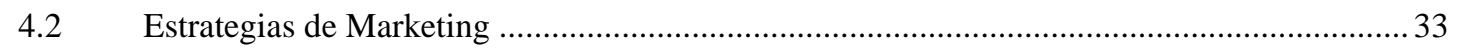

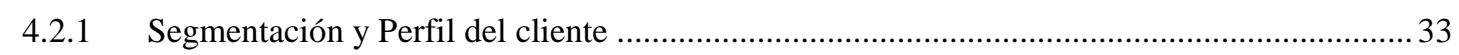

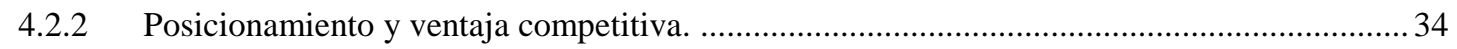

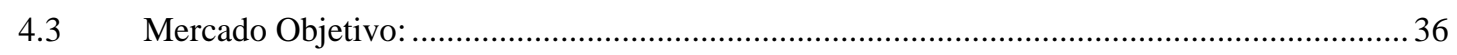

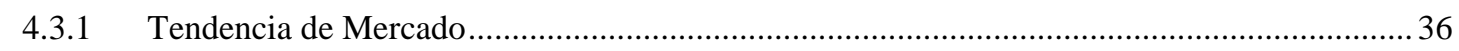

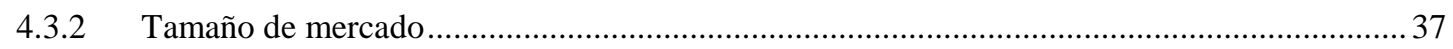

4.3.3 Mercado Objetivo …….......................................................................................... 38 
4.3.4 Identificación de agentes (clientes, usuarios, compradores, prescriptores, intermediarios,

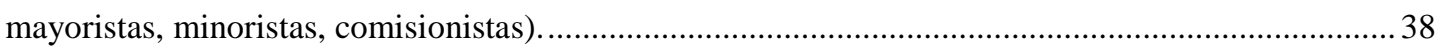

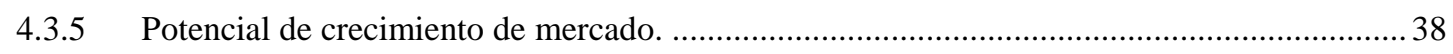

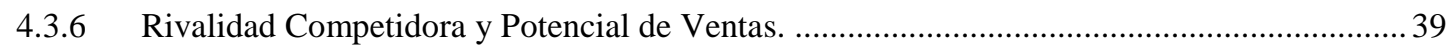

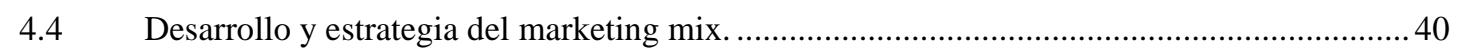

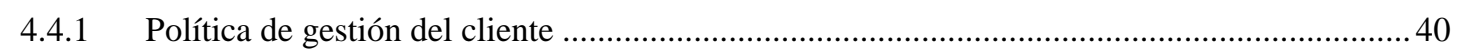

4.4.2 Estrategia de producto: especificaciones, calidad, variabilidad y diversificación. ..................4 41

Estrategia de precios: análisis de costos y precios................................................................. 42

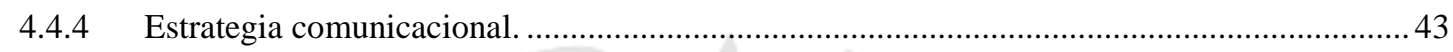

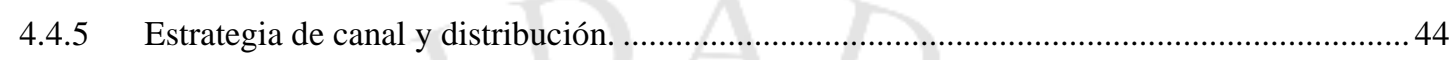

4.5 Plan de Ventas (objetivos anuales, alcance de la oferta) y Proyección de la Demanda

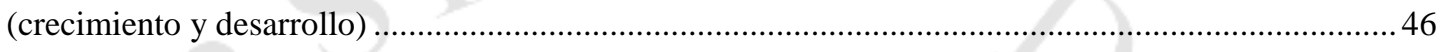

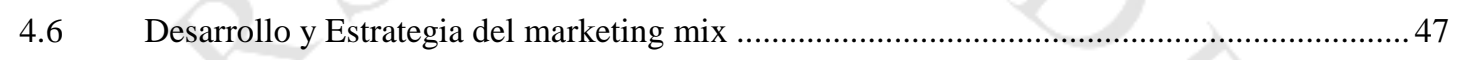

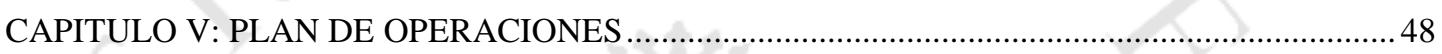

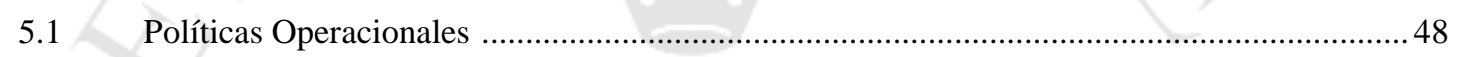

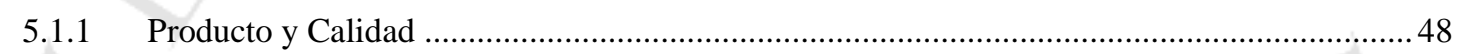

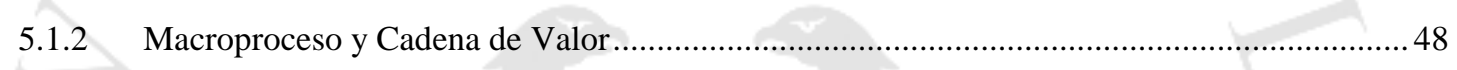

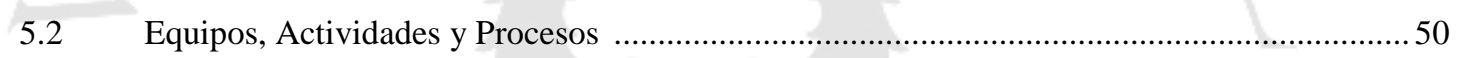

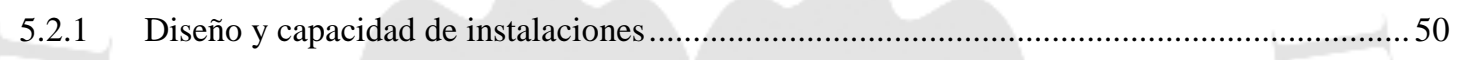

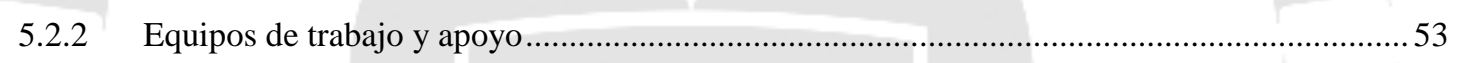

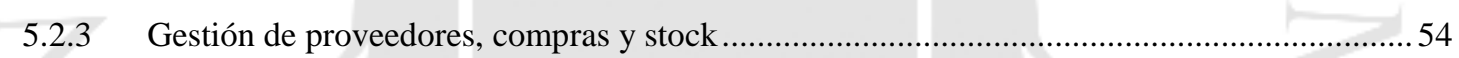

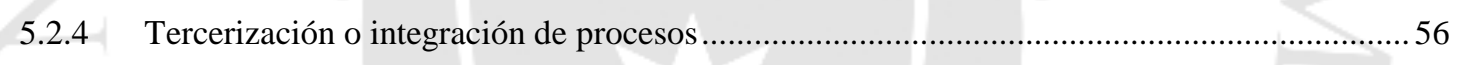

5.2.5 Proceso de elaboración de bienes y/o prestación de servicios ................................................57

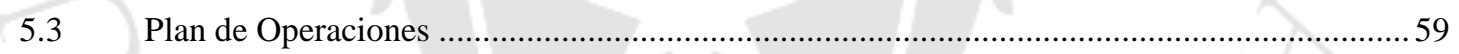

CAPITULO VI: ESTRUCTURA ORGANIZACIONAL Y RECURSOS HUMANOS .....................6 60

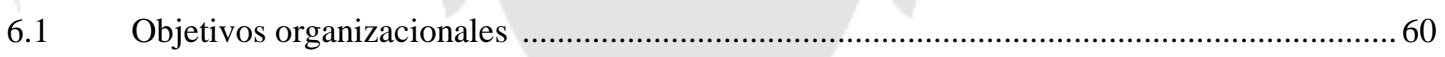

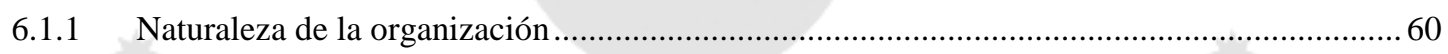

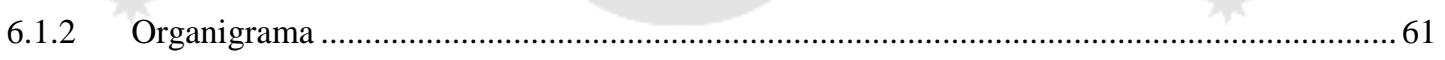

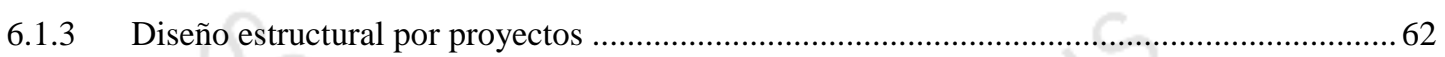

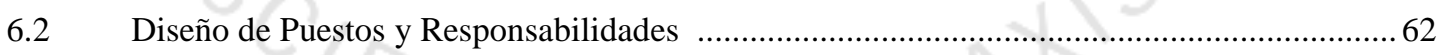

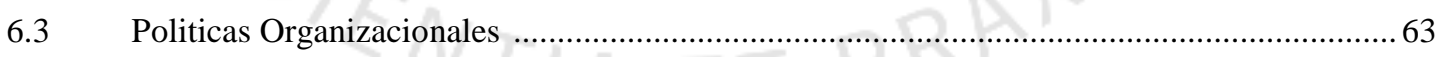

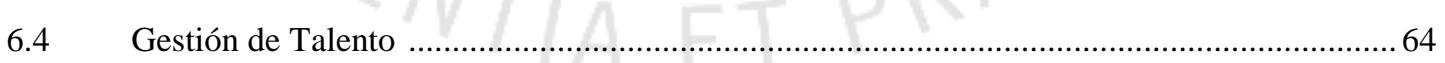

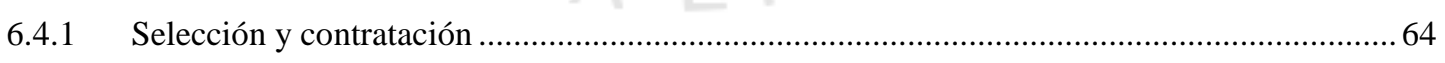

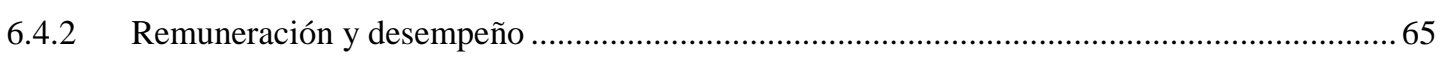

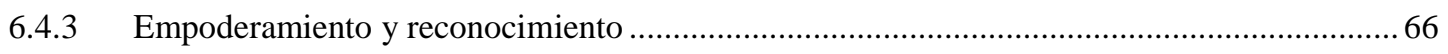

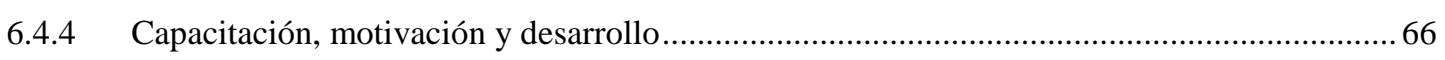

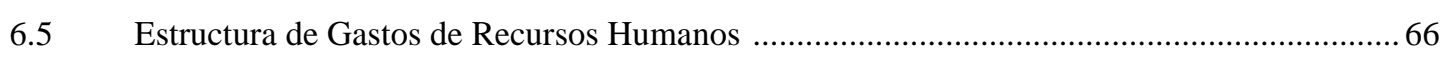

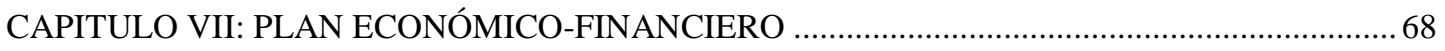

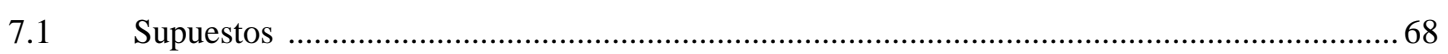

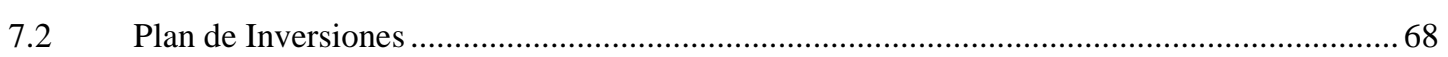




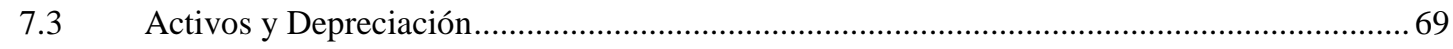

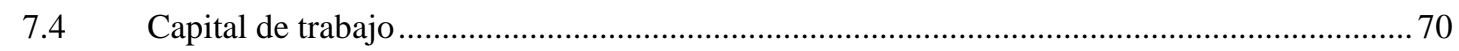

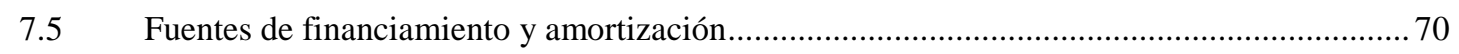

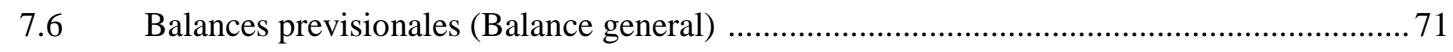

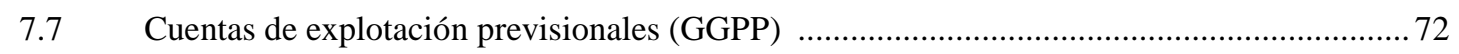

7.8 Análisis de viabilidad y rentabilidad financiera ............................................................. 73

7.9 Proyección de ventas y Flujo de Tesorería (Cash flow) .......................................................74

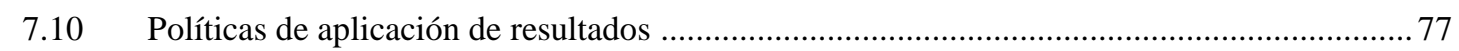

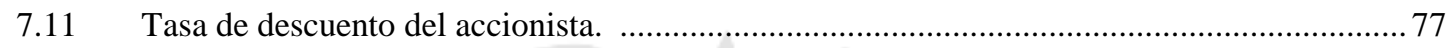

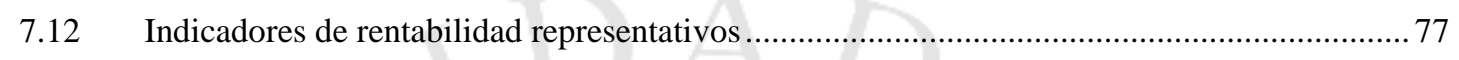

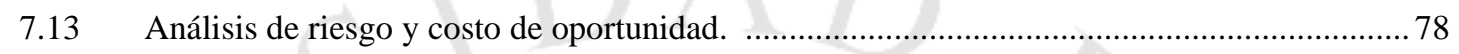

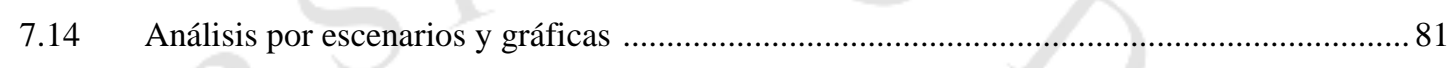

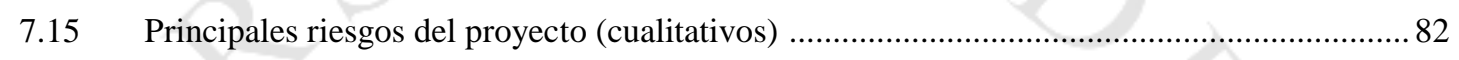

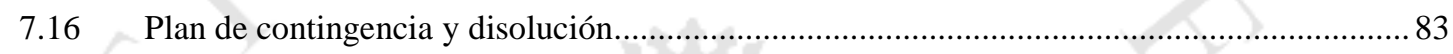

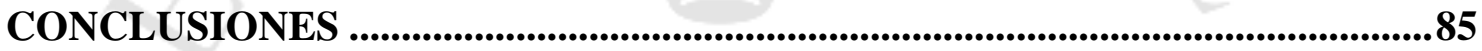

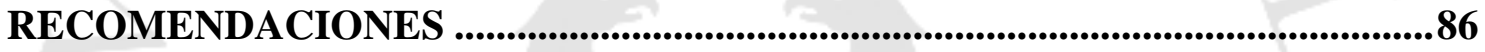

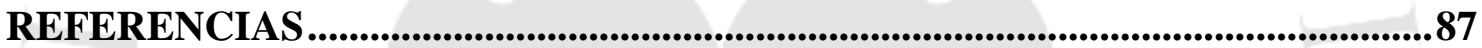

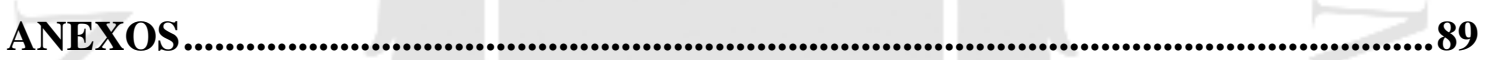




\section{INDICE DE GRÁFICOS}

Gráfico $N^{\circ} 1$ : Boletín Estadístico $\mathrm{N}^{\circ} 18$ - Setiembre 2018 .......................................................... 11

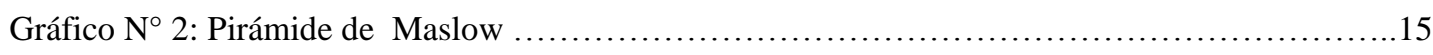

Gráfico $N^{\circ}$ 3: Población Económicamente Activa, según sexo, edad y nivel de educación alcanzado.20

Gráfico $\mathrm{N}^{\circ} 4$ Población estimada por distrito en Lima Metropolitana ..............................................2 21

Gráfico $N^{\circ}$ 5: Producto Principal, Real y Aumentado .....................................42

Gráfico $\mathrm{N}^{\circ}$ 6: Ubicación de principales bares en San Borja.......................................................... 45

Gráfico $N^{\circ} 7$ : Ubicación de principales bares en Santiago de Sutrco..................................................46

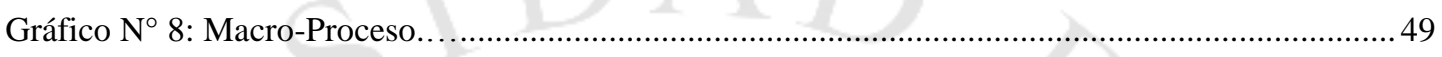

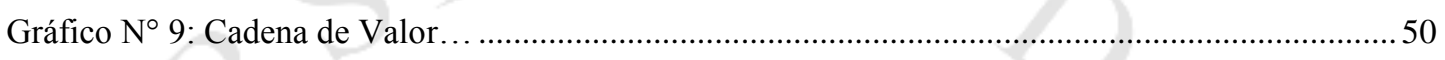

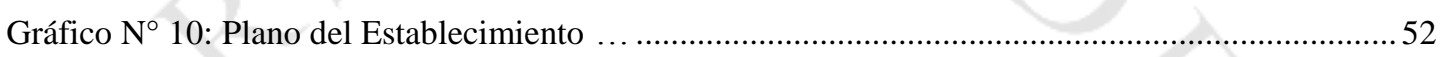

Gráfico N ${ }^{\circ}$ 11: Sistema de Surtidor de Cerveza (Beertap).............................................................5

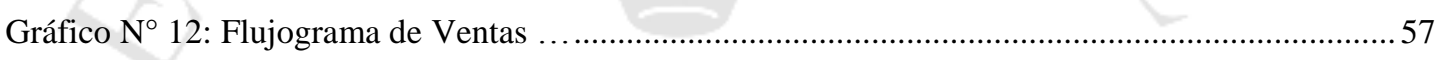

Gráfico $N^{\circ}$ 13: Flujograma de Compras y Producción ...............................................................58

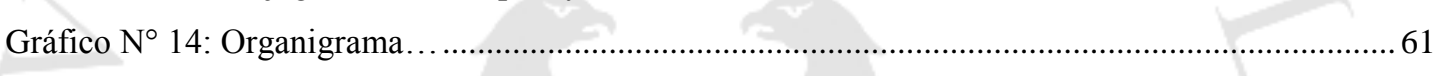

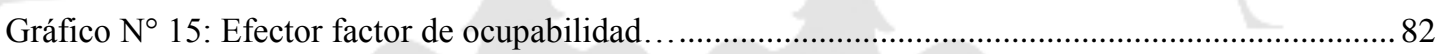




\section{INDICE DE TABLAS}

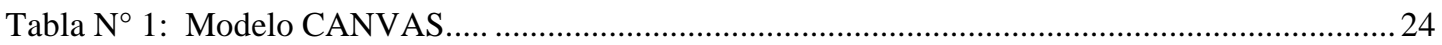

Tabla $\mathrm{N}^{\circ}$ 2: Matriz de Evaluación de Factores Externos ....................................................

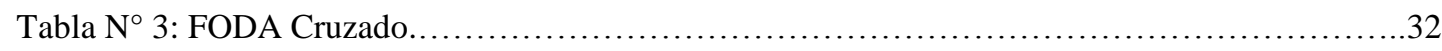

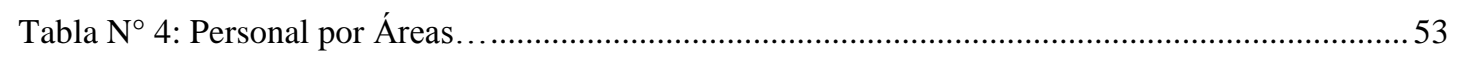

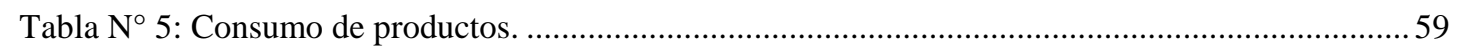

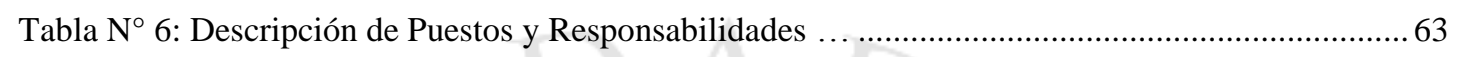

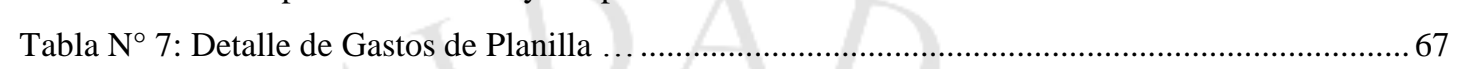

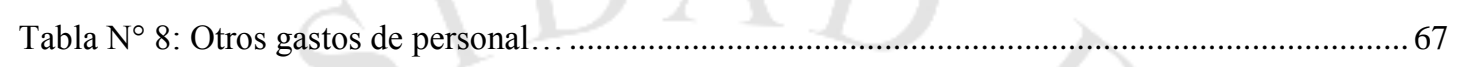

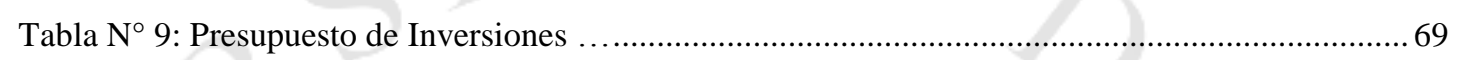

Tabla $\mathrm{N}^{\circ}$ 10: Tasas de Interés Activas Anuales Promedio del Sistema Bancario.................................. 71

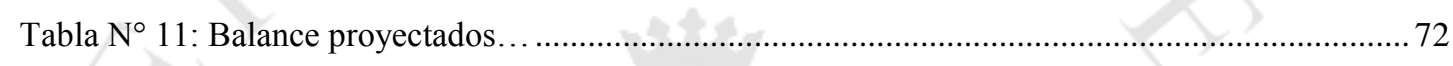

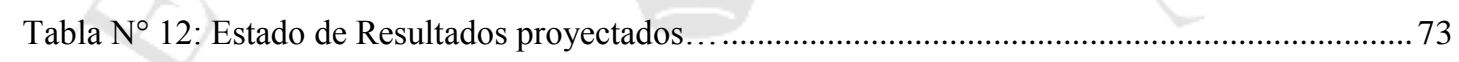

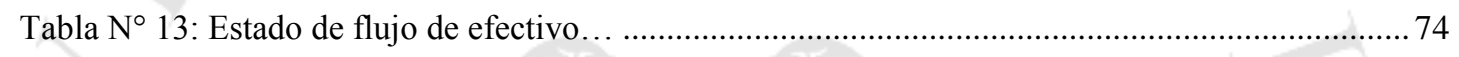

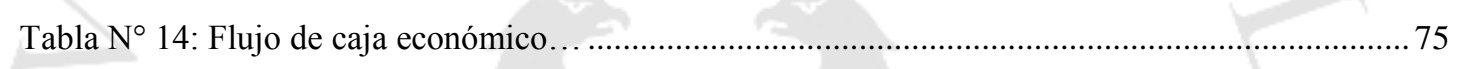

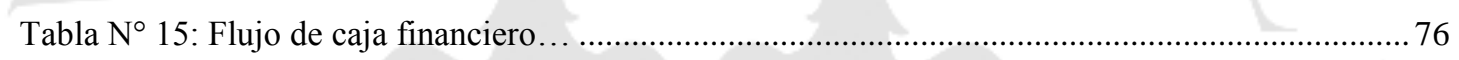

Tabla $\mathrm{N}^{\circ}$ 16: Cálculo de tasa de descuento................................................................................ 77

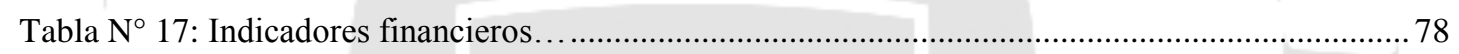

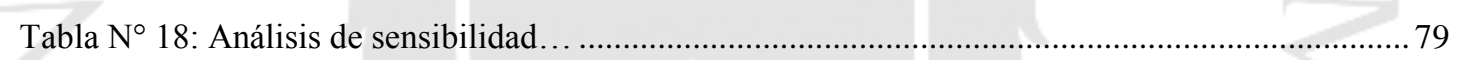

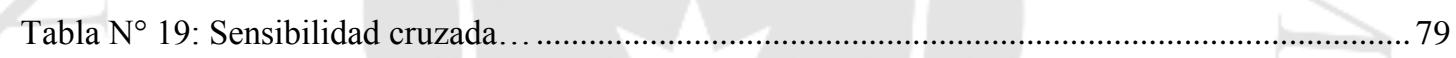

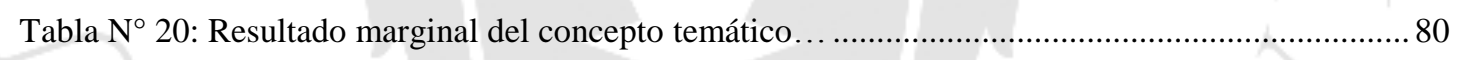

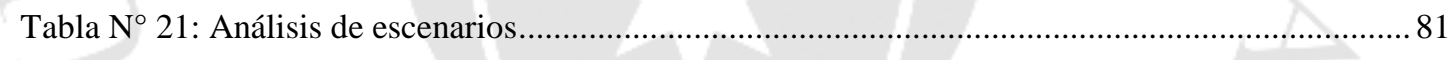

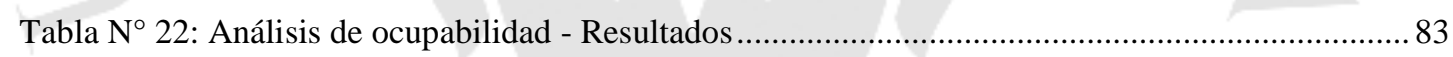




\section{Resumen Ejecutivo.}

Este documento tiene como objetivo probar la factibilidad de abrir un bar con autoservicio en una ubicación cercana a un centro empresarial en distritos como Santiago de Surco, donde se ofrecerán bebidas con y sin alcohol, en una carta variada de cocteles, y piqueos. Un elemento diferenciador de esta propuesta es que además del servicio convencional que brinda un bar, este establecimiento ofrecerá mesas surtidoras de cerveza (chopp) donde el cliente se podrá servir de manera fácil y cómoda cerveza en su propia mesa, pagando por los mililitros consumidos efectivamente, disminuyendo tiempos de espera en la toma de pedido y en la atención de la orden de pedido. El servicio estará conectado a un software o aplicación de gestión para este tipo de negocios que podrá incluir también la oferta de una tarjeta pre-pago del establecimiento para hacer las recargas que desee.

Otro elemento diferenciador es que el bar será un punto de encuentro donde la administración y el cliente podrán proponer eventos temáticos que incentiven la oferta de temas como música en vivo, stand up comedy, juegos y eventos como cata de vinos $\mathrm{u}$ otros licores, de tal forma que cree una comunidad de contactos en redes sociales y web.

Para lograr el objetivo antes mencionado se ha desarrollado en cada capítulo la viabilidad comercial, operativa y financiera para probar la factibilidad de la implementación del negocio. Para un mejor entendimiento se presenta un resumen de cada capítulo.

En el primer capítulo se explica en qué consiste la idea del bar con autoservicio, sus ventajas y cumplimiento de necesidades. Además se explica de manera introductoria los conceptos que incluidos en la propuesta que servirán como justificación de la misma y que posteriormente justificará el potencial de éxito de negocio. Adicionalmente se define el marco teórico indispensable para probar las hipótesis planteadas de estrategia, objetivos, de impacto social y comercial. En este capítulo se indica por ejemplo que con base a información estadística consultada, la tendencia de crecimiento que ha tenido el sector comercio, específicamente en restaurantes es de $2.75 \%$ a Julio de 2018, este crecimiento con respecto a Julio de 2017. Adicionalmente, se pudo comprobar que este incremento es motivado principalmente por el auge 
gastronómico en el país, el incremento de ofertas turísticas en este rubro y también por la aparición y decreto de días como: Día del Pisco Sour, del Chilcano, de la Algarrobina, etc

En el segundo capítulo se plantea el diseño y metodología con la que se prueba la hipótesis y solución del modelo de negocio del bar con autoservicio, se determina las herramientas cuantitativas de investigación de mercado (encuestas), así como el muestreo de las mismas para obtener fiabilidad en los resultados. Asimismo, se indican las observaciones realizadas con respecto a bares competidores, entrevistas a expertos en el rubro de bares-restaurantes. Por último se analizaron las tendencias y patrones, con el objetivo de proponer el business model canvas final del proyecto que ayudaron a perfeccionar el modelo de negocio.

En el tercer capítulo, se procedió a determinar los lineamientos sobre los cuáles se crea el bar con autoservicio como son la visión, misión y valores de la empresa, la cultura organizacional, así como sus objetivos estratégicos en base a los análisis externos: PESTEL, e internos: Cinco fuerzas de Porter, lo que permitirá identificar las fortalezas, oportunidades, debilidades y amenazas - FODA, y sus respectivas estrategias cruzadas de éxito.

En el cuarto capítulo, se incluyó todo lo relacionado a la determinación del mercado disponible, potencial y objetivo, sobre el que se determina la segmentación de mercado que permite plantear las estrategias de penetración en el mercado de bares, así como asegurar relaciones rentables con nuestros potenciales clientes.

Asimismo en este capítulo se identificó un mercado objetivo de 139,081 personas correspondiente a la cantidad de personas mayores de edad, con ingresos propios y que tienen educación superior universitaria residentes en los distritos de Barranco, Jesús María, La Molina, Miraflores, San Borja, San Isidro, San Miguel, Santiago de Surco y Surquillo, zona 7 según la Asociación Peruana de Empresas de Investigación de Mercado - APEIM y con base en información estadística sobre Población Económicamente Activa, según sexo, edad y nivel de educación alcanzado y a la Población estimada por distritos ambos para Lima Metropolitana. 
En el quinto capítulo, se determina el enfoque de operaciones de eficiencia planteada para el modelo de negocio propuesto. En base a esto, se analizó la forma más eficaz de establecer los procesos de venta y abastecimiento, así como la planificación con proveedores e inventarios que permita generar un mayor valor por recurso invertido. Esto incluye la definición de equipos de trabajo, procesos y actividades más apropiados para el negocio.

En el sexto capítulo, el enfoque está basado en la definición del organigrama y los perfiles por trabajador. Esto incluye determinar las políticas de gestión del talento, programa de remuneraciones, selección y contratación, así como la estructura de gastos de recursos humanos.

En el séptimo capítulo, se desarrolla el plan económico-financiero sobre el cual se realizaron la proyección de ventas que asciende a S/ 1,185,855 soles, como la estructura de costos y de gastos. Otro aspecto importante que se tomó en cuenta relacionado con la implementación del bar es la inversión total necesaria que se determinó en S/ 283,610 soles con base a la inversión fija tangible e intangible, siendo la inversión inicial calculada en un 25\% (relación deuda / patrimonio) de la inversión total requerida resultando en S/ 70,903 soles, la misma que en definitiva será financiada con capital propio y con capital de terceros, llámense estos últimos entidades bancarias del mercado local de oferta de capital. Teniendo en cuenta esto, se realizó el análisis del retorno de la inversión a través del cálculo de la Tasa Interna de Retorno (TIR), la determinación del costos de la inversión por sus siglas en inglés Weight Average Cost of Capital (WACC), la comparación de ambas, complementados con otros índices financieros, así como con la comprobación de estrategias adicionales de contingencia para escenarios favorables y desfavorables muestran la rentabilidad del negocio. La viabilidad financiera presentada en este capítulo se sustenta en la rentabilidad del negocio obtenida reflejada en un VAN financiero positivo de S/ 135,896, una TIR financiera de $37 \%$ mayor al WACC de resultante de $10 \%$.

Como últimos puntos se presentan las conclusiones alcanzadas en este proyecto de empresa, así como las recomendaciones respectivas. 


\section{Aspectos generales del negocio}

\subsection{Presentación de la empresa.}

Esta idea de negocio está basada en la apertura e implementación de un bar que ofrezca además del servicio y propuesta convencional, es decir cocteles, snacks y piqueos, una propuesta diferente, novedosa y útil, donde se le brinde al cliente mesas de autoservicio de cerveza donde el propio cliente se servirá directamente en mesa, la cual contará con un surtidor de cerveza (chopp), y pagará por lo efectivamente consumido en mililitros, este es un concepto que actualmente ha sido introducido muy incipientemente en el mercado peruano por pequeñas cervecerías que producen y venden directamente su propia cerveza artesanal como se verá más adelante en el punto 1.3 Motivación del proyecto de este documento. Este concepto de autoservicio en mesa permite mayor comodidad al cliente, mejores tiempo de atención y respuesta, así como menor uso de envases (desperdicios). Asimismo el bar ofrecerá actividades que incentiven la concurrencia de clientes con preferencias en temas de entretenimiento como música en vivo, shows de stand up comedy y otros. Como parte de la demostración de la viabilidad comercial de esta propuesta se realizó un estudio cuantitativo de mercado a través de una encuesta (ver resultado a pregunta 11 del Anexo 2) en la que se puede apreciar que la valoración y aceptación por el elemento temático como música en vivo y stand up comedy es del $62.6 \%$ del total de encuestados.

Es importante señalar que en el Perú la curva del sector comercio en lo que se refiere al rubro de restaurantes bar, cafés, etc. ha tenido un comportamiento ascendente en los últimos 7 meses del año 2018, periodo en el que la variación porcentual con respecto al año 2017 ha sido de $2.75 \%$, lo cual es una oportunidad para llevar a cabo esta empresa.

Asimismo, es importante señalar que al ser una propuesta nueva, no llevada a cabo en el país antes, es necesario realizar los estudios de mercado pertinentes para analizar, identificar el segmento de mercado conveniente para esta propuesta que asegure la rentabilidad esperada del negocio, la cual debe estar basada en indicadores económicos y análisis financiero que asegure la continuidad y vigencia de esta idea de negocio. 


\subsection{Marco teórico y Mercado (benchmarking y mejores prácticas empresariales).}

La experiencia en este tipo de negocios revisada en información secundaria relevante proveniente de reportes estadísticos, reportes de prensa especializada en el sector, indica que entre el año 2017 y el periodo de Enero a Julio de 2018 el sector de servicios, en específico en lo que se refiere a Restaurantes, ha existido un incremento del orden de $2.75 \%$, cerrando a Julio con una variación positiva de $2.56 \%$ como se puede apreciar en el Gráfico $\mathrm{N}^{\circ} 1$ presentado. (INEI, 2018).

Gráfico $N^{\circ} 1$ : Boletín Estadístico $N^{\circ} 18$ - Setiembre 2018

PRODUCCIÓN DEL SECTOR RESTAURANTES

(Variación porcentual respecto a similar mes del año anterior)

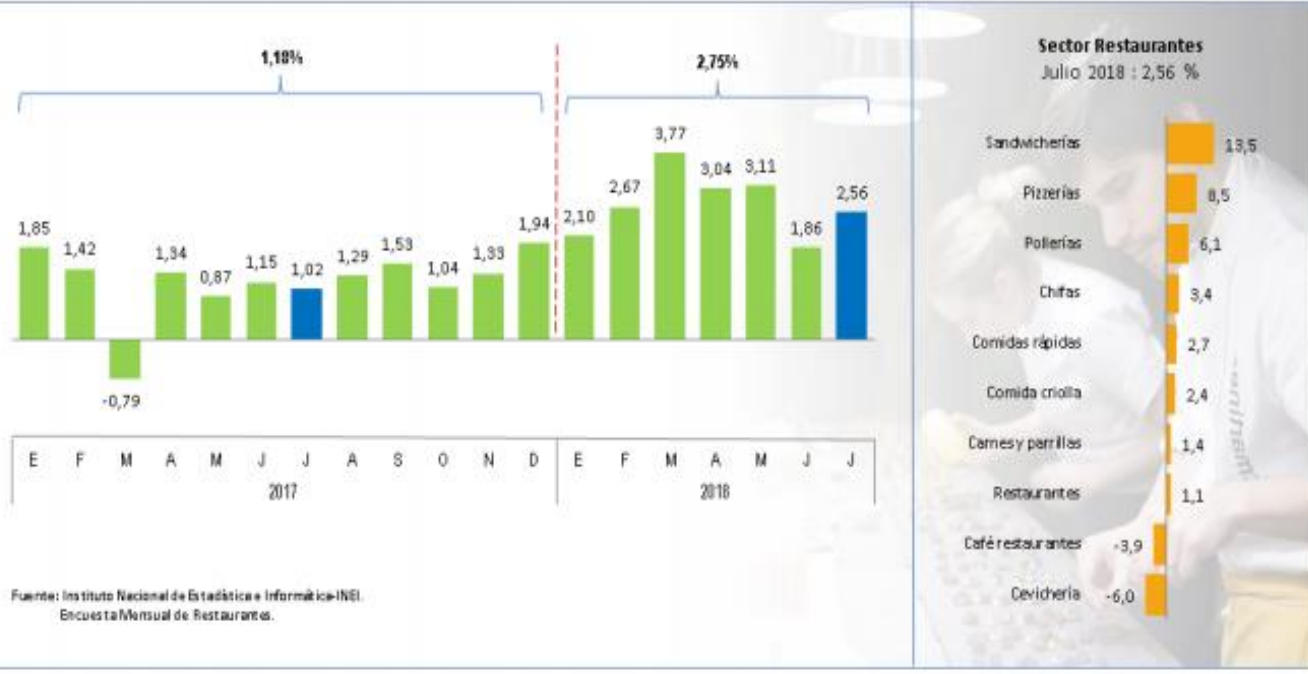

Fuente: Instituto Nacional de Estadística e Informática - INEI

En lo referente al Autoservicio, que consiste en la oferta de mesas con surtidores de cerveza tipo "chopp" se revisó información proveniente de internet con dos proveedores que ofrecen este tipo de mesa de autoservicio de cerveza, siendo el más completo y que entrega una solución integral es el de eBeer system (http://www.ebeersystem.com/), donde se explica en detalle las bondades y características del sistema, donde también se puede solicitar presupuestos de los productos, servicios y paquetes que ofrecen.

De acuerdo a una publicación del diario El Comercio del 30 de septiembre del 2018, se destacan 7 bares que ofrecen como diferenciador música en vivo, que de acuerdo a nuestro estudio de mercado es la primera opción temática que prefieren los potenciales clientes (ver Anexo $\mathrm{N}^{\mathrm{a}} 2$ 2: respuesta a la pregunta 11). La mayoría 
de estos bares están dirigidos a un público joven en lo cuáles se intenta atraer la mayor cantidad público y se encuentran concentrados en los distritos de Barranco y Miraflores, por lo que existe una oportunidad de negocio para un bar dirigido a un público de mayor edad y con apreciación por la comodidad y atención.

Este análisis tendrá que ser complementado con información específica sobre bares, generada por los gestores de esta idea de negocio y/o por terceros, siendo la fuente de estos últimos provenientes de empresas especializadas en estudios económicos y de mercado para obtener conclusiones respecto a la recolección de data de primera mano y poder concluir sobre la viabilidad y vigencia en el tiempo de este negocio.

A lo largo de la investigación se utilizarán diversas herramientas que permitirán el análisis correcto sobre las variables que impactan en el negocio.

Para nuestro análisis estratégico de los factores externos se utilizará el análisis del macro entorno desarrollado por Kotler y Keller (2012), en el cual nos indica que como empresa se deben monitorear 6 fuerzas claves: demográfica, económica, sociocultural, natural, tecnológico y político legal. Dentro del mismo, también se distingue los conceptos de moda pasajera (imprevisible y de corta duración), tendencias (definido como secuencia de hechos con cierta intensidad y duración y mega tendencias (gran cambio que se forma lentamente y que influye en nosotros en el largo plazo).

Para calcular la demanda se aplicarán los conceptos de mercado potencial, definido como un conjunto de consumidores interesados por la oferta de mercado; mercado disponible como consumidores que tiene accesos y capacidad económico además del interés sobre una oferta de mercado; y mercado meta como porción calificado a la cual se dirige la empresa (Kotler y Keller, 2012).

También se abarcará el concepto de cultura empresarial, de acuerdo a lo descrito por Javier Calvo Pérez, la cultura nos indica a seguir en el futuro, así como los lineamientos para plantear estrategias y como todos los miembros de la organización reaccionarán ante diversas situaciones, incluso ayudará frente a supuesto no establecidos, de forma que esto no afecte su personalidad. En base a esto define el concepto de "conciencia colectiva" como un grupo de personas que 
responden de forma similar ante una situación o en aspectos personales, ya que estarán identificados con su líder. (Calvo Perez, 2012)

Para la evaluación financiera, se utilizará el concepto de valor presente neto (VPN o NPV por sus siglas en inglés) como principal herramienta para la toma de decisiones. Según Ross et al. (2012) éste se define como el cálculo de la diferencia entre la suma de flujos descontados futuros y el costo inicial del mismo. Como regla de inversión se define que si este indicador es mayor a 0 se acepta el proyecto, pues genera valor en el tiempo de ejecución. Sobre los mismos flujos descontados se calcula la Tasa Interna de Retorno que es el porcentaje de rentabilidad del proyecto y tiene como principal regla que debe ser mayor a la tasa de descuento, pues esta representa el costo de la inversión de capital. Si bien ambas reglas se complementan siempre se priorizará la primera” (p.135).

Adicionalmente, para los temas relacionados a determinación de costos de capital se utilizará el modelo de valuación de activos de capital (CAPM por sus siglas en inglés) que se define como "una fórmula que determina que el rendimiento esperado de un valor es igual a las tasa libre de riesgo más el beta multiplicado por la diferencia entre el rendimiento esperado y la tasa libre de riesgo (prima de capital). Este modelo nos indica que el rendimiento está relacionado con su beta (indicador de riesgo que muestra el comportamiento de los rendimientos de la empresa frente al mercado) de manera lineal” (Ross et al., 2012, p.392).

\subsection{Motivación del proyecto.}

La propuesta está motivada por la identificación de una necesidad de entretenimiento de los consumidores del servicio de bar o de clientes asiduos a este tipo de establecimientos a satisfacer. Otro punto a considerar es que el modelo de negocio de cualquier bar puede ser revisado y analizado con la finalidad de ser replicado y/o mejorarlo. La propuesta que aquí se presenta ha incluido un elemento diferente e innovador: el autoservicio de cerveza a través de un grifo surtidor a ser consumido directamente por el cliente en su mesa acondicionada para este fin. En el país, específicamente en Lima, existen bares que ofrecen el autoservicio de cerveza como: "Sierra Andina" en Miraflores y "Barranco Beer Company" en el distrito del mismo nombre, este último fue mencionado en el artículo siguiente:"10 bares en Lima para disfrutar cerveza artesanal" (RPP, 
2018). Sin embargo, se puede apreciar con claridad que la propuesta ofrecida por estos bares es diferente a la propuesta que en este proyecto se ofrece. La propuesta de bar desarrollada en este proyecto tiene principalmente como promesa el ofrecer una experiencia nueva en un ambiente acogedor y funcional, basada en el autoservicio de cerveza en mesa, sistema que incluye un software que registra la cerveza consumida en mililitros y que permite la liquidación rápida y fácil de la cuenta a pagar por el cliente. El otro elemento que esta propuesta ofrece es el temático como: música en vivo, stand up comedy, catas, u otra que sea de la preferencia del cliente, de tal forma que la estadía de cliente en el bar sea más agradable y entretenida.

\subsection{Percepción de la necesidad: análisis problema-solución.}

De acuerdo a la Pirámide de Maslow sobre la clasificación de necesidades (ver Gráfico $\mathrm{N}^{\circ}$ 2) se puede apreciar que el entretenimiento y diversión se ubican en el tercer nivel, donde están ubicadas las necesidades sociales y de aceptación social. Basados en esto podemos afirmar que el asistir a un bar es una forma de satisfacer esta necesidad de entretenimiento y de aceptación social, necesidades humanas que normalmente son satisfechas luego de asegurar las necesidades fisiológicas básicas y las necesidades de protección. Basados en lo anteriormente expuesto se identifica una primera limitante que está relacionada a la determinación del segmento objetivo al cual se apuntará, el mismo que se definirá con el estudio de mercado respectivo basados en el comportamiento de los diferentes niveles socio-económicos con los que se cuenta en Lima Metropolitana. La segunda limitante que se identificó es lo relacionado al elemento de autoservicio de cerveza, el cual es una propuesta relativamente nueva en el país. Sin embargo, en respuesta a esta limitante la propuesta de bar ofrecida descansa en ofrecer un valor agregado a lo propuesto por un bar clásico (elemento que también es ofrecido por la presente propuesta), enfocado justamente en el conjunto del autoservicio de cerveza así como la oferta de eventos temáticos como: música en vivo, stand up comedy, catas, juegos y propuestas que nazcan de las preferencias del cliente. 


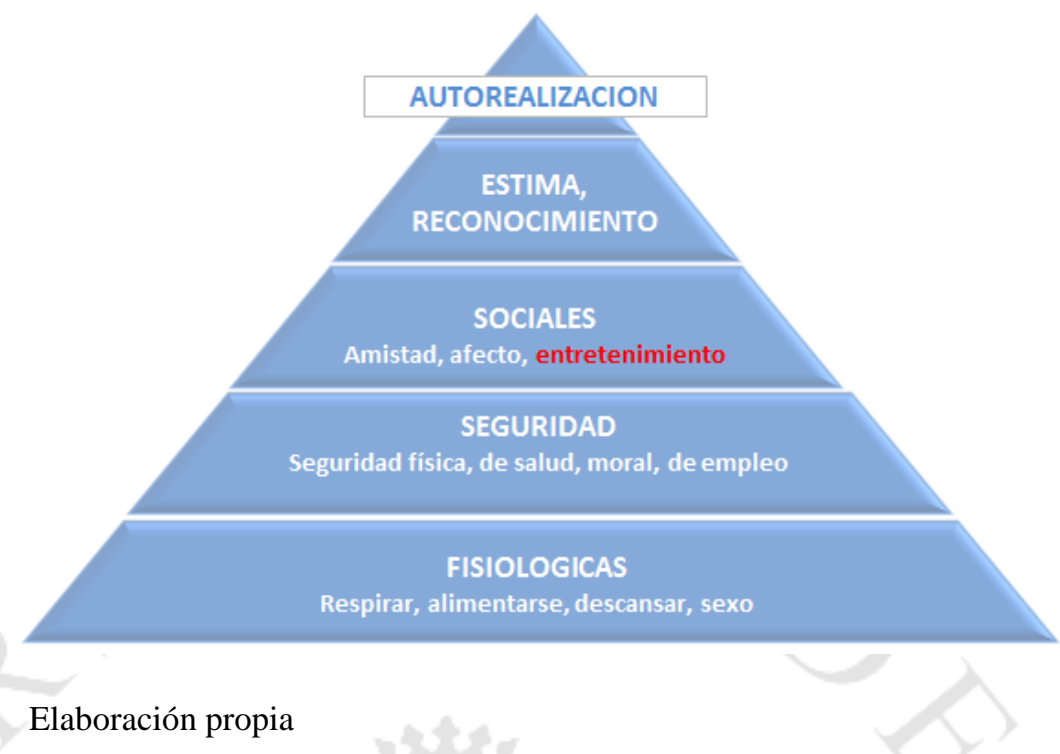

\subsection{Descripción de la idea y la oportunidad.}

El modelo de negocio de bar que se ofrece con este agregado de autoservicio de cerveza y de eventos temáticos puede encontrar su lugar en el mercado de bares y restaurantes de la ciudad de Lima y del país. Tomando como base el Boletín Estadístico $\mathrm{N}^{\circ} 18$ de Setiembre 2018 del INEI relacionado a la producción de restaurantes se puede ver que en los últimos años, específicamente desde el año 2017 y a Julio del año 2018 ha existido un incremento del sector comercio, en el rubro de restaurantes de $2.75 \%$ a Julio 2018 (ver Gráfico ํำ, pág.11). Además de que el segmento de mercado al que nos dirigimos es amplio y diverso, creemos que con las estrategias de marketing, de operación, de gestión, de análisis financiero y de inversión adecuados es posible tener resultados óptimos de rentabilidad.

\subsection{Justificación del atractivo de la propuesta.}

Esta propuesta es innovadora en el rubro, incentiva la relación de ganar-ganar entre cliente y los propietarios del establecimiento, a través de eventos temáticos y lo innovador del producto ofrecido.

Como se indicara antes, el bar contará con autoservicio de cerveza (chopp) a través de una maquina surtidora de cerveza ubicada en mesa, donde el cliente podrá servirse sin necesidad que haya un mesero que le tome la orden, que en términos de tiempo de atención supone una reducción, también podrá ver cuánto 
consumió y en consecuencia cuanto es lo que pagará por el producto. Para el propietario no habrá desperdicio del producto y no manejará botellas retornables.

Asimismo, esta propuesta ofrece la posibilidad de expansión de locales en la ciudad de Lima en el mediano y largo plazo. Esto se podrá validar con un análisis de resultados financieros de otra rueda de inversión que no está en el alcance de esta propuesta de empresa.

\subsection{Estrategia inicial y Objetivos de alcance.}

El éxito de este negocio dependerá del correcto análisis y medición que se haga de las variables internas y externas que afecten al negocio y al sector económico al que pertenece; es decir saber por ejemplo ¿cuál es la frecuencia con la que una persona asiste a un bar?, ¿de qué edad es?, ¿a qué sector socio-económico pertenece?, ¿cuánto dinero está dispuesto a gastar en el establecimiento?, ¿dónde prefiere la ubicación del mismo?, ¿va solo o acompañado?, ¿qué regulaciones y disposiciones legales se deben cumplir para la apertura del establecimiento? Estas preguntas serán respondidas a través de un análisis PESTEL del Macro entorno, del análisis y aplicación de técnicas de macro y micro segmentación, de la aplicación de herramientas de estudio de mercado como encuestas, entrevistas, y otras que se irán incorporando a la realización de esta idea de negocio.

Una vez concluida esta primera etapa se utilizarán las buenas prácticas de gestión que se deben aplicar en este tipo de negocios, orientado ciertamente al control eficiente de los costos e inventarios, a la maximización de la rentabilidad sin descuidar el control de calidad del almacenamiento y condiciones de los suministros, así como del servicio.

\subsection{Impacto comercial y responsabilidad social.}

La propuesta de valor ofrecida a través de la creación de un bar de las características indicadas en los puntos anteriores busca tener un impacto en el mercado de esta clase de establecimientos. Es un modelo de negocios innovador, que rompe con los esquemas convencionales aplicados en un bar, como se verá en el análisis de competencia (punto 4.3.6), el concepto de bar autoservicio no 
existe en el mercado peruano, y de acuerdo a la encuesta aplicada los potenciales clientes muestran un interés inicial sobre el mismo (ver anexo 2).

Las líneas de ingresos que se obtendrán con este modelo es variado: ingresos producto de la venta de cerveza en máquinas surtidoras con autoservicio, ingresos por venta de tarjetas para recargas en autoservicio de cerveza, ingresos por organización de eventos temáticos, ingresos por venta de cócteles y piqueos a la carta. El tener estas líneas de ingresos identificadas suponen costos relacionados que pueden ser registrados de manera rápida y controlados de manera eficiente. Teniendo esta data en un software de gestión integral aplicado a este rubro es muy fácil hacer seguimiento de los costos y márgenes de manera rápida y oportuna, lo que trae como consecuencia controlar eficientemente suministros y costos, y tener los márgenes estimados en la etapa de planeamiento inicial.

Por otro lado, contar con una base de datos de clientes y usuarios producto del servicio ofrecido, se convierte en una red de contactos privilegiada donde podemos identificar data como: sexo, edad, frecuencia de asistencia al establecimiento, importes gastados en el establecimiento por tipo de producto, preferencia de comida y bebida, clientes interesados en proponer eventos temáticos, etc.

Por último, y no por eso menos importante, el objetivo es brindar a los clientes un espacio agradable, accesible, con autoservicio y con una atención rápida y amable, donde puedan reducir el estrés luego de las clases, de la jornada laboral, donde se puedan encontrar con amigos y familia, y divertirse con el plus que descansa en la oferta de eventos temáticos que inclusive ellos puedan proponer a la administración del establecimiento. 


\section{Idea, Investigación y Validación de solución}

\subsection{Diseño y metodología de la investigación.}

De acuerdo a las necesidades identificadas en el capítulo 1, se planteará la siguiente metodología de investigación para formulación de la hipótesis y validación de la misma:

Necesidad de mercado: Personas buscan un lugar de entretenimiento con la mayor percepción de comodidad posible, que se diferencie en todo aspecto con las propuestas actuales.

Metodología de investigación de mercado: Se utilizarán herramientas estadísticas de marketing tanto cualitativas como cuantitativas para confirmar el mercado potencial, identificar tendencias y validar la viabilidad comercial.

- Encuestas (cuantitativo): En base a las dos herramientas anteriores, se elaborará un cuestionario de preguntas que nos permita confirmar adecuadamente el perfil del cliente al cuál se apunta, de forma que podamos definir un mercado potencial y objetivo sobre el cuál se realizarán las proyecciones de viabilidad económica. (ver Anexos Nros.1 y 2 , página 72 y 74 , respectivamente).

- Visitas de Observación (cualitativo) de bares restaurantes: Se planteará una guía de entrevistas (ver Anexo 3) que abarcará preguntas sobre funcionamiento del negocio, conocimiento de los clientes, preferencias, necesidades por cubrir y otros conceptos que nos permitirá visualizar mejor y enfocarnos en el cumplimiento de esta propuesta.

- Entrevistas a expertos (cualitativo): Se realizarán entrevistas a expertos en el rubro de bares restaurantes en cuanto a la administración y operación del negocio, así como en lo que se refiere a asesoría en barra y licores y en decoración. (ver Anexo 4).

- Entrevistas a profundidad (cualitativo); Se realizarán entrevistas a profundidad a potenciales clientes de un bar autoservicio, por medio de las cuales se buscará conocer en detalle sus preferencias y opiniones con el objetivo de validar si la propuesta de negocio ofertada les parece novedosa, si asistirían a un bar de las características propuestas (autoservicio y elementos temáticos), y sacar las conclusiones respectivas. (ver Anexo 5). 
Estudio de viabilidades: La parte final de la investigación abarcará la validación de la viabilidad económica, operativa y comercial, así como el plan de marketing que realice el soporte correcto del proyecto de negocio.

\subsection{Validación de hipótesis.}

En base la necesidad aterrizada en el punto anterior, se plantean las siguientes hipótesis de investigación:

Hipótesis principal (Hi): "El bar con autoservicio logra satisfacer la necesidad encontrada de un lugar de entretenimiento y ocio orientado a la comodidad, con una propuesta innovadora que permitirá crear relaciones de intercambio y redituables con los clientes, logrando una viabilidad comercial, operativa y económico-financiera".

Esta hipótesis principal se traducirá en la factibilidad del negocio, la misma que será posible teniendo en cuenta las siguientes hipótesis secundarias:

Hipótesis secundaria 1: "La estrategia comercial está alineada adecuadamente al perfil del cliente potencial, quienes son personas de 25 años a más con recursos propios están interesados en asistir a un bar con autoservicio de cerveza de propuesta temática".

Hipótesis secundaria 2: "La operación soporta adecuadamente el plan de ventas mediante procesos eficientes de atención y servicio, así como de preparación de los productos incluidos en la carta del bar el negocio".

Hipótesis secundaria 3: "El plan de recursos humanos está alineado con los objetivos del negocio"

Hipótesis secundaria 4: "El bar es viable desde el aspecto económico-financiero".

Hipótesis nula (Ho): “Un bar con autoservicio de las características señaladas no es factible".

\subsection{Validación de la solución.}

El modelo de negocio planteado posee una propuesta de valor viable orientado a la satisfacción del cliente y sus necesidades, manteniendo un esquema operativo y de procesos eficiente que será la base para un esquema financiero atractivo para 
los accionistas, entre otros stakeholders. Esto será validado en los resultados de la investigación de mercado y el análisis de la viabilidad económica.

\subsection{Muestreo poblacional.}

En términos socioeconómicos, el proyecto apunta al perfil de población ocupada con educación superior universitaria en Lima Metropolitana que residan en los distritos de Barranco, Jesús María, La Molina, Miraflores, San Borja, San Isidro, San Miguel, Santiago de Surco y Surquillo. Es importante señalar que los distritos indicados en su mayoría están clasificados en la zona 7 según la Asociación Peruana de Empresas de Investigación de Mercado - APEIM, y corresponden a un nivel socioeconómico A y B.

Gráfico $\mathrm{N}^{\circ}$ 3: Población Económicamente Activa, según sexo, edad y nivel de educación alcanzado

INDICADORES LABORALES DE LIMA METROPOLITANA

POBLACIÓN OCUPADA, SEGÚN SEXO, GRUPOS DE EDAD Y NIVEL DE EDUCACIÓN, 2007-2016

\begin{tabular}{|c|c|c|c|c|c|c|c|c|c|c|}
\hline $\begin{array}{c}\text { Principales } \\
\text { caracteristicas }\end{array}$ & 2007 & 2008 & 2009 & 2010 & 2011 & 2012 & 2013 & 2014 & 2015 & 2016 \\
\hline Total & 4016.7 & 4040.9 & 4135.4 & 4332.1 & 4414.8 & 4484.9 & 4594.2 & 4642.6 & 4689.9 & 4782.2 \\
\hline Hombre & 2246.5 & 2278.7 & 2293.7 & 2396.4 & 2460.7 & 2488.1 & 2534.1 & 2538.7 & 2576.0 & 2630.2 \\
\hline Mujer & 1770.2 & 1762.2 & 1841.7 & 1935.7 & 1954.1 & 1996.8 & 2060.0 & 2103.9 & 2113.9 & 2152.0 \\
\hline \multicolumn{11}{|l|}{ Grupos de edad } \\
\hline 14 a 24 años & 942.5 & 922.8 & 905.6 & 970.2 & 972.8 & 989.3 & 979.7 & 921.0 & 951.9 & 969.3 \\
\hline 25 a 44 años & 2128.0 & 2159.1 & 2229.1 & 2294.7 & 2366.1 & 2395.6 & 2470.9 & 2535.1 & 2547.9 & 2592.8 \\
\hline 45 a 49 años & 294.8 & 282.6 & 289.7 & 298.0 & 303.2 & 306.4 & 313.9 & 318.0 & 316.2 & 297.0 \\
\hline 50 a 64 años & 541.6 & 554.1 & 577.3 & 615.7 & 616.5 & 636.8 & 647.7 & 682.2 & 684.1 & 714.6 \\
\hline 65 y más años & 109.8 & 122.3 & 133.7 & 153.5 & 156.3 & 156.9 & 182.0 & 186.4 & 189.8 & 208.5 \\
\hline \multicolumn{11}{|l|}{ Nivel de educación } \\
\hline Primaria 1/ & 456.6 & 427.1 & 433.2 & 443.3 & 445.3 & 413.1 & 430.7 & 394.9 & 373.3 & 380.2 \\
\hline Secundaria & 2091.2 & 2049.5 & 2114.7 & 2281.8 & 2252.3 & 2244.6 & 2268.6 & 2184.9 & 2287.3 & 2273.1 \\
\hline Superior no universitaria & 715.0 & 744.9 & 715.3 & 746.1 & 773.1 & 804.6 & 841.7 & 932.0 & 896.8 & 905.3 \\
\hline Superior universitaria & 753.9 & 819.4 & 872.1 & 860.9 & 944.1 & 1022.7 & 1053.2 & 1130.8 & 1132.6 & 1223.5 \\
\hline
\end{tabular}

VIncluye sin nivel e inicial.

Fuente: Instituto de Estadística e Informática - INEI 
Gráfico $\mathrm{N}^{\circ}$ 4: Población estimada por distrito en Lima Metropolitana

\begin{tabular}{|c|c|c|c|c|c|c|c|c|c|c|c|c|c|c|}
\hline \multirow{3}{*}{ UBIGEO } & \multicolumn{13}{|c|}{$\begin{array}{l}\text { POBLACIÓN ESTIMADA AL } 30 \text { DE JUNIO, POR AÑOS CALENDARIO Y SEXO, } \\
\text { SEGÚN DEPARTAMENTO, PROVINCIA Y DISTRITO, 2012-2015 }\end{array}$} & \multirow[b]{3}{*}{$\%$} \\
\hline & \multirow{2}{*}{$\begin{array}{c}\text { DEPARTAMENTO, } \\
\text { PROVINCIAYY } \\
\text { DISTRITO } \\
\end{array}$} & \multicolumn{3}{|c|}{2012} & \multicolumn{3}{|c|}{2013} & \multicolumn{3}{|c|}{2014} & \multicolumn{3}{|c|}{2015} & \\
\hline & & Total & Hombre & Mujer & Total & Hombre & Mujer & Total & Hombre & Mujer & Total & Hombre & Mujer & \\
\hline 150100 & LIMA & $8,481,415$ & $4,120,828$ & $4,360,587$ & $8,617,314$ & $4,184,422$ & $4,432,892$ & $8,755,262$ & $4,249,046$ & $4,506,216$ & $8,894,412$ & $4,314,286$ & $4,580,126$ & \\
\hline 150104 & BARRANCO & 31,959 & 14,823 & 17,136 & 31,298 & 14,511 & 16,787 & 30,641 & 14,201 & 16,440 & 29,984 & 13,892 & 16,092 & $0.34 \%$ \\
\hline 150113 & JESUS MARIA & 71,364 & 32,170 & 39,194 & 71,439 & 32,195 & 39,244 & 71,514 & 32,220 & 39,294 & 71,589 & 32,245 & 39,344 & $0.80 \%$ \\
\hline 150114 & LA MOLINA & 157,638 & 72,532 & 85,106 & 162,237 & 74,557 & 87,680 & 166,912 & 76,614 & 90,298 & 171,646 & 78,695 & 92,951 & $1.93 \%$ \\
\hline 150122 & MIRAFLORES & 84,473 & 37,518 & 46,955 & 83,649 & 37,162 & 46,487 & 82,805 & 36,798 & 46,007 & 81,932 & 36,422 & 45,510 & $0.92 \%$ \\
\hline 150130 & SAN BORJA & 111,568 & 51,416 & 60,152 & 111,688 & 51,476 & 60,212 & 111,808 & 51,536 & 60,272 & 111,928 & 51,596 & 60,332 & $1.26 \%$ \\
\hline 150131 & SAN ISIDRO & 56,570 & 24,472 & 32,098 & 55,792 & 24,134 & 31,658 & 55,006 & 23,793 & 31,213 & 54,206 & 23,447 & 30,759 & $0.61 \%$ \\
\hline 150136 & SAN MIGUEL & 135,086 & 62,820 & 72,266 & 135,226 & 62,890 & 72,336 & 135,366 & 62,960 & 72,406 & 135,506 & 63,030 & 72,476 & $1.52 \%$ \\
\hline 150140 & SANTIAGO DE SURCC & 326,928 & 150,273 & 176,655 & 332,725 & 152,725 & 180,000 & 338,509 & 155,169 & 183,340 & 344,242 & 157,586 & 186,656 & $3.87 \%$ \\
\hline \multirow[t]{2}{*}{150141} & SURQUILLO & 92,328 & 41,820 & 50,508 & 92,012 & 41,454 & 50,558 & 91,686 & 41,078 & 50,608 & 91,346 & 40,688 & 50,658 & $1.03 \%$ \\
\hline & & & & & & & & & & & \multicolumn{3}{|c|}{ Total } & $12.28 \%$ \\
\hline
\end{tabular}

Fuente: Instituto de Estadística e Informática - INEI

Las bases de datos estadísticas mencionadas en el párrafo anterior se pueden apreciar en los gráficos siguientes (ver Gráficos $\mathrm{N}^{\circ} 3$ y 4), en los que se indica que en el año 2015 la población ocupada con un nivel de educación superior universitaria es de 1,132,600 personas. Asimismo, la población total de Lima Metropolitana para el año 2015 es de 8,894,412 personas, dentro de la cual se puede obtener la población total de los distritos objetivo indicados anteriormente, la misma que asciende a 1,092,379 personas para el año 2015, número de personas que representa el $12.28 \%$ de la población total de personas en Lima Metropolitana. Este porcentaje se aplicó a la población con educación superior universitaria y dio como resultado un total de 139,081 personas, número considerado para el cálculo de la muestra representativa resultante calculada a través de la aplicación Google docs, la misma que fue de 384 personas a ser encuestadas.

\subsection{Análisis de tendencias y patrones.}

De acuerdo a las tendencias globales identificadas para el 2017 por la investigadora de mercado Euromonitor, existe una oportunidad de negocio en las siguientes: (Kasriel-Alexander, 2017)

- Compras más rápidas: Actualmente, el consumidor tiende a ser exigente con los servicios que adquiere, es impaciente y busca que estos se adapten a ellos, de forma que encuentren la manera más rápida de satisfacer sus necesidades, con la menor cantidad de molestias posibles (esto incluye locación, precio, comodidad, conveniencia, facilidades).

- Post- Compra: Existe una valorización aumentada sobre la experiencia post- compra, como forma de fidelización del cliente, esto quiere decir que 
la experiencia del servicio debe ir más allá de la primera compra o la relación formada en el punto de venta, se debe otorgar beneficios posteriores que permitan que los cliente se vuelvan recurrentes.

\subsection{CANVAS del modelo de negocio.}

Para diseñar el modelo de negocio se usó la herramienta llamada Canvas, la cual es una de las más usadas por la metodología Lean Startup, se ha tomado la herramienta señalada en el libro "Diseñando la propuesta de valor" (Osterwalder, 2015)

Esta herramienta está compuesta principalmente por una propuesta de valor, en torno de la cual se definen los elementos internos y externos que influyen sobre ella y que harán posible que esta sea cumplida. Consta de 3 partes:

- Lado izquierdo, relacionado con Proveedores externos e internos de todas aquellas relaciones, actividades, recursos clave, así como los costos necesarios para entregar la propuesta de valor del negocio.

- Lado derecho, relacionado con Clientes, y todas aquellas relaciones, actividades e ingresos necesarios para asegurar la entrega de la propuesta de valor de la empresa.

- Centro, Relacionado con la Propuesta de valor que se compromete a entregar la empresa al cliente.

Incorporando en esta herramienta Canvas la idea de negocio de implementar un bar con autoservicio, hay que indicar que la propuesta de valor definida busca ofrecer al cliente una experiencia de entretenimiento basada en el autoservicio de cerveza a través de grifos surtidores tipo chopp en mesa (consumo por mililitros). Adicionalmente, esta propuesta ofrece eventos temáticos como: música en vivo, stand up comedy, catas, etc.

Para lograr cumplir con esta promesa de entretenimiento se han identificado clientes (mercado meta) conformados principalmente por hombres y mujeres adultos, con recursos propios quienes están mayoritariamente en el rango de 25 años a más de 50 años de edad, según los resultados obtenidos en la encuesta realizada (ver Anexo $\mathrm{N}^{\circ}$ 2, pregunta 2, página 78), Por otro lado, se han identificado recursos y equipos necesarios para hacer viable esta propuesta tales 
como colaboradores en cada una de los puestos de trabajo identificados, proveedores de equipos de cerveza, mobiliario, de bebidas y alimentos, de alquiler de local, etc. Por último, como consecuencia de lo desarrollado antes se ha incluido en este modelo los principales ingresos y costos derivados de la actividad y la propuesta que ofrece el negocio al cliente, ver la Tabla $\mathrm{N}^{\mathrm{a}} 1$ a continuación: 
Tabla $\mathrm{N}^{\circ} 1$ - Modelo CANVAS

\begin{tabular}{|c|c|c|c|c|}
\hline Relaciones Clave & Actividades Clave & Propuesta de Valor & Relaciones con los clientes & Mercado Meta - Clientes \\
\hline "Agente Inmobililario (alquiler) & "Colocación de clientes & \multirow{7}{*}{$\begin{array}{l}\text { * Ofrecer una experiecia nueva basada en: } \\
\text { - Bar temático: charlas, stand up, música } \\
\text { - Autoservicio de cerveza con grifo en } \\
\text { mesa (chopp) } \\
\text { - Ambiente, decoración y layout acogedor } \\
\text { y funcional }\end{array}$} & *Atención directa y personal & \multirow{7}{*}{$\begin{array}{l}\text { Adultos con las siguientes } \\
\text { características: } \\
\text { 1. Demográfico: Entre } 25 \text { y } 50 \text { años que } \\
\text { perciben ingresos en Lima. } \\
\text { 2. Costumbres: Frecuentan restaurante } \\
\text { y/o bares luego del trabajo y frecuentan } \\
\text { con amigos fuera del trabajo ylo sus } \\
\text { parejas } \\
\text { ar. Patrón de consumo: Dedican entre } \\
100 \text { y } 200 \text { soles semanales a ocio }\end{array}$} \\
\hline * Proveedor de mesas con surtidor & * Habilitación de la mesa, atención en la barra & & & \\
\hline \multirow{5}{*}{$\begin{array}{l}\text { * Proveedor de mobiliario } \\
\text { × Distribuidores de licores } \\
\text { × Proveedores de alimentos y bebida } \\
\text { "Experto en decoración y barras } \\
\text { ×Bancos locales }\end{array}$} & * Limpieza, mantenimiento y seguridad & & * Organizar eventos semanales, quincenales & \\
\hline & *Contratación y preparación de las temáticas & & * Ofrecer barra de licores & \\
\hline & $\begin{array}{l}\text { *Actividades promocionales (incluye programas de } \\
\text { Ifidelización con bancos) }\end{array}$ & & & \\
\hline & \begin{tabular}{|c|} 
Recursos Clave \\
\end{tabular} & & \begin{tabular}{|c|} 
Canales de Distribución \\
\end{tabular} & \\
\hline & 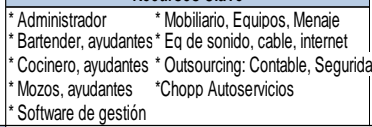 & & $\begin{array}{l}\text { *Creación de pagina web / facebook para anuciar, } \\
\text { recibir feedback } \\
\text { *Búsqueda de promotores de venta para atraer } \\
\text { clientes }\end{array}$ & \\
\hline \begin{tabular}{|l|} 
Estructura de Costos \\
\end{tabular} & & & Flujos de Ingresos & \\
\hline \multirow{2}{*}{\multicolumn{2}{|c|}{$\begin{array}{l}\text { * Manejo de costos de insumos y personal. } \\
\text { *Crear Valor a través de eventos temáticos. Costos de bandas, comediantes, etc. } \\
\text { *Costos Fijos: Alquiler de local, payroll, internet, cable } \\
\text { *Costos Variables: Compra licores, alimentos y preparado de eventos } \\
\text { * Inversión inicial en Acondicionamiento de local, mobiliario, equipos, menaje, decoración, ala }\end{array}$}} & \multirow{2}{*}{\multicolumn{2}{|c|}{$\begin{array}{l}\text { *Consumo de cerveza por medio del surtidor (por ml consumido) } \\
{ }^{*} \text { Ingreso por alimentos, otros licores }\end{array}$}} & \\
\hline & & & & \\
\hline
\end{tabular}

Elaboración propia

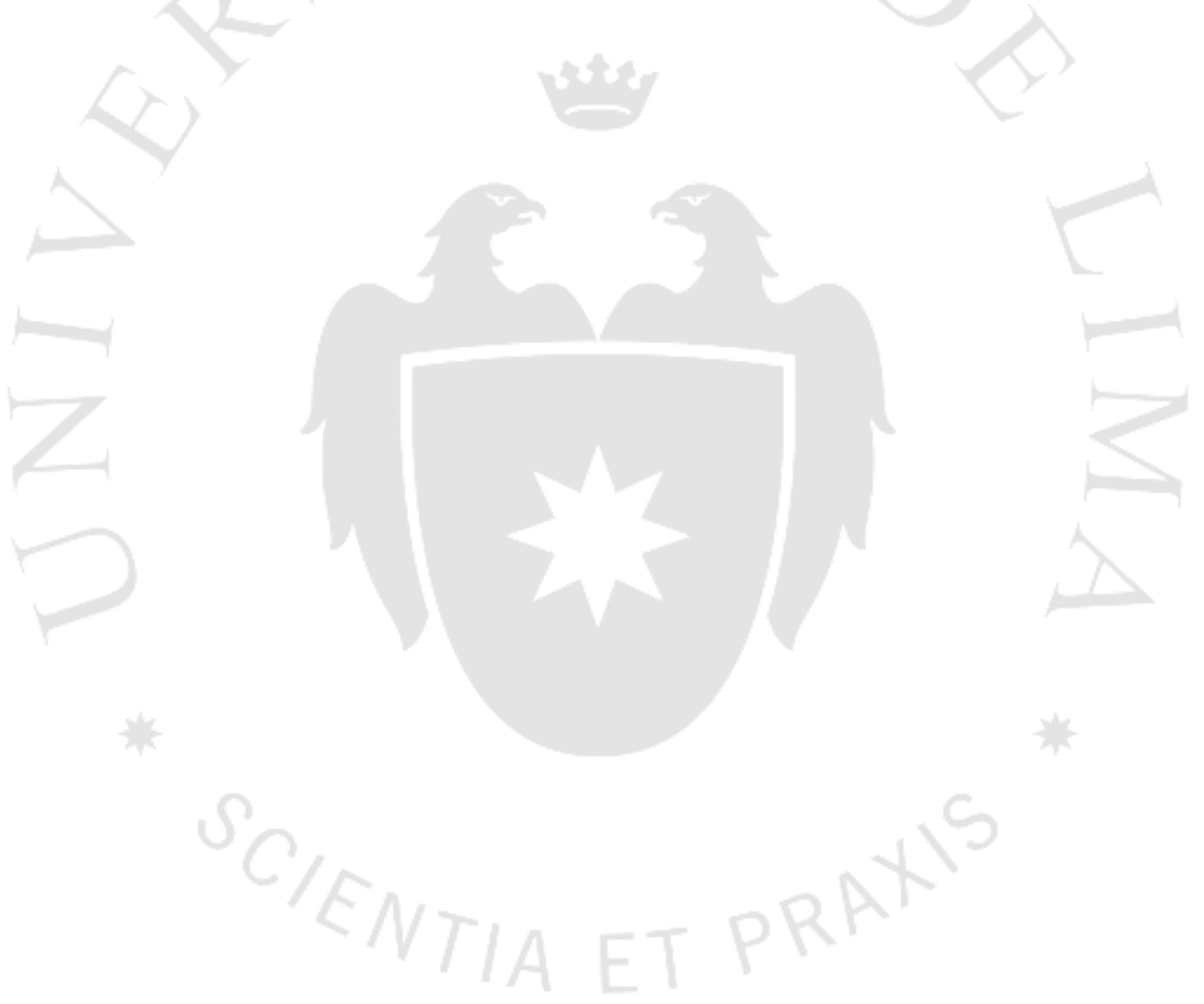




\section{Planeamiento Estratégico.}

\subsection{Visión.}

"Ser la mejor opción de entretenimiento y ocio para personas que busquen pasar un momento agradable, en un ambiente acogedor y funcional”.

Con esta definición, la empresa se compromete con ofrecer una propuesta de valor diferente que hace poco ha ingresado al mercado actual, que nos permitirá adquirir una ventaja competitiva en un mercado amplio con un número variado de protagonistas.

\subsection{Misión.}

"Brindar un servicio eficiente que priorice la satisfacción del cliente con enfoque en la comodidad, que promueva la diversión y propuestas temáticas en un bar con autoservicio.".

\subsection{Valores y ética.}

A continuación se definen los valores sobre los cuales operará la empresa:

- Ofrecer comodidad y tranquilidad a los clientes durante su estadía en el local.

- Crear una relación constante con el cliente que sobrepase los límites físicos del local.

- Incentivar la creación de una propuesta temática variada y hacia el consumo de cerveza orientado al autoservicio.

- Promover el consumo y entretenimiento responsable.

- Sustituir el uso de plástico en las cañitas para cocteles, jugos, gaseosas y el uso del tecnopor (poliestireno expandido) en los envases para llevar alimentos y descartables, por diferentes opciones como productos ya ofertados en el mercado peruano que son biodegradables y $100 \%$ ecológicos, fabricados en base a caña de azúcar, féculas de arroz, maíz, papa, camote y también de bambú que tienen una duración entre 60 y 120 días aproximadamente. De hecho existen proveedores en el mercado peruano que son además de inversión capital peruano tales como: Ecopack y Qapac Runa quienes ofrecen estos productos a precios bajos. 


\subsection{Cultura organizacional.}

La cultura organizacional está orientada hacia la eficiencia en todo lo realizado por las personas que trabajan dentro de la compañía. Todo debe estar enfocado en lograr la comodidad y conveniencia de los clientes. Asimismo, se trabajará en crear un ambiente donde se incentive la creación de una comunidad entre los clientes, la transmisión de tranquilidad y la interacción y conversación de los asistentes al bar a través de la propuesta temática.

\subsection{Objetivos Estratégicos.}

Esta propuesta tiene los siguientes objetivos estratégicos:

- Posicionar nuestra propuesta "Bar con Autoservicio" basados en la oferta de una experiencia de entretenimiento con elementos temáticos y de buen servicio.

- Tener un nivel de ventas de S/ 1,000,000 en el primer año.

- Lograr un punto de equilibrio (break even point), es decir cubrir los costos operativos y gastos fijos al finalizar el cuarto mes desde la apertura del negocio.

- Ofrecer puestos de trabajo en el rubro de bar y retener el talento humano bajo una política de capacitación y de incentivos.

- Fidelizar al cliente a través de la constante observación de sus necesidades y de la mejora continua de los estándares de atención y servicio.

\subsection{Análisis externo: Político, legal, circunstancial, económico, geográfico, social, demográfico, cultural, tecnológico, ambiental (PESTEL).}

Se realizará un análisis de factores externos que podrían ser riesgosos para el proyecto, con el objetivo de identificar las oportunidades de negocio y amenazas potenciales, utilizando la metodología PESTEL:

Ámbito político: No existen factores relevantes que puedan representar un riesgo potencial hacia el negocio. Si bien el país se encuentra hace varios meses en una coyuntura política complicada por el enfrentamiento entre el poder legislativo y el poder ejecutivo, esto no tiene un impacto sobre el sub-segmento restaurantes del sector comercio, dado que la tendencia en este sector es de variaciones 
positivas en los últimos 3 años, tal como se indicó el punto 1.2 Marco teórico y Mercado.

Ámbito económico: La economía peruana ha venido en desaceleración desde el 2017; sin embargo, para el 2018 se proyecta un crecimiento del PBI en 4 por ciento, principalmente basado en el crecimiento de inversión pública y privada, asociado a una recuperación en el nivel de empleos, debido a la recuperación del sector construcción y la reversión del efecto negativo ocasionado por el Fenómeno del Niño Costero, de acuerdo a lo indicado en el Reporte de Inflación del Banco Central de Reserva del Perú - BCRP de Septiembre del 2018, el cual proyecta un crecimiento del PBI igual de 4 por ciento para el año 2019. (Banco Central de Reserva del Perú, 2018).

Ámbito social: De acuerdo a lo informado en el diario Gestión: "Peruanos gastan más de S/ 100 soles en consumo de cerveza que hace 5 años". (Diario Gestion, 2017), llegando a asignar un presupuesto anual de S/ 428.5. Esto nos indica que existe una tendencia a aumentar el consumo de esta bebida alcohólica dentro del país sobre otras que nos ayuda a orientar la oferta de productos dentro del bar.

Ámbito ecológico: Los bares generan cierta cantidad de desperdicios diaria, los cuales se clasifican entre orgánicos relacionados a comidas, bebidas, papel y cartón, así como inorgánicos producto de botellas de plástico, envases descartables. Estos últimos son los que tienen un impacto negativo en el medio ambiente.

Ámbito legal: El marco legal para los negocios relacionados a restaurantes y bares es un riesgo importante, debido a las regulaciones para su funcionamiento que son constantemente auditadas. Dentro de estos requerimientos se encuentran licencias de funcionamiento, normatividad sobre sanidad y cumplimientos tributarios, tal como lo señala en el Texto Único Ordenado de la Ley 28976, Ley marco de Licencia de Funcionamiento del 20 de Abril de 2017 publicado en El Peruano, Asimismo, mediante la Resolución Ministerial N 822/2018/MINSA se aprueba la Norma Técnica Sanitaria N 142-MINSA/2018/DIGESA que regula sobre los 
Principios Generales de Higiene (PGH) que deben cumplir los restaurantes y servicios afines.

\subsection{Análisis interno: Competidores potenciales, clientes, proveedores, productos sustitutos, barreras de entrada (PORTER).}

De acuerdo a Michael Porter, son 5 fuerzas las que define la situación de competencia dentro de una industria, y estas mismas a su vez influyen en su potencial. Estas son los competidores potenciales, poder de negociación sobre los proveedores, poder de negociación sobre los clientes, amenazas de productos sustitutos y barreras de entrada. La base de la estrategia se debe basar sobre el conocimiento de estos conceptos para que muestren las fortalezas y debilidades de la empresa (Porter, 1989)

Según lo explicado anteriormente, se realizó el análisis interno correspondiente:

Competidores potenciales: Los principales competidores son otros bares que se encuentren cercano a centros empresariales o zonas de entretenimiento para realizar after-office a finales de semana. Entre estos se encuentran los locales dentro del Centro Comercial Caminos del Inca y bares aledaños al Parque Kennedy en el distrito de Miraflores y a la conocida "calle de las pizzas" en la avenida Diagonal y alrededores. La mayoría de estos poseen una propuesta parecida, diferenciándose solo en precio, locación y temática. Tales son los casos de "Entre Copas Bar" en Av. El Polo 781, Santiago de Surco (frente al Centro Comercial El Polo.), al cual se visitó y observó, teniendo retroalimentación por parte del personal de atención sobre cocteles y piqueos de mayor rotación en el bar, horarios de atención, cantidad y turnos de personal del establecimiento, días de música en vivo, etc (ver Anexo $\mathrm{N}^{\circ} 3$ ). Otros competidores potenciales son: “The Corner Sports Bar \& Grill” en la Av. Larco 1207, Miraflores, Bazar Bar y La Destileria Bar, en la calle Francisco de Paula Camino $N^{\circ} 231$ y $N^{\circ} 330$ respectivamente, ambos en Miraflores, Estos dos bares no llegan a tener un salón mayor a los $100 \mathrm{~m}^{2}$ considerando barra, lo cual en dimensiones, distribución de espacio, decoración y en propuesta temática de música en vivo se asemeja a la oferta del Bar con autoservicio,. Sin embargo su público en mayoría está entre los 25 y 35 años de edad. 
Clientes: La cantidad de competidores en el mercado, trae como consecuencia que se tenga un poder de negociación bajo con relación a nuestros potenciales clientes. Nuestro servicio no cubre necesidades básicas, por lo que es necesario mantener una propuesta de valor competitiva que permita ganar mercado.

Proveedores: De acuerdo a la experiencia y a la información proporcionada por el experto en restaurantes entrevistado con respecto a la inversión inicial requerida para implementar un bar (ver Anexo $\mathrm{N}^{\circ} 4$, pág. 88) se puede preparar una lista del mobiliario, menaje, alimentos, bebidas y servicios que se requiere de terceros para implementar y mantener en funcionamiento un negocio de estas características:

Alimentos y bebidas

Surtidores y software

Eventos y noches temáticas

Personal de atención

Seguridad, mantenimiento y limpieza

Mobiliario, equipamiento de cocina y salón y menaje..

El nivel de influencia de cada uno varía, en los primeros 3 grupos se mantiene un nivel bajo, debido a que los proveedores son únicos con varios clientes, acercándose a un tipo de mercado de competencia monopolística. En los últimos 3 existe un nivel medio, principalmente porque la oferta aumenta; sin embargo, no se puede negociar precios o términos diferenciados.

Productos sustitutos: Como sustitutos directos se encuentran otros bares temáticos, así como bares regulares y discotecas. En el caso de los indirectos existen restaurantes, cines, teatro y otros tipos de entretenimiento. En todos los rubros mencionados existe bastante competencia, tal como se puede concluir de las respuestas a la encuesta realizada (ver Anexo 2). Se han identificado también bares temáticos en los distritos de Santiago de Surco, Cercado de Lima, Miraflores, etc. que son exitosos, tal es el caso del bar "La Basílica" en Av. Primavera 640, Santiago de Surco, que cuenta con una propuesta temática del "cielo y el infierno" y que ofrece una carta con tragos clásicos y de su propia autoría, al igual que en piqueos, los cuales buscan resaltar su propuesta temática. 
Este bar tiene dos niveles. En el primer nivel de $80 \mathrm{~m}^{2}$ aproximadamente cuenta con una barra muy amplia de unos 7 a $8 \mathrm{~m}^{2}$ y con 10 mesas aproximadamente. En el segundo nivel cuenta con 8 mesas de mayor capacidad de ocupantes y de mayor privacidad. No tiene música en vivo y su público oscila entre los 25 y 50 años a más, estando claramente orientado a un nivel socioeconómico A y B, "Sukha” en calle Dos de Mayo, Miraflores es un a bar lounge con temática de un templo oriental, de hecho tiene un Budda de unos 3 metros de alto y cuenta con nn salón muy amplio mayor a los $100 \mathrm{~m}^{2}$ y con boxes ubicados en un segundo nivel, la distribución de espacios del nbar es bastante buena y su público asiduo se ubica en los niveles socioeconómicos $\mathrm{B}$ y $\mathrm{C}$, en un rango de 25 a más de 50 años, "Estadio" en Jr. De la Unión 1047, Centro de Lima, es un bar que tiene 18 años de existencia y que por su nombre tiene una temática basada en el fultbol, su carta de piqueos y tragos refuerza su propuesta temática, siendo la cerveza en chopp su producto más consumido. En términos de espacio es muy grande (sobrepasa los $100 \mathrm{~m}^{2}$ ) y cuenta con varios ambientes. Su público frecuente tiene un rango amplio predominando los de 25 a más de 50 años. Aprovecha las múltiples temporadas de campeonatos de futbol extranjero y local para captar público. “Expreso Oriente Restobar" en Calle Alcanfores 463, Miraflores, “Ayahuasca Restobar" en Avenida Prolongación San Martin 130, Barranco y Oceanus Lounge bar del Hotel Los Delfines en San Isidro. Estos bares han sido catalogados como los 7 bares temáticos más geniales de Lima en un arículo periodístico del 11 de Octubre del 2018 (El Comercio, 2018).

Barreras de entrada: La principal barrera de entrada recae en las licencias de funcionamiento y regulaciones tributarias, así como la ubicación y tamaño del local de atención para asegurar y atender el flujo de personas.

Para ahondar más en todo aquello que puede afectar la propuesta del negocio, se ha elaborado una matriz de Evaluación de Factores Externos (EFE), la cual nos permite analizar factores externos como los económico, político, legal, social, ambiental, demográfico, etc. pueden impactar en la viabilidad del negocio.

Como resultado de este análisis realizado (ver Tabla $\mathrm{N}^{\circ} 2$ ) se ha obtenido $\mathrm{u}$ puntaje total de 3.1, es decir por encima del promedio. Este resultado está altamente influenciado por indicadores que señalan que en el país el incremento 
de consumo de cerveza es real con respecto a años anteriores y principalmente en la tendencia positiva en el rubro de restaurantes del Sector Comercio.

Tabla $N^{\circ} 2$ - Matriz de Evaluación de Factores Externos

\begin{tabular}{|c|c|c|c|c|}
\hline \multicolumn{5}{|c|}{$\begin{array}{l}\text { Factores determinantes del Exito } \\
\text { (Oportunidades y Amenazas) }\end{array}$} \\
\hline \multicolumn{2}{|c|}{ Oportunidades } & Peso & Calificacion & $\begin{array}{l}\text { Resultado } \\
\text { ponderado }\end{array}$ \\
\hline 1 & Tendencia positiva en el rubro de Restaurantes del Sector Comercio & 0.14 & 4 & 0.56 \\
\hline 2 & Pocos bares tematicos en Lima & 0.12 & 3 & 0.36 \\
\hline 3 & Unica propuesta de autoservicio de cerveza & 0.12 & 3 & 0.36 \\
\hline 4 & Incremento del gasto destinado a consumo de cerveza en el Peru & 0.13 & 4 & 0.52 \\
\hline
\end{tabular}

\section{Amenazas}

1 Gran numero de negocios sustitutos en entretenimiento

2 Pocos Proveedores de licores y cerveza

3 Fuerte afectacion de regulaciones municipales y tributarias

4 Incemento de precio y/o cancelacion de contarto de alquiler

\begin{tabular}{|l|}
\hline 0.13 \\
\hline 0.14 \\
\hline 0.11 \\
\hline 0.11 \\
\hline 3 \\
\hline 2 \\
\hline 2 \\
\hline
\end{tabular}

\begin{tabular}{|l|}
\hline 0.39 \\
\hline 0.42 \\
\hline 0.22 \\
\hline 0.22 \\
\hline
\end{tabular}

Total

Elaboración propia

\subsection{Análisis sectorial e Identificación de riesgos y amenazas. Análisis FODA.}

En base a los análisis previos externos e internos se definen los principales puntos de Fortalezas, Oportunidades, Debilidades y Amenazas a manera de resumen y enfoque estratégico

Fortalezas:

- Surtidores autoservicio que permite mejor atención a clientes y eficiencia en procesos.

- Temática flexible de acuerdo a la situación o día de la semana

\section{Debilidades:}

- Concentración de proveedores de cerveza y alimentos puede dificultar gestión de costos.

- Competidores cercanos en zonas de influencia para bares y restaurantes.

Oportunidades:

- Clientes potenciales con mayor disposición a gastar en entretenimiento

- Economía peruana en recuperación para los próximos años

- Tendencias globales en experiencia de compra que se ajustan al negocio propuesto. 
Amenazas:

- Regulaciones varias de funcionamiento y tributarias pueden ser causales de multa o cierres temporales.

- Gran cantidad de bares y restaurantes en el mercado, con diferentes conceptos y temáticas

\subsection{Estrategia de éxito (FODA cruzado).}

A continuación proponemos la estrategia cruzada para los factores externos e internos:

Tabla No 3 - FODA Cruzado

\begin{tabular}{|c|c|c|}
\hline Externo & $\begin{array}{l}\text { Fortalezas } \\
\text { Surtidores autoservicio que permite } \\
\text { mejor atención a los clientes y } \\
\text { eficiencia de procesos. } \\
\text { Temática flexible de acuerdo a la } \\
\text { situación o día de la semana. }\end{array}$ & $\begin{array}{l}\text { Debilidades } \\
\text { Concentración de proveedores de } \\
\text { cerveza y alimentos puede dificultar } \\
\text { gestión de costos } \\
\text { Competidores cercanos en zonas de } \\
\text { influencia para bares y restaurantes }\end{array}$ \\
\hline $\begin{array}{l}\text { Oportunidades } \\
\text { Clientes potenciales con mayor disposición a } \\
\text { gastar en entretenimiento } \\
\text { Economía peruana en recuperación para los } \\
\text { próximos años } \\
\text { Tendencias globales en experiencia de compra } \\
\text { que se ajustan al negocio propuesto. }\end{array}$ & $\begin{array}{l}\text { Aprovechar las temáticas flexibles y } \\
\text { concepto de autoservicio para } \\
\text { direccionar la demanda creciente a } \\
\text { este tipo de bares. }\end{array}$ & $\begin{array}{l}\text { Aprovechar mayor consumo potencial } \\
\text { en cerveza y uso de surtidores con el } \\
\text { objetivo de mejorar negociaciones } \\
\text { para obtener mejores tarifas y } \\
\text { promociones. }\end{array}$ \\
\hline $\begin{array}{l}\text { Amenazas } \\
\text { Regulaciones varias de funcionamiento y } \\
\text { tributarios pueden causales de multa o cierres } \\
\text { temporales. } \\
\text { Gran cantidad de bares y restaurantes en el } \\
\text { mercado, con diferentes conceptos y temáticas }\end{array}$ & $\begin{array}{l}\text { Utilizar las eficiencias del concepto de } \\
\text { autoservicio para el cumplimiento de } \\
\text { obligaciones y diferenciarse de los } \\
\text { conceptos tradicionales de bares. }\end{array}$ & $\begin{array}{l}\text { Optimizar relación con proveedores y } \\
\text { competidores (aprovechando } \\
\text { cercanía) para obtener las mejores } \\
\text { prácticas del mercado. }\end{array}$ \\
\hline
\end{tabular}

Elaboración propia 


\section{Plan de marketing}

\subsection{Planteamiento de objetivos generales de marketing.}

Se han separado los objetivos generales de marketing en 2 grupos de estrategias: Fidelización y experiencia

- Lograr un ratio de ocupación promedio de 70 por ciento jueves a sábado en los horarios de apertura en el primer año de operación.

- Obtener cero anotaciones en el libro de reclamaciones del local durante los primeros 3 meses de apertura.

\section{$\underline{\text { Consumo }}$}

- Conseguir un ticket promedio mayor a 100 soles por mesa en el primer trimestre operación.

- Superar un consumo promedio de 800 litros de cerveza al mes en el primer semestre de operación

\subsection{Estrategias de marketing:}

\subsubsection{Segmentación y Perfil del cliente.}

Luego de implementar las herramientas cuantitativas (cuestionarios) y cualitativas (observación y entrevista), se define el cliente objetivo bajo 3 aspectos:

- Demográfico: Rango de edades entre 25 y 50 años, que perciben ingresos y trabajan en diversas zonas de Lima. Los clientes potenciales en este rango de edades están dispuestos a movilizarse para llegar un lugar de entretenimiento de su interés, según se puede apreciar en el Anexo $\mathrm{N}^{\circ} 2$ en la respuesta a la pregunta número 2 que refiere al rango de edad objetivo de los que respondieron la encuesta.

- Costumbres: Frecuentan restaurantes (o resto bares) después de trabajar, de acuerdo a lo indicado en el estudio de mercado, normalmente acompañados por amigos fuera del trabajo y/o su pareja (no se busca pasar el tiempo de ocio con los compañeros del trabajo). Esto se puede visualizar en los resultados de la encuesta en la pregunta 
4, (ver Anexo 2) donde se puede ver que la opción más marcada fue la de restaurantes por encima de centros comerciales y la de cine y teatro.

- Patrón de consumo: Dedican entre 100 y 200 soles de su presupuesto personal semanal para tiempo de ocio y están dispuestos a pagar entre 8 y 12 soles por una cerveza de 350 mililitros dentro un local. De acuerdo a los resultados de la encuesta, el $41.2 \%$ dedica dichos importes en entretenimiento y $57.4 \%$ considera que un rango de precio adecuado es entre 8 y 12 soles.

\subsubsection{Posicionamiento y ventaja competitiva.}

En lo referido a posicionamiento dentro del mercado, se ha identificado el ambiente y precio como aspectos claves que pueden influir en el proceso de decisión de los clientes, esto se refleja en el estudio de mercado (ver Anexo $\mathrm{N}^{\circ}$ 2), dónde los conceptos de ambiente, comodidad, atención y precio son los factores más importantes para la elección de una bar. El bar autoservicio estaría enfocado en el tema de ambiente a un precio competitivo, esto último debido a que se propone incrementar el consumo en mililitros de cerveza promedio por persona con respecto a un local de la competencia. Como se puede apreciar la propuesta de bar autoservicio está alineada directamente con los conceptos de comodidad, atención y precio (factores claves para elegir un bar según el Anexo $\mathrm{N}^{\circ} 2$ ), al colocar los grifos dispensadores de cerveza los clientes obtienen acceso inmediato al producto, por lo que se reducirán ampliamente los tiempos de espera (es importante resaltar que la atención de los mozos es un concepto que se mantiene) y logra que el cliente sientan la libertad de servirse las cantidades que desee lo que aumenta la sensación de comodidad. En lo que se refiere a precio, la compra de únicamente el líquido mas no los envases, permite un ahorro en la compra de cerveza, por lo que se puede lograr un precio competitivo sin sacrificar el margen, y a esto se le puede agregar el trade off entre mayor cantidad de litros consumidos contra un precio menor, como es un negocio de márgenes altos, se pueden ceder puntos para lograr mayor consumo por ticket promedio y ocupabilidad. 
Por último en lo que se refiere a ambiente, el concepto de autoservicio afecta indirectamente, pues dicha propuesta permite cierta flexibilidad para la creación de eventos temáticos que incentiven el consumo dentro del local (un ejemplo son los concursos por mesa).

La estrategia de ventaja competitiva se caracterizará por la diferenciación basada en los aspectos de concepto y ambiente. La primera corresponde al autoservicio de cerveza con surtidores de chopp en mesa bajo un consumo de mililitros, concepto que ha sido bien valorado por la encuesta realizada cuyas respuestas están en el Anexo $\mathrm{N}^{\circ} 2$, y por los resultados de las entrevistas a profundidad realizadas a potenciales clientes (ver Anexo $\mathrm{N}^{\circ} 5$ - conclusiones). La segunda tiene que ver con la versátil temática propuesta (música en vivo, stand up comedy, catas) para aprovechar la oportunidad de consumo de los clientes potenciales, así como la comodidad en la estadía y ambientación propia del local, tal como se observa en el estudio de mercado en el Anexo $\mathrm{N}^{\circ} 2$, el ambiente y la comodidad son 2 de los 3 factores más importantes que el cliente potencial aprecia, esto se complementa con los resultados obtenidos de las encuestas a profundidad realizadas a potenciales clientes (ver Anexo $\mathrm{N}^{\circ} 5-$ conclusiones). El enfoque en estos aspectos es muy importante para satisfacer al cliente, a la vez que se abarca el factor precio y atención. Adicionalmente, se puede observar que conforme al estudio de mercado realizado la variedad de la carta no es uno de los factores más importantes para elegir un local, por lo que optaremos por una carta de bar y piqueos estándar.

De acuerdo a lo expuesto anteriormente, se puede confirmar que la propuesta y posicionamiento de ventaja competitiva está alineada a las características detalladas en el punto 4.2.1.Segmentación y perfil del cliente. 


\subsection{Mercado objetivo:}

\subsubsection{Tendencia de mercado.}

Lo analizado de las fuentes estadísticas del sector comercio del país señaladas en el marco teórico y proporcionado por los boletines estadísticos del Instituto de Estadística e Informática - INEI, así como de las respuestas obtenidas de la encuesta realizada (ver Anexo $\mathrm{N}^{\circ} 2$ ), ha permitido identificar 3 influencias relevantes sobre el mercado:

- Sustitutos: En el rubro de entretenimiento suelen aparecer nuevos competidores como bares restaurantes, cafeterías, salas de teatro, que buscan tomar una parte del presupuesto destinado para ocio. Como podemos ver en la pregunta 4 del cuestionario aplicado (Anexo $\mathrm{N}^{\circ} 2$ ), frecuentar centros comerciales, cines y teatros son las segunda y tercera opción, respectivamente, luego de restaurantes para frecuentar luego del trabajo.

- Acompañantes y ubicación: Los clientes potenciales prefieren distanciarse en lo posible de sus lugares del trabajo, por lo que prefieren acompañantes diferentes a sus colegas y están dispuestos a movilizarse para llegar a un lugar interés. La conveniencia en distancia no es un punto relevante, ni valorado. Como se puede observar en el Anexo $\mathrm{N}^{\circ} 2$, las personas prefieren asistir a restobares con amigos fuera del trabajo o sus parejas, y la conveniencia es el penúltimo factor valorado para la elección de un bar.

- Frecuencia: Se aprecia que la mayoría de personas visita bares menos de 1 vez al mes, por lo que se estima que solo deben ir para ocasiones especiales y no hay fidelización trabajada. Esto de acuerdo a lo revisado en la pregunta 8 del cuestionario (Anexo $\mathrm{N}^{\circ} 2$ ), dónde un $42.2 \%$ afirma que asiste a bares menos de 1 vez al mes.

Se puede resumir que los potenciales consumidores del bar propuesto actualmente poseen un presupuesto propio asignado hacia ocio $y$ entretenimiento (entre 100 y 200 soles semanales en su mayoría de acuerdo a lo visto en el Anexo $\mathrm{N}^{\circ}$ 2) y lo asignan en diversas actividades (como teatro, cine, centros comerciales, restaurantes, entre otros), entre las 
cuáles se encuentran los bares y asisten a 1 vez al mes o menos, esto quiere decir que no existe una fidelización consistente por parte de la competencia (los clientes asignan menos del 25 por ciento de su presupuesto mensual en ocio). Asimismo, es importante indicar que lo anteriormente indicado fue validado por lo manifestado por clientes potenciales entrevistados sobre el particular, clientes quienes están dentro de los aspectos considerados para la definición del cliente objetivo (ver Anexo $\mathrm{N}^{\circ}$ 5)

Complementando con el estudio de observación (Anexo $\mathrm{N}^{\circ} 3$ ), se puede observar que el ticket promedio suele ser muy alto (por encima de 100 soles) para lugares que cumplen con 3 de los 4 principales factores para la elección de un bar (atención, comodidad y ambiente según el Anexo º2), por lo que la frecuencia se ve afectada. Con la propuesta de valor presentada y posicionamiento se busca obtener los mismos factores y alinear la variable precio, al mantener un precio por 350 mililitros entre 8 y 12 soles (de acuerdo a lo establecido en la encuesta en el Anexo N²). Esto permitirá que los clientes frecuenten más el bar, complementándose con la estrategia de unirse con programas de fidelización de bancos locales que se explicará en el punto 4.4.2 y las estrategias promocionales que derivarán de las noches temáticas. En otras palabras, el buen servicio (mediante atención y comodidad) junto con un ambiente temático diverso (no estático) alineado con precios competitivos logrará la recompra frente a los competidores.

Esto se encuentra alineado con el posicionamiento y ventaja competitiva desarrollada en el punto anterior, debido a que la propuesta de valor no es contraria a las tendencias de mercado y se adapta a las mismas para aprovechar las mismas.

\subsubsection{Tamaño de mercado.}

Mercado total para un bar son todos los mayores de edad en Lima que asciende a aproximadamente 7,963,000 personas, de acuerdo a cifras publicadas en el Reporte de Mercado de Agosto 2017 de CPI. Dentro de 
este grupo, se encuentra un grupo de personas que viven en distritos de interés identificados en el capítulo 3 y asciende a 1,092,379 personas como mercado disponible.

\subsubsection{Mercado objetivo.}

De acuerdo a lo calculado en el capítulo 3, se identificaron a 139, 081 que tienen un grado de instrucción superior que será nuestro mercado objetivo.

4.3.4. Identificación de agentes (clientes, usuarios, compradores, prescriptores, intermediarios, mayoristas, minoristas, comisionistas). Los principales agentes identificados para este negocio son:

- $\quad$ Promotores, encargados de la difusión de la propuesta del bar y de construir y mantener red de contactos.

- $\quad$ Proveedores de cerveza y licores, que están identificados como distribuidores y mayoristas según sea el caso

- $\quad$ Proveedores de comida y productos perecibles, quienes pueden ser: distribuidores, mayoristas y detallistas.

- $\quad$ Proveedores de actividades temáticas (música en vivo, stand up comedy y shows), que pueden ser empresas que provean estos servicios o freelance.

- Bancos locales con programas de fidelización basados en descuentos promocionales.

La identificación de los agentes principales del negocio se puede deducir de la observación realizada en la visita del 7 de Agosto de 2018 al bar de nombre "Entre Copas" (ver Anexo 3) y se identifica con el objetivo de llegar al segmento objetivo determinado en el punto 4.2.1.

\subsubsection{Potencial de crecimiento del mercado.}

El crecimiento del negocio estará determinado por los elementos que promuevan la propuesta del bar como: precio competitivo, de acuerdo a la percepción de valor del cliente, al consumo que tengan en el bar los clientes, lo cual exige una variedad de comidas y bebidas dentro de una 
carta (menú) concreta y que combine opciones clásicas y propias generadas por la experiencia y sugerencia del cliente. Esto ha sido validado en la entrevista a expertos en gestión de bar restaurantes, y en asesoría en tendencias del mercado realizada (ver anexo 4).

La principal limitante se encuentra en la capacidad instalada, que está relacionada con el espacio y su distribución. Con el objetivo de que los clientes no lleguen a ser atendidos, no se debe superar la zona crítica (100 por ciento de capacidad) y se debe mantener por debajo para no afectar la calidad del servicio (Chase, 2014).

\subsubsection{Rivalidad competidora y Potencial de ventas.}

Los principales competidores, son restaurantes, lo que claramente se puede ver en las respuestas obtenidas en la encuesta realizada (Anexo $\mathrm{N}^{\circ}$ 2), específicamente en la pregunta 4 donde se solicita: Indique qué lugares frecuenta normalmente luego del trabajo, la opción Restaurantes obtuvo un $57.09 \%$, donde entendemos que es porque son lugares más tranquilos y con otra propuesta de entretenimiento. De hecho el cliente que prefiere esta opción es a quien se debe atraer. Otros bares claramente también son competidores, en especial aquellos que tengan 2 o más locales. Sin embargo se puede afirmar que la propuesta temática ofrecida es lo que diferencia, como se verá en el siguiente párrafo donde los bares con mayor reconocimiento ofrecen servicios diferentes al del presente proyecto.

A continuación se enumeran los competidores y una breve descripción de sus fortalezas y debilidades, de acuerdo al artículo periodístico "7 bares para escuchar música en vivo" del 30 de septiembre del 2018 y a la guía de observación detallada en el Anexo 2:

- Entrecopas: Ubicado en la Av. El Polo, se caracteriza por una carta variada y por música en vivo los fines de semana. El local no es amplio y los tiempos de atención son muy largos.

- Victoria Bar: Ubicado en Barranco, es un lugar espacioso con música en vivo en el que se ofrecen distintos cócteles. Su enfoque está en la 
diversión sobre la comodidad, está localizado en lugar bastante concurrido con competencias cercanas.

- La Noche de Barranco: También localizado en Barranco, es un establecimiento tradicional identificado por ofrecer conciertos, de acuerdo a un cronograma. El establecimiento no es tan espacioso con la relación al público que atraen, por lo que la comodidad no es su principal diferenciador.

De esta manera se puede confirmar que el posicionamiento y ventaja competitiva expuesta en el punto 4.2.2 es diferente a las propuestas actuales de los competidores del mercado.

\subsection{Desarrollo y estrategia del marketing mix.}

\subsubsection{Política de gestión del cliente.}

Como resultado del estudio de marketing, la encuesta realizada dio como resultado que el potencial cliente del bar tiene preferencia por la oferta de actividades temáticas como: música en vivo, stand up comedy en un $57.8 \%$ del total de la muestra. Asimismo, la respuesta a la pregunta: Por favor indique su posición sobre un nuevo concepto de bar con un sistema de autoservicio de cerveza en el cuál usted pagaría por mililitros, y no por envase, obtuvo un resultado de 79.9\% compuesto por las opciones de "Me interesa" con un 55.4\% y de "Me gusta mucho" con 24.6\%. En consecuencia, los resultados anteriormente indicados permiten validar que la estrategia debe estar basada en la entrega de un servicio que incluya estas opciones. Esto será complementado con estar incluidos con descuentos promocionales dentro los programas de fidelización con grandes bancos, pues estos poseen un gran alcance (mediante medios web y aplicaciones) que permitirá ser conocidos por su amplia base de clientes (las aplicaciones de estos programas mantienen más de 100 mil descargas a la fecha de la investigación, según lo indicado en Google Playstore).

Adicionalmente, se ha incluido en la estrategia de gestión al cliente tener una política basada en la asignación de los recursos de la empresa alineados a las preferencias y expectativa de valor del cliente, así como 
también un control adecuado de costos e inventarios relacionados al negocio, tales como: productos perecibles almacenados, nivel de bebidas alcohólicas y no alcohólicas en stock, de tal forma que no se generen excesos en desperdicios y mermas; también los costos operativos como horas hombre en cocina, en barra, en mesas, en entrada como personal de recepción y de seguridad. Esto de acuerdo a lo especificado en la pregunta 5 de la entrevista a expertos en el Anexo $\mathrm{N}^{\circ} 3$.

Por último, de acuerdo a lo identificado en el punto 4.3.1 en tendencias de mercado, existe una oportunidad en la recompra, debido a que un $42.2 \%$ asiste menos de 1 vez al mes y $29.8 \%$ una vez más. El objetivo es que la propuesta de valor basada en ambiente y comodidad logré que los clientes aumenten su frecuencia. Esto se encuentra como objetivo estratégico en el punto 4.1.

\subsubsection{Estrategia de producto: especificaciones, calidad, variabilidad $y$} diversificación.

El producto propuesto es un servicio como se aprecia en el Gráfico $\mathrm{N}^{\circ} 5$, donde el producto principal comprende los elementos principales de la propuesta de valor que ofrece el negocio a nuestros clientes, es decir una experiencia agradable, divertida y entretenida.

Para lograr que el cliente logre la experiencia antes indicada es necesario entregar un producto diferente, el mismo que consiste en ofrecer mesas de autoservicio de cerveza a través de un grifo surtidor que le permite servirse directamente y pagar por los mililitros efectivamente servidos, esto de acuerdo a lo establecido en el punto 4.2.1.

Adicionalmente, shows en vivo ya sea de música o de un stand up comedy, realización de eventos corporativos y catas. Estos elementos acompañados de una carta de cocteles y de piqueos variada permiten también llegar al cliente convencional que busca encontrar licores y cocteles que ofrecen 
los bares clásicos. Dichas características también forman parte del posicionamiento y ventaja competitiva descrita en puntos anteriores.

Gráfico $\mathrm{N}^{\circ} 5$ - Producto Principal, Real y Aumentado

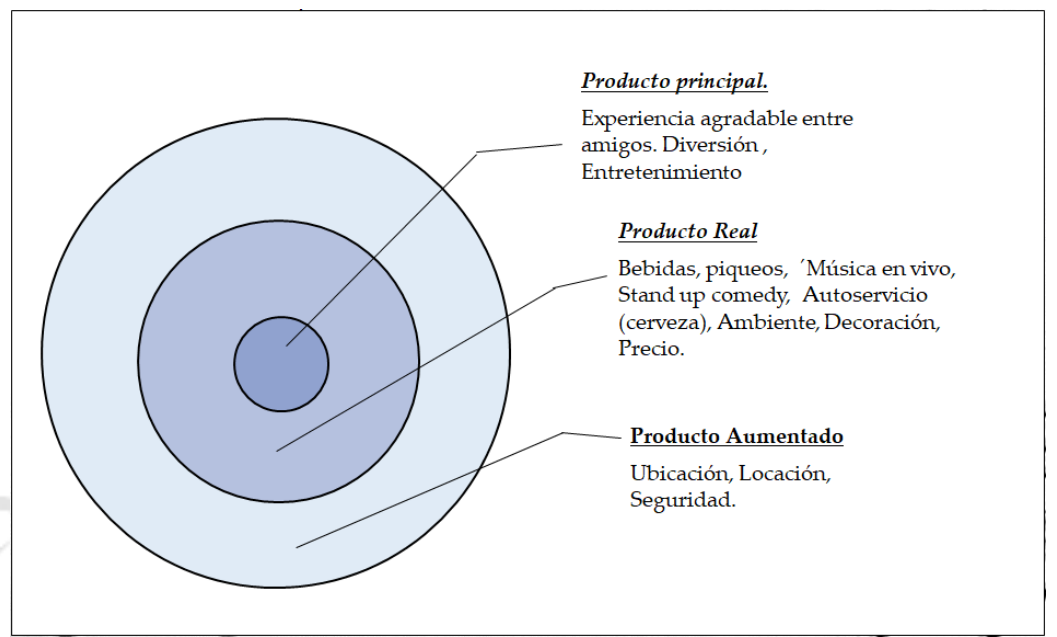

Elaboración propia

El diferenciador frente a la competencia descrita en el punto 4.3.6

Rivalidad competidora y Potencial de ventas se encuentra en el producto real, pues es el que contiene la ventaja competitiva.

\subsubsection{Estrategia de precios: análisis de costos y precios.}

La estrategia de precios adoptada para el negocio está basada en la determinación del precio de venta a ofrecer para los productos y servicios ofrecidos, donde es calculado en base al costo directo que significa: bebidas y piqueos, y a los costos operativos y gastos indirectos como: alquiler del local, servicios públicos, planillas de sueldos del personal contratado, etc., base que sirve para determinar el margen esperado conforme a la captura y expectativa de valor que tendrá el cliente sobre el servicio.

Como parte del estudio de mercado se realizó un estudio cualitativo consistente en la observación realizada en un bar del distrito de Santiago de Surco ubicado en la Av. El Polo frente al Centro Comercial El Polo de nombre "Entre Copas" (ver Anexo $\mathrm{N}^{\circ}$ 3) en la que se preguntó a personal del bar (mozo y barman) sobre la capacidad y ocupación del 
establecimiento en cada uno de los días de la semana que ofrecen atención, así como a las preferencias de sus clientes en cuanto a comidas y bebidas que ofrece su carta. Como resultado de este estudio se determinó un precio de ticket promedio de S/ 118 (incluye IGV), de acuerdo a la determinación del ticket promedio, indicada en el Anexo $\mathrm{N}^{\circ} 5$.

Dicho monto se encuentra dentro de los rangos descritos en el punto 4.2.1 dónde se define el presupuesto asignado por lo clientes potenciales entre 100 y 200 soles.

\subsubsection{Estrategia comunicacional.}

La estrategia de comunicación a utilizar para difundir la propuesta de valor del negocio y se posicione en el mercado será principalmente a través de:

- $\quad$ Publicidad digital en redes sociales y web, también. Esto incluye entrar en las bases de datos de los buscadores (Google maps) y diversas páginas de opinión (por ejemplo Trip Advisor), así como en redes sociales de manera activa (Facebook e Instagram principalmente).

- Presencia dentro de las aplicaciones en los programas de fidelización de bancos locales para obtener reconocimiento dentro de los usuarios de los mismos.

- Creación de redes de promotores de venta e influenciadores, a quienes se les pagará con consumo dentro del local y montos fijos, respectivamente. El objetivo es que estos aseguren un flujo constante de consumidores dentro del local.

Al tratarse de un concepto nuevo, las campañas iniciales serían en redes sociales, explicando cómo funciona el nuevo concepto y explotando sus principales bondades frente a la competencia, tales como reducción de tiempos de espera, mejores precios y temáticas diversas. Esto se realizaría a través de redes sociales inicialmente, mediante el uso de publicaciones en foto o video tanto en Facebook e Instagram, con el objetivo de obtener flujo de visitantes en dichas redes. También se incluirá una página web 
dónde se podrá gestionar reservas y obtener mayor información sobre la empresa.

Posteriormente, se trabajará con promotores e influenciadores con el objetivo para asegurar flujo de clientes al local mediante un plan de beneficios (tanto en efectivo como en consumo) y ganar el "Zero Moment of Truth". De acuerdo a Google este momento se define como "el paso adicional dentro del proceso de compra del cliente, en el cuál estos buscan información acerca de un estímulo que recibieron" (Google, 2018) Esto aplicará, complementará a las pautas publicitarias por redes y al estímulo visual del local, de forma que cliente obtenga más información del mismo.

El nombre del bar sería Bar-ullo, se busca que sea un nombrendefácil recordación por parte de los clientes.

Como parte de la entrevista a expertos (ver Anexo $\mathrm{N}^{\circ} 3$ ), se define el presupuesto de marketing en 3 por ciento de las ventas. La distribución de las mismas puede variar dependiendo de la estrategia puntual, pero no deberá exceder dicho porcentaje. Las comunicaciones deberán ser dirigidas a las personas que cumplan con las características detalladas en el capítulo 4.2.1, para asegurar su flujo dentro del establecimiento.

\subsubsection{Estrategia de distribución y canal.}

La estrategia de distribución en este tipo de negocio está estrechamente relacionada con la localización del establecimiento.

Luego de revisar la concentración de bares en los distritos donde los clientes de nuestro mercado objetivo suelen asistir es posible darse cuenta que son los distritos de San Borja y Santiago de Surco donde existen zonas convenientes para la apertura del bar con autoservicio (ver Gráfico $\mathrm{N}^{\circ} 6 \mathrm{y}$ Gráfico 7) y adicionalmente están cerca a centros empresariales, centros comerciales, restaurantes y otros bares, por lo que no habría complicaciones con licencia de funcionamiento en trámite y costos. En 
conclusión, por la razón antes mencionada, y debido a que el precio de mercado y el precio de venta del metro cuadrado en los distritos de San Isidro y Miraflores es mayor, son convenientes las áreas que se muestran a continuación:

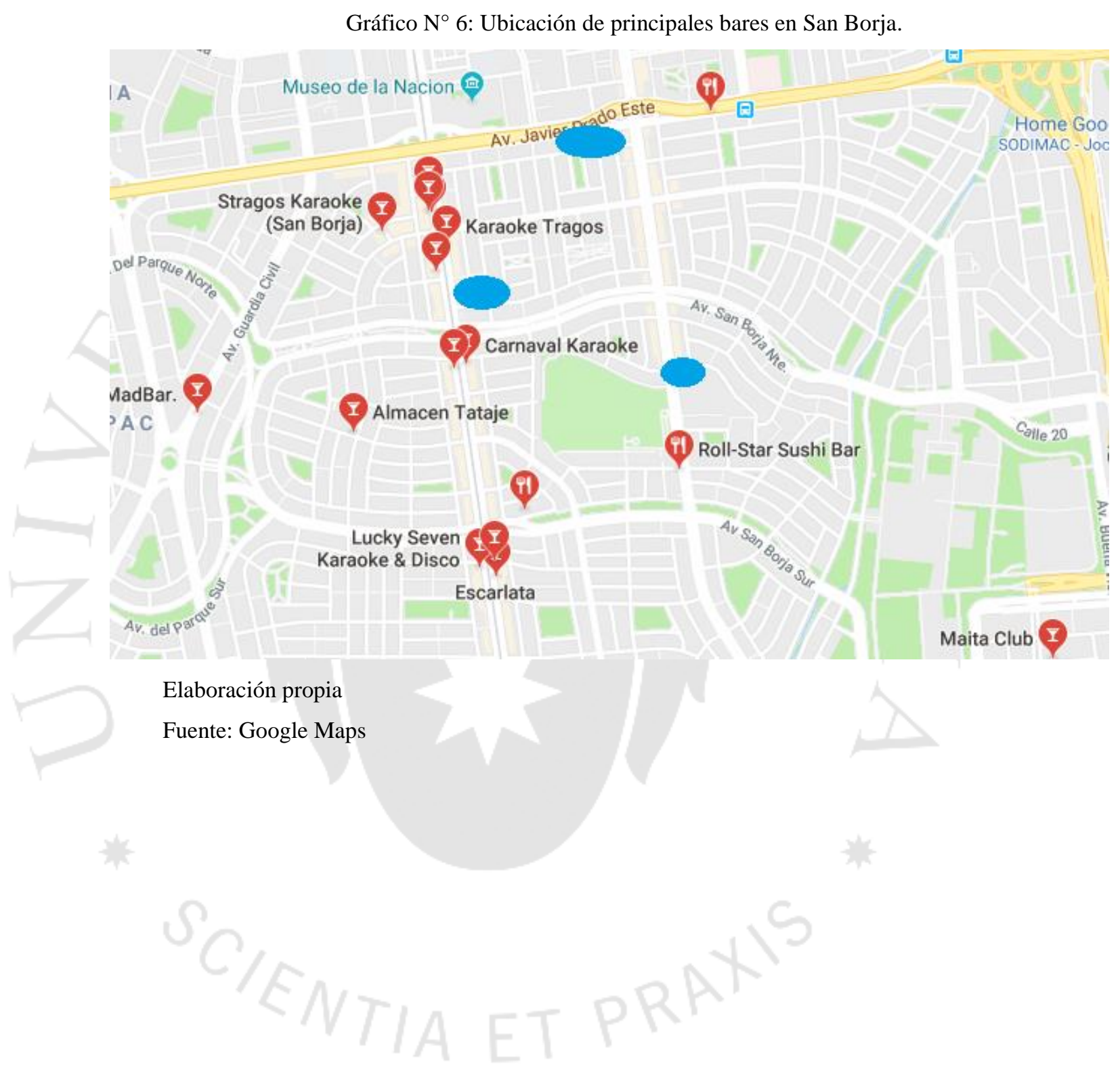


Gráfico $N^{\circ}$ 7: Ubicación de principales bares en Santiago de Surco

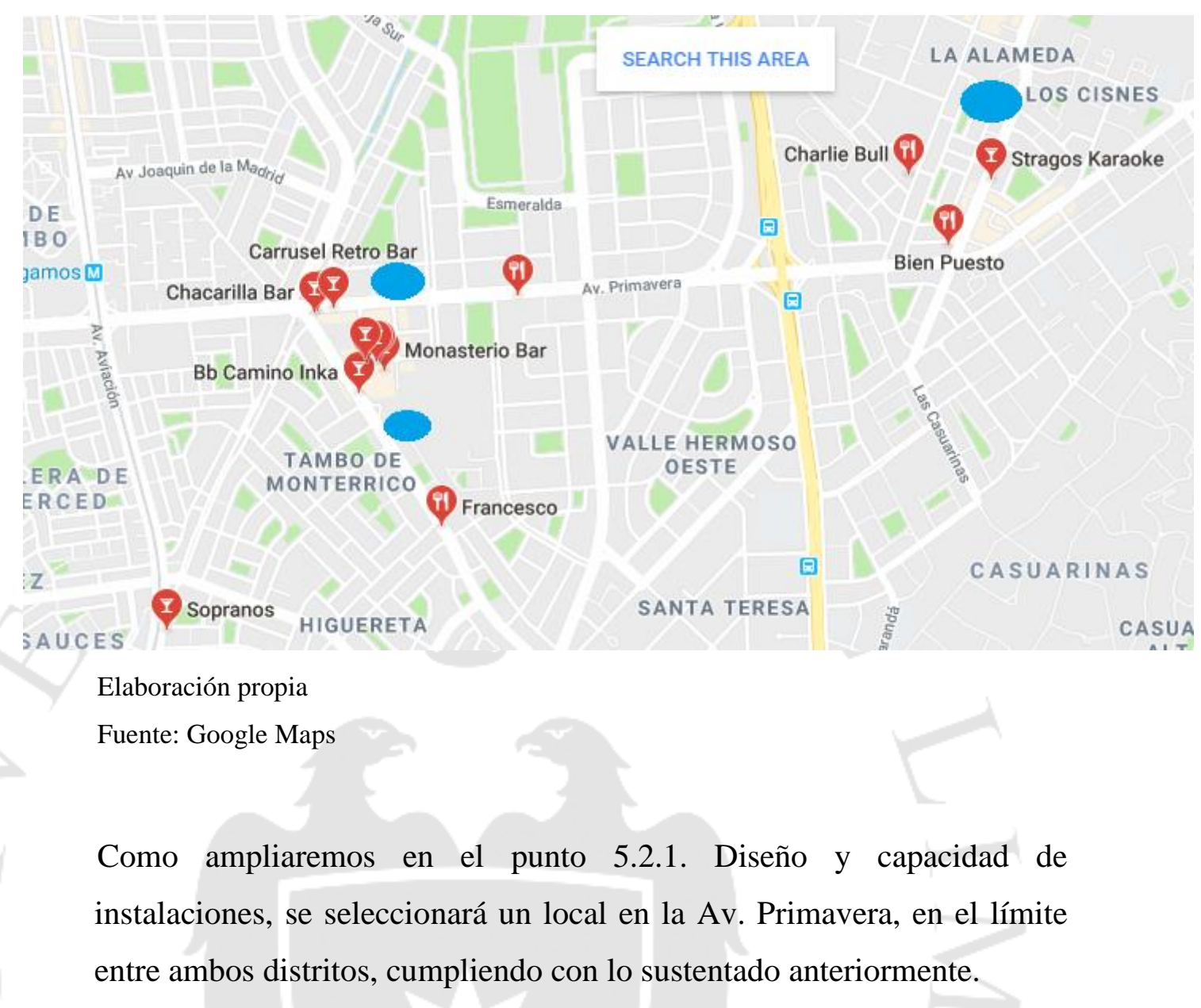

4.5. Plan de Ventas (objetivos anuales, alcance de la oferta) y Proyección de la

\section{Demanda (crecimiento y desarrollo).}

El plan de ventas se ha estimado en base al ticket promedio de S/ 118 para una mesa de 2 personas con un promedio de tiempo de permanencia de 2 horas, de acuerdo a lo mostrado en el Anexo 6, tomando en cuenta los precios de la carta del bar Entre Copas visitado (ver Anexo $N^{\circ} 3$ ).

El resultado de esta estimación del ticket promedio arrojó un ingreso mensual de S/ 125,126.25 y una venta total anual de S/ 1,478,095, considerando estacionalidad y un incremento en ventas para el segundo año de 10\%, para el tercer año de $20 \%$ y para el cuarto año de $10 \%$ respectivamente. 


\subsection{Conclusiones sobre la viabilidad comercial}

Luego de lo expuesto en los puntos anteriores, se identifica una necesidad de mercado para un bar temático enfocado en la comodidad y atención, que posea nuevos conceptos que atraen a los potenciales clientes a incrementar su asistencia y el consumo dentro del local.

En base a esto se define al cliente como un consumidor que aprecia la temática, conceptos novedosos, buena atención y comodidad, que invierte parte de su presupuesto mensual en ocio y que está usualmente acompañado por amigos fuera del ambiente laboral, por lo que debe poseer un poder adquisitivo que lo permita. El concepto de bar con noches temáticas y sistema autoservicio de cerveza, cumple con estas expectativas y para atraerlos se buscará una estrategia de comunicación basada en redes sociales, internet y promotores de ventas que aseguren el flujo de los mismos. El estudio cuantitativo detallado en el Anexo 1 respalda el interés de los clientes potenciales en esta idea.

Luego de alinear las necesidades de mercado con los conceptos propuestos, se puede concluir que el proyecto es comercialmente viable, debido a que podrá generar el nivel de ventas requerido para operar adecuadamente. 


\section{Plan de Operaciones}

\subsection{Políticas Operacionales}

\subsubsection{Diseño y calidad del producto o servicio}

El servicio del bar está definido por las siguientes características que se combinan con productos:

- Alimentos o bebidas: Productos estándares, la principal característica de estos productos es la simplicidad de los mismos. Con base a la visita de observación realizada a diferentes bares y en específico al Bar "Entrecopas" (ver Anexo $N^{\circ}$ 03) es posible apreciar que el patrón de preferencias en consumo de sus clientes es por los cocteles clásicos como pisco sour, chilcanos etc, asi como por el lado de alimentos o piqueos la tendencia también es por los cásicos como: tequeños, chicharrón de pollo, etc.

- Atención: La recepción de pedidos y el servicio de un mozo es un atributo destacable para el cliente.

- Autoservicio en cerveza: Uno de los diferenciadores, habilitar los grifos con medidor para el consumo de cerveza es considerado un servicio.

- Eventos temáticos: La elaboración de ambientación especial es un servicio de valor agregado que se otorgará dentro del bar.

Basados en la experiencia de la visita a bares competidores (ver Anexo $\mathrm{N}^{\circ}$ 3) y a la información y datos recolectados en la entrevista a expertos (ver Anexo $\mathrm{N}^{\circ} 4$ ) se puede concluir que en un bar con autoservicio la proporción entre servicio y producto es de $75 \%$ y $25 \%$ respectivamente donde existe la combinación entre una fábrica de servicios (atención al cliente) y autoservicio (consumo del cliente por grifo medidor).

\subsubsection{Macro-proceso y cadena de valor}

El macro proceso elaborado para el bar con autoservicio (ver Gráfico $\mathrm{N}^{\circ}$ 8) está alineado con la misión de la empresa que parte de priorizar la satisfacción de la necesidad de entretenimiento y comodidad del cliente, para lo cual se deben asegurar el cumplimiento de procesos como el de 
gestión y planificación de compras (adquisición de bienes y servicios), de producción o preparación de piqueos y cocteles, de gestión del talento humano (plan de capacitación e incentivos), la planificación de la venta que tiene un constante foco en observar y atender las nuevas necesidades o cambios en las preferencias del cliente.

Asimismo, en cuanto a la cadena de valor se han identificado actividades claves para mantener una ventaja competitiva frente a otras propuestas (productos sustitutos). Es así que el aseguramiento y mantenimiento de la infraestructura diseñada para el bar que descansa en el ambiente y espacio agradable y entretenido (propuesta temática) y el correcto funcionamiento de las máquinas surtidoras de cerveza (autoservicio) es imprescindible. Asimismo, la adquisición de insumos, preparación del salón (mesas y barra), marketing (contactos en redes sociales) y el programa posventa que tienden a asegurar la fidelización del cliente son muy importantes (ver Gráfico $\mathrm{N}^{\circ}$ 9)

Gráfico $\mathrm{N}^{\circ}$ 8: Macro-Proceso

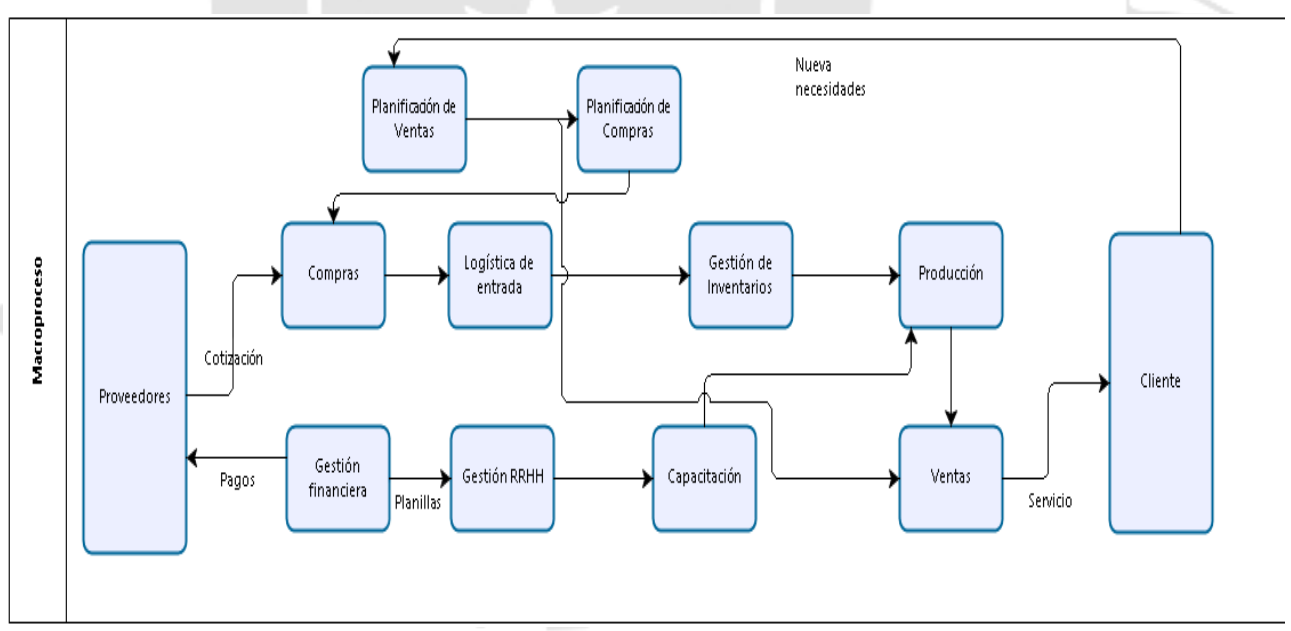

Elaboración propia 
Gráfico $N^{\circ} 9$ Cadena de Valor

\begin{tabular}{|c|c|c|c|c|}
\hline \multicolumn{5}{|c|}{ Infraestructura: Local en Surco, compra de surtidores con medidor } \\
\hline \multicolumn{5}{|c|}{ Recursos Humanos: Reclutamiento de meseros y cajeros } \\
\hline \multicolumn{5}{|c|}{ Tecnología: Software de facturación, medios de pago, fidelización } \\
\hline \multicolumn{5}{|c|}{ Compras: Alimentación, bebidas, equipos de sonido, decoración } \\
\hline $\begin{array}{l}\text { Logística interna: } \\
\text { Adquirir insumos } \\
\text { y productos para } \\
\text { la atención. } \\
\text { Contratación de } \\
\text { servicios para } \\
\text { eventos }\end{array}$ & $\begin{array}{l}\text { Operaciones: } \\
\text { Preparar el } \\
\text { salón para los } \\
\text { comensales, } \\
\text { limpieza y } \\
\text { armado de } \\
\text { ambientación }\end{array}$ & $\begin{array}{l}\text { Logística } \\
\text { externa: } \\
\text { Recibir } \\
\text { pedidos, } \\
\text { habilitación } \\
\text { de mesas. }\end{array}$ & $\begin{array}{l}\text { Marketing: } \\
\text { Contacto en } \\
\text { redes } \\
\text { sociales, } \\
\text { promociones. }\end{array}$ & $\begin{array}{c}\text { Post-Venta: } \\
\text { Programas } \\
\text { de } \\
\text { fidelización }\end{array}$ \\
\hline
\end{tabular}

Elaboración propia

\subsection{Equipos, actividades y procesos.}

\subsubsection{Diseño y capacidad de instalaciones.}

Para definir la localización del bar, se han tomado los siguientes criterios: zonas donde se encuentran competidores, nivel de flujo de personas y el otorgamiento de licencias de funcionamiento. Si bien en el capítulo anterior, se propuso lugares sin competencia, estos normalmente se encontraban lejos de zonas de influencia o residenciales donde el otorgamiento de una licencia de funcionamiento sería difícilmente otorgada debido a la zonificación establecida por cada municipio distrital, en particular el de Santiago de Surco. Asimismo, es importante indicar que tanto los proveedores de bebidas como de eventos tienen la facilidad de llegar al local. A continuación se muestran los datos del local escogido:

- $\quad$ Dirección: Av. Primavera - San Borja (Frente CC Caminos del Inca)

- Precio: S/.12,350 (US\$25.33 en m2)

- Flujo de personas: Se encuentra cercano a una zona relevante de bares y discoteca, por lo que es un lugar de accesibilidad para clientes.

- Licencias: En la zona escogida funcionan varios locales de similares características, lo que facilitaría el trámite de la licencia de funcionamiento respectiva. 
- Competencia: Si bien hay otros locales cercanos, la propuesta es diferente, así como el público objetivo identificado en esta propuesta.

- Número de mesas: 10 mesas, divididas en 5 mesas redondas con capacidad para 4 personas y 5 mesas rectangulares o boots (4 con surtidores) con capacidad para 6 personas. Se permitiría la posibilidad de que los comensales puedan estar de pie, sobre todo para temáticas de fines de semana. 
A continuación se incluye el plano propuesto, esto fue diseñado por la arquitecta Ximenna Carbonell a medida para el presente proyecto:

Gráfico $\mathrm{N}^{\circ}$ 10: Plano del Establecimiento

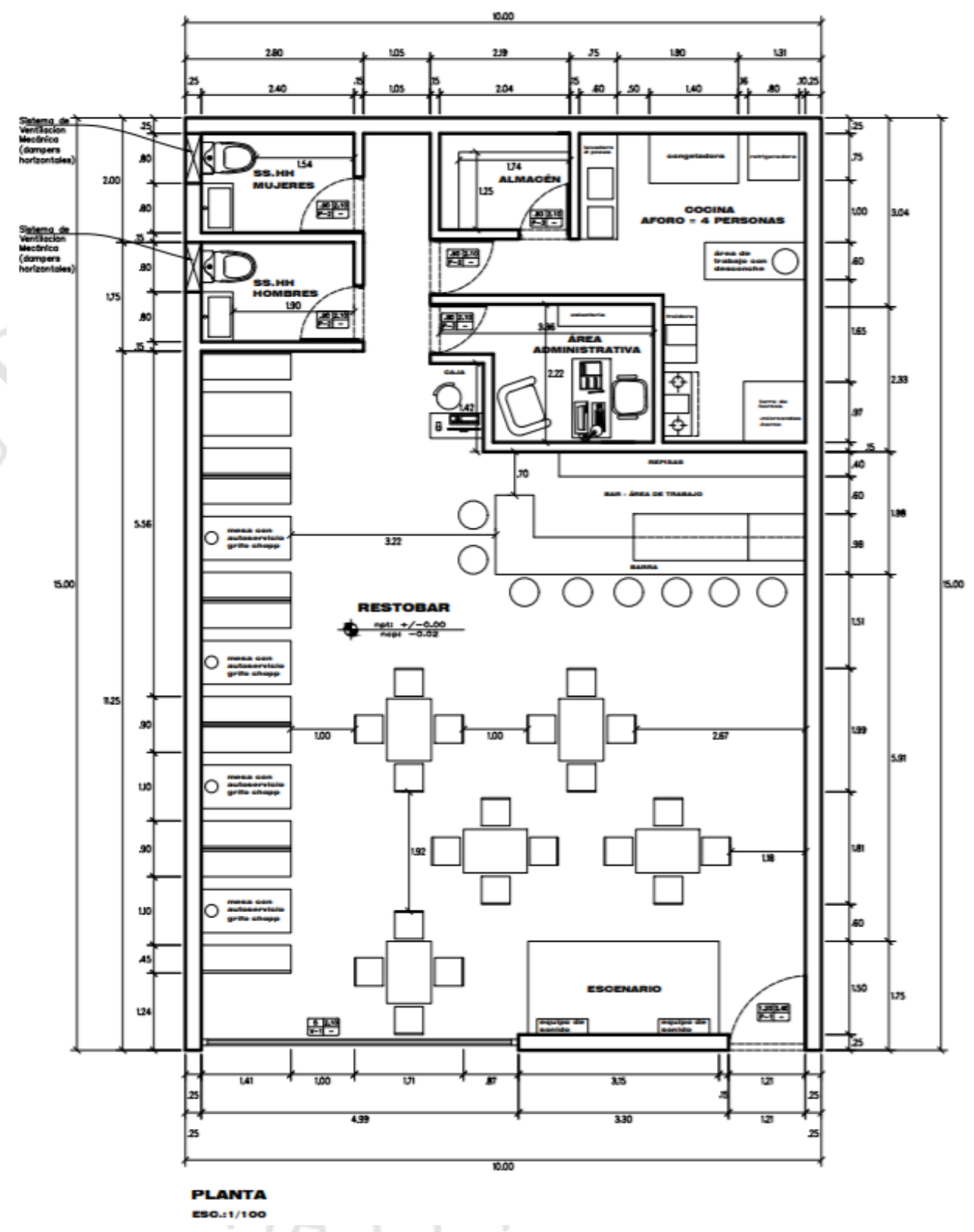

Elaboración propia

Si bien existe el concepto novedoso del autoservicio, la distribución de zonas mantiene elementos de un bar tradicional como las mesas con atención tradicional y una barra. Se incluye un escenario de tamaño reducido para dejar espacios libres que motiven la sensación de comodidad dentro del local. El almacén debe mantener una proporción mediana, 
debido a que si bien la carta no es especializada y no existe la necesidad de mantener inventarios complejos, los contenedores de cerveza son grandes y pueden ocupar buena parte del espacio.

\subsubsection{Equipos de trabajo y apoyo.}

Los equipos de trabajo y de apoyo se han definido por las actividades y áreas que se deben ejecutar para brindar los servicios de entretenimiento y diversión, así como la fabricación y preparación de piqueos y cocteles, ofrecidos en la propuesta de valor planteada. A continuación se puede apreciar en detalle el requerimiento de personal por dichas áreas, la profesión u oficio, el nivel de experiencia y su condición de contratación a tener en cuenta en el primer año de funcionamiento del establecimiento. (Ver Tabla $\mathrm{N}^{\circ}$ 4). Es importante indicar que luego del primer año de funcionamiento se evaluarán los indicadores de servicio y calidad, ingresos y rentabilidad del negocio, la situación macroeconómica del país y el desempeño de los colaboradores y sobre los resultados de dicha evaluación se podrá reconsiderar la modalidad de contratación de los colaboradores.

Tabla $N^{\circ}$ 4: Personal por Áreas

\begin{tabular}{|c|c|c|c|c|c|c|}
\hline Área & Cant & Turnos & Total & $\begin{array}{l}\text { Modalidad de } \\
\text { contratación }\end{array}$ & Profesión / Oficio & Años de Experiencia \\
\hline \multicolumn{7}{|l|}{ Adminitración } \\
\hline Administrador & 1 & 2 & 2 & Plazo fijo & Administrador & 5 años o más \\
\hline Cajero & 1 & 2 & 2 & Plazo fijo & Admin / Contador & 3 años o más \\
\hline Contador & 1 & 1 & 1 & Tercero / Honorarios & C.P.C. & 5 años o más \\
\hline \multicolumn{7}{|l|}{ Atención directa a cliente } \\
\hline Valet Parking & 1 & 2 & 2 & Tercero / Honorarios & Chofer / Ed.Secund & 3 años o más en manejo \\
\hline Anfitriona & 1 & 2 & 2 & Tercero / Honorarios & Practicante Turismo & 1 año o más \\
\hline Jefe de Mozos & 1 & 2 & 2 & Plazo fijo & Adm.hotelera & 5 años o más \\
\hline Mozos & 3 & 2 & 6 & Tercero / Honorarios & Adm.hotelera & 3 años o más \\
\hline Ayudantes & 2 & 2 & 4 & Tercero / Honorarios & Educ. secundaria & 1 año o más \\
\hline \multicolumn{7}{|l|}{ Cocina } \\
\hline Jefe de Cocina & 1 & 2 & 2 & Plazo fijo & Cheff & 5 años o más \\
\hline Ayudante & 1 & 2 & 2 & Tercero / Honorarios & Estudiante cocina & 1 año o más \\
\hline \multicolumn{7}{|l|}{$\underline{B \text { arra }}$} \\
\hline Bartender & 1 & 2 & 2 & Plazo fijo & Egresado Cocteleria & 3 años o más \\
\hline Ayudante & 1 & 2 & 2 & Tercero / Honorarios & Estudiante coctekeria & 1 año o más \\
\hline \multicolumn{7}{|l|}{ Otros servicios } \\
\hline Almacenero & 1 & 2 & 2 & Plazo fijo & IST Compras & 3 años o más \\
\hline Música & 1 & 1 & 1 & Tercero / Honorarios & & \\
\hline Comediante stand up & 1 & 1 & 1 & Tercero / Honorarios & & \\
\hline Personal limpieza & 1 & 2 & 2 & Tercero / Honorarios & Educ. secundaria & 1 año o más \\
\hline Vigilante & 1 & 2 & 2 & Tercero / Honorarios & Educ. secundaria & 1 año o más \\
\hline
\end{tabular}

Elaboración propia 
Por otro lado, se identificó como un producto clave, el cual es el elemento diferenciador de la propuesta del proyecto y es necesario evaluar su utilización bajo la compra del sistema o del alquiler del mismo, para lo cual hemos identificado dos proveedores: el primero "ebeer" (http://www.ebeersystem.com/) y el segundo "Drink Command" (https://www.drinkcommand.com/). El equipo del segundo proveedor (beertap) es el que se muestra a continuación:

Gráfico $N^{\circ}$ 11: Sistema de Surtidor de Cerveza (Beertap)

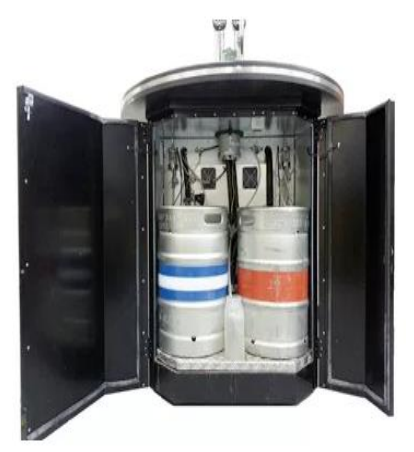

The 'Wet Side'

Lockable chilled storage for $2 \times 50$ litre kegs (or smaller kegs if required) with chiller plate, drainage container and electronic FOB detectors.

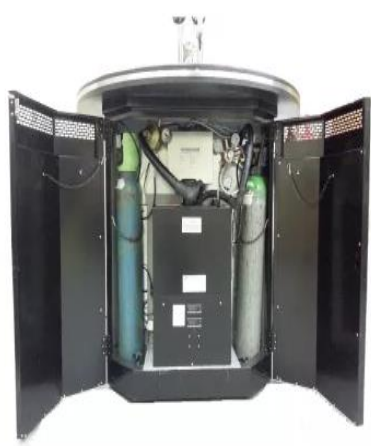

The 'Dry Side'

Powerful glycol chilled beer line cooler with recirc to the taps which keep the beer cold right to the taps. Storage for 2 gas bottles of different mixes if required (eg stout and lager) plus gas regulators.

Fuente: Drink Command

\subsubsection{Gestión de proveedores, compras y stock.}

La selección de proveedores es muy importante en el proceso de compras, stock y almacenamiento. El punto de partida es el detalle de los elementos de esta propuesta:

- Ambiente agradable, para esto es necesario la contratación de un experto arquitecto de interiores, para el diseño y la decoración del establecimiento. Como consecuencia de la asesoría experta del arquitecto de interiores y de expertos en tendencia de decoración y temática de bares se comprará el mobiliario y equipos para sala de atención, barra y cocina, objetos de decoración como luminarias, cuadros, etc., y para baños, etc. 
- Autoservicio de cerveza a través de mesas surtidoras de cerveza (grifos chopp), donde se ha identificado al proveedor clave que proveerá el sistema surtidor de cerveza (chopp), el cual incluye un software para contabilizar el flujo de cerveza consumido, toma, emisión y atención de pedido en mesa y emisión de la cuenta del consumo de cerveza. La compra de este equipo incluye servicio de mantenimiento del equipo y del software de atención, tal como lo indica las páginas web consultadas: www.ebeersystem.com, www.drinkcommand.com.

- Carta de platos de piqueo, cocteles, licores, diseñada por un experto, donde la compra de estos productos se hará a reconocidos distribuidores mayoristas de cerveza, licores y gaseosas y en la parte de alimentos a distribuidores mayoristas de frutas y verduras, papas pre cocidas para freír y nuggets de pollo. Este punto ha sido validado en detalle por los expertos en el rubro de bar restaurantes entrevistados, a través de sus respuestas e información proporcionada. (ver Anexo $\mathrm{N}^{\circ} 4$ ), y por la información recolectada en la visita a un bar competidor llamado "Entrecopas" (ver Anexo No 3).

- Temática, que tiene que ver con la propuesta de música en vivo, stand up comedy, juegos para los clientes, donde se contratarán bandas de música, freelance, dedicados a este rubro.

Un aspecto importante a tener en cuenta en la selección de proveedores es que las empresas proveedoras de licores y de alimentos estén debidamente constituidas y que sus stocks para venta sean de procedencia licita, dado que según un artículo de un diario local informó lo siguiente: "CCL: 30\% de bebidas alcohólicas que se consumen en Perú son informales". (Diario Gestión, 2018). Con base en esta información es muy importante que el bar con autoservicio tenga especial cuidado con la trazabilidad de las bebidas alcohólicas que comprará a sus proveedores para lo cual será necesario hacer las verificaciones respectivas, como ver si el proveedor del establecimiento se encuentra inscrito en el Registro de Comercializadores de Bebidas Alcohólicas del Ministerio de la 
Producción, al que se puede acceder en la página web de dicho ministerio con este link: https://www.produce.gob.pe/index.php/shortcode/serviciosmype-e-industria/bebidas-alcoholicas. Asimismo, será necesario verificar si el proveedor tanto de bebidas alcohólicas como de alimentos cuenta con los registros sanitarios de bebidas alcohólicas y de alimentos de consumo humano respectivos que son emitidos por la Dirección General de Salud Ambiental - DIGESA del Ministerio de Salud.

De igual forma el establecimiento deberá verificar la situación legal, tributaria y financiera de sus proveedores en las plataformas existentes como centrales de riesgo y reportes crediticios, así como el portal de SUNAT y de la Cámara de Comercio de Lima, etc., de tal forma que pueda asegurar que sus proveedores estén debidamente habilitados para operar y vender los productos requeridos por el negocio.

\subsubsection{Tercerización 0 integración de procesos.}

En el bar con autoservicio se dan procesos relacionados a servicios que pueden ser tercerizados como servicio de contabilidad, de vigilancia, de anfitrionas, de ayudantes de cocina.

La razón por la que se considera tercerizar las actividades indicadas anteriormente es porque éstas son complementarias y de apoyo al corazón del negocio (core business) como es la atención directa al cliente y al aseguramiento de los estándares de calidad en la atención en salón, en barra y en la preparación de los piqueos y cocteles a través de personal calificado con experiencia y entrenado para esos fines.

Una evaluación luego del primer año de actividad del establecimiento permitirá una visión más clara de aquel personal contratado como tercero que pudiera ser incorporado a planilla de sueldos por su buen desempeño y en la medida que los objetivos de rentabilidad del negocio sea alcanzado, lo que permitirá contar con personal calificado identificado con la cultura de la empresa que pueda ser tomado en cuenta en la potencial apertura de otra sede del establecimiento. 


\subsubsection{Proceso de Elaboración de bienes y Prestación de servicio.}

A continuación se presentan los flujogramas relacionados a los Procesos de Ventas, así como los relacionados a los procesos de Compras y Producción (ver Gráfico $\mathrm{N}^{\circ} 12$ Flujograma de Ventas y Gráfico $\mathrm{N}^{\circ} 13$ Flujograma de Compras y Fabricación), basados en las áreas identificadas de servicio y de fabricación-preparación de bebidas y piqueos.

Estos procesos tienen que ver con la atención directa al cliente desde que llega al bar y su permanencia en el establecimiento. Asimismo, el proceso de compras y fabricación tienen que ver con las actividades que se originan y se realizan propiamente en cocina, barra y almacén.

Grafico $\mathrm{N}^{\circ}$ 12. Flujograma de Ventas

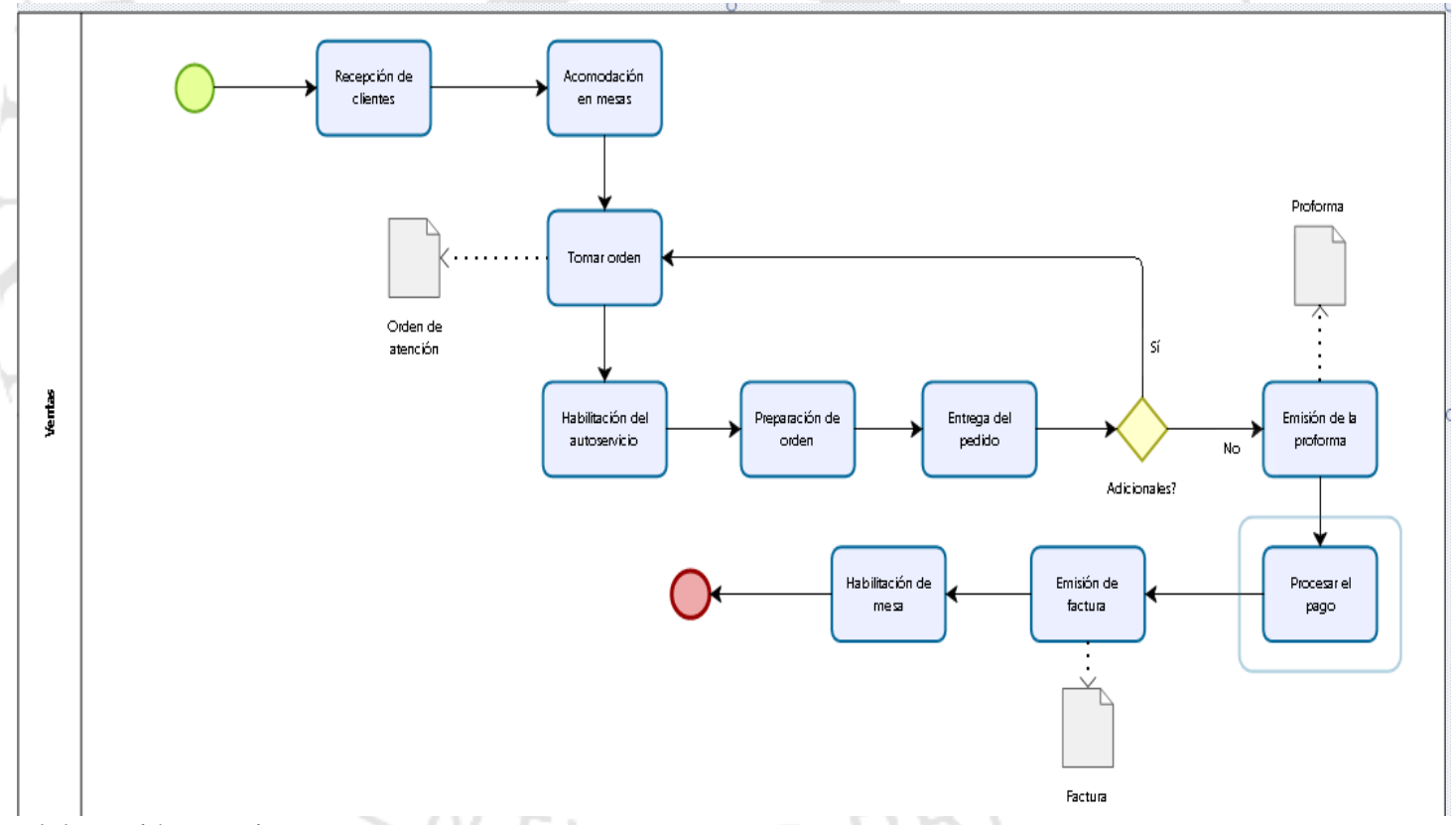

Elaboración propia

El proceso de ventas es bastante estándar, el nuevo concepto se distingue por la habilitación del autoservicio, esto quiere decir encontrar el barril de cerveza de la marca solicitada e instalarla en la mesa. El software de medición permitirá que la facturación se realice de manera automática. Es importante que al emitir la proforma se apague el sistema de surtidor de autoservicio para no incurrir en venta no pagada. 
Parte de procesar el pago, está en el uso de los POS y en ingresar el dinero en la caja registradora. Al final de cada turno se debe realizar la liquidación de la caja con el objetivo de realizar el depósito en los días siguientes. También se brindarían opciones de pago como BBVA Wallet y Yape como aplicativos que no requieren el uso directo de una tarjeta de crédito, ambos conectados a cuentas corrientes del negocio, esto ayudaría en la experiencia del cliente, pues otorgaría mayores opciones que no ofrecen todos los competidores y estaría asociado al factor de comodidad y atención especificado en el Anexo $\mathrm{N}^{\circ} 2$ como factor para elegir un bar.

Esto último se verá complementado dentro de la estrategia comercial (explicada en el capítulo anterior), de estar dentro de los planes de fidelización de los bancos locales, ya que estas aplicaciones normalmente están ligadas a uno de estos, y su uso será fomentado con los descuentos promocionales.

Gráfico $\mathrm{N}^{\circ}$ 13. Flujograma de Compras y Producción

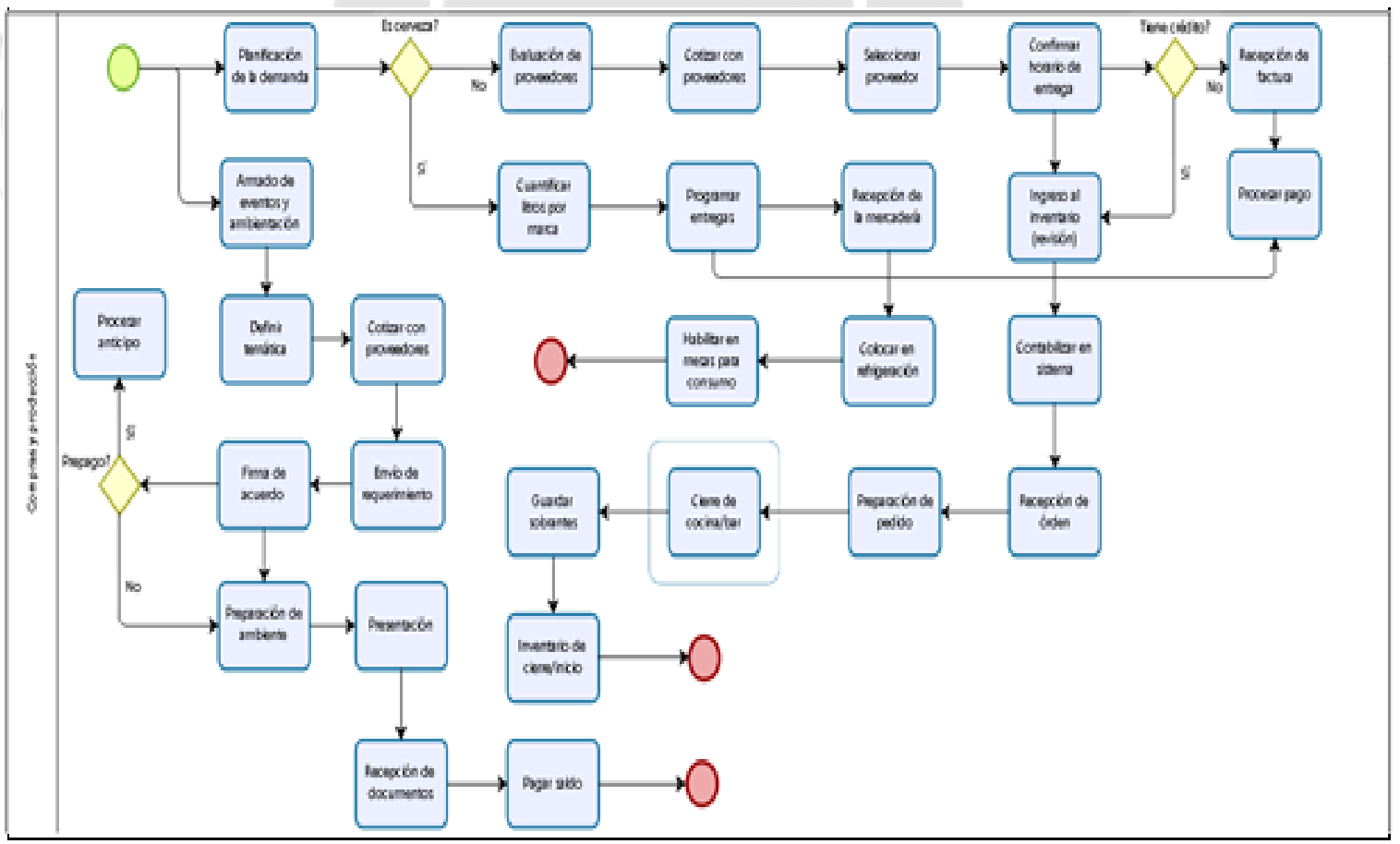

Elaboración propia

El proceso de compra y producción abarca todo lo relacionado con la negociación con proveedores, la logística de entrada y salida, así como la 


\section{Plan de Recursos Humanos}

\subsection{Objetivos Organizacionales}

Para definir la naturaleza de los objetivos de una organización se hace referencia a (Koontz, 2012):

"los objetivos establecen los resultados finales, y los generales deben apoyarse en los particulares. Así éstos forman una jerarquía, es decir una red. Más aún organizaciones y gerentes tienen metas múltiples que en ocasiones son incompatibles y pueden llevar a conflictos dentro de la organización, del grupo y hasta entre individuos. El gerente tendrá que elegir entre un desempeño a corto o a largo plazo, y los intereses personales quizá tengan que subordinarse a los objetivos organizacionales". (p.118).

Los objetivos que se desarrollarán en este capítulo tienen que ver con la generación de rentabilidad, de un buen clima, laboral y de desempeño de sus colaboradores. Objetivos que asegurarán la continuidad de la empresa en el tiempo.

\subsubsection{Naturaleza de la Organización.}

La implementación del modelo de negocios "Bar con Autoservicio" está orientada hacia la atención de una necesidad de entretenimiento identificada en el mercado, para lo cual reúne una serie de recursos: humanos, económico-financieros, físicos; de objetivos y actividades bajo un objetivo claro de generación de rentabilidad y de bienestar y satisfacción para sus grupos de interés como son: clientes, usuarios, proveedores internos y externos, colaboradores y sus familias, accionistas, gobierno, fisco, etc., tal como se puede ver en los elementos definidos en el Canvas utilizado para este modelo de negocio en el punto 2.6 y en la Tabla $\mathrm{N}^{\circ} 1$ Modelo Canvas.

Por otro lado, la empresa en su aspecto jurídico será una sociedad anónima cerrada con la presencia de 2 o más accionistas (límite de número de accionistas: 20), y se constituirá conforme a lo indicado la Ley General de 
Sociedades del Perú - Ley 26887 en su Sección Séptima: Formas Especiales de la Sociedad Anónima, Título I en sus artículos 234 a 248.

\subsubsection{Organigrama.}

Conforme a lo señalado en el punto 5.2.2 donde se detalla las áreas y puestos requeridos para el funcionamiento de la empresa se ha diseñado un organigrama. A continuación se muestra el organigrama funcional de la empresa, en el cual se ha diferenciado por tipo de contratación del recurso humano requerido. Así tenemos que las posiciones en azul son las que estarán bajo un régimen de dependencia, es decir en la planilla de sueldos de la compañía, y en el caso de las posiciones en verde son aquellas que estarán bajo la modalidad de contratación de locación de servicios o como proveedor de servicios de la compañía (tercerizados), ya sea con una empresa o persona jurídica que provea el tipo de servicio indicado o a través de una persona natural directamente.

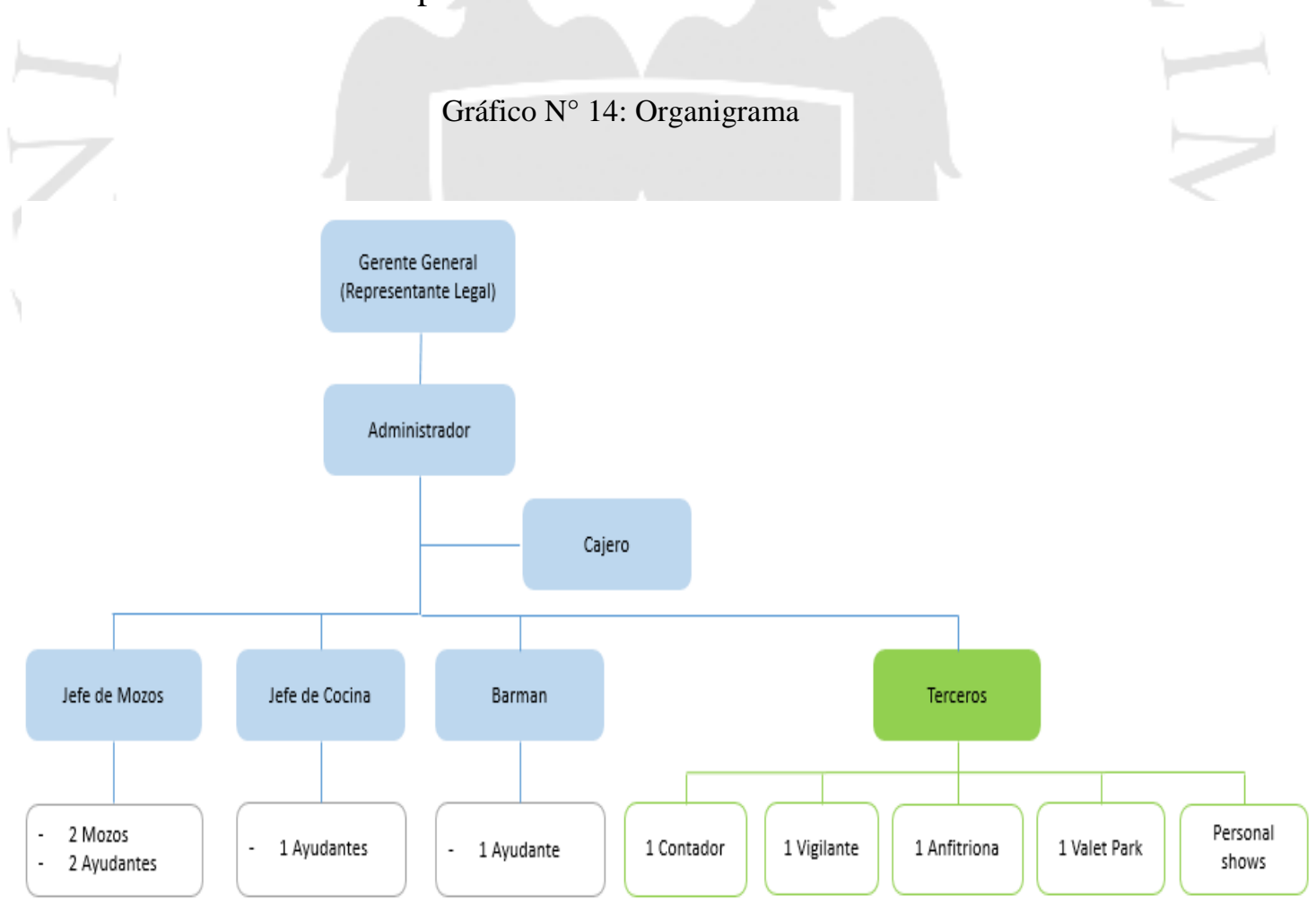

Elaboración propia 


\subsubsection{Diseño estructural por proyecto.}

(Stephen P. Robbins, 2009) señala:

"La estructura de una organización es un medio para ayudar a la administración a alcanzar sus objetivos. Como éstos se derivan de la estrategia general de la empresa, es lógico que estrategia y estructura deban estar relacionadas de cerca. Dicho de manera más específica, la estructura debe seguir a la estrategia. Si la administración hace un cambio significativo en su estrategia para la organización, la estructura necesitará ser modificada para dar acomodo y apoyo a este cambio.” (p.534).

En este sentido, un negocio de este rubro puede presentar características de una estructura mecanicista donde la cadena de mando, la especialización y experiencia son importantes mantener del primer nivel hacia el segundo, hacia el tercero o cuarto. Sin embargo se buscará tener una combinación entre la estructura mecanicista y la estructura orgánica, dado que si bien se deben respetar niveles jerárquicos determinados como: Nivel 1: Gerente general - Administrador, Nivel 2: Jefe de Mozos - Jefe de Cocina - Barman - Terceros, Nivel 3: Ayudantes de cocina y de barra - Limpieza - Vigilancia - Anfitriona - Terceros. Hay funciones cruzadas que requieren actividades de retroalimentación para corregir errores y para la propuesta de mejoras, recomendaciones y sugerencias tanto de los colaboradores a administrador y gerente y viceversa, como también de los clientes hacia los niveles de la empresa.

\subsection{Diseño de Puestos y Responsabilidades}

En el punto 5.2.2 relacionado a la definición de los equipos de trabajo y apoyo del negocio se dividió en las siguientes áreas:

- Administración.

- Atención directa al cliente.

- Cocina.

- Barra.

- Otros servicios 
Teniendo en cuenta esta clasificación es que se han diseñado los puestos. En la Tabla $\mathrm{N}^{\circ} 6$, donde se pueden apreciar las responsabilidades, funciones, ocupación o profesión requerida para cada puesto.

Tabla Nº ${ }^{\circ}$ Descripción de Puestos y Responsabilidades

\begin{tabular}{|c|c|c|c|c|}
\hline Área / Puesto & Cant & $\begin{array}{l}\text { Modalidad de } \\
\text { contratación }\end{array}$ & Req. Mínimo & Responsabilidades y Funciones \\
\hline \multicolumn{5}{|l|}{ Adminitración } \\
\hline Gerente General & 1 & Plazo fijo & Administrador & $\begin{array}{l}\text { Coordinar actividades de marketing y realizar las aprobaciones de } \\
\text { pagos, decisiones de inversión y financiamiento. Definir } \\
\text { proveedores tercerizados cuando aplique. }\end{array}$ \\
\hline Administrador & 1 & Plazo fijo & Administrador & $\begin{array}{l}\text { Velar por el correcto funcionamiento del local, de normas y } \\
\text { horarios. Programar los pagos y revisar el cumplimiento de } \\
\text { obligaciones contables. }\end{array}$ \\
\hline Cajero & 1 & Plazo fijo & Admin / Contador & $\begin{array}{l}\text { Responsable de cuadre de caja diario. Entrega de las cuadraturas al } \\
\text { administrador e ingresar las remesas en la caja fuerte del local. }\end{array}$ \\
\hline Contador & 1 & Outsorcing / Honorarios & C.P.C. & $\begin{array}{l}\text { Cumplimiento de obligaciones contables frente a la contabilidad } \\
\text { tributaria. Elaboración de estados financieros a la gerencia general }\end{array}$ \\
\hline \multicolumn{5}{|l|}{ Atención directa a cliente } \\
\hline Valet Parking & 1 & Tercero / Honorarios & Chofer / Ed.Secund & Encargarse del estacionamiento de los automóviles de los clientes \\
\hline Anfitriona & 1 & Tercero / Honorarios & Practicante Turismo & $\begin{array}{l}\text { Buen trato y disposición con cliente. Apoyo a personal de servicio } \\
\text { en mesa }\end{array}$ \\
\hline Jefe de Mozos & 1 & Plazo fijo & Adm.hotelera & $\begin{array}{l}\text { Supervisar el cumplimiento de la labor de los mozos, así como } \\
\text { apoyo en la solución de conflictos con clientes. Manejar y gestionar } \\
\text { cronogramas de trabajo de los mozos. }\end{array}$ \\
\hline Mozos & 3 & Plazo fijo & Adm.hotelera & $\begin{array}{l}\text { Atender a los clientes del local, ubicarlos, presentarles la carta y } \\
\text { explicarles las dudas que tengan sobre el sistema de autoservicios. }\end{array}$ \\
\hline Ayudantes & 2 & Plazo fijo & Educ. secundaria & Apoyar a los mozos \\
\hline \multicolumn{5}{|l|}{ Cocina } \\
\hline Jefe de Cocina & 1 & Plazo fijo & Cheff & $\begin{array}{l}\text { Coordina con Administrador Compras y Gestión de Ayudantes de } \\
\text { Cocina. Reporta a Administrador }\end{array}$ \\
\hline Ayudante & 1 & Tercero / Honorarios & Estudiante cocina & Coordina y Reporta a Jefe de Cocina. \\
\hline \multicolumn{5}{|l|}{ Barra } \\
\hline Bartender & 1 & Plazo fijo & Egresado Cocteleria & $\begin{array}{l}\text { Preparación de bebidas alcohólicas para los clientes de acuerdo a } \\
\text { requerimiento. }\end{array}$ \\
\hline Ayudante & 1 & Tercero / Honorarios & Estudiante coctekeria & Apoyar al bartender \\
\hline \multicolumn{5}{|l|}{ Otros servicios } \\
\hline Comprador/Almacenero & 1 & Plazo fijo & IST Compras & $\begin{array}{l}\text { Coordina con administrador compras y almacenamiento de } \\
\text { productos e insumos. Realiza el control de stocks. }\end{array}$ \\
\hline Música & 1 & Tercero / Honorarios & Educ. secundaria & Contrata con Adnministrador. \\
\hline Comediante stand up & 1 & Tercero / Honorarios & Educ. secundaria & Contrata con Adnministrador. \\
\hline Personal limpieza & 1 & Tercero/ Honorarios & Educ. secundaria & Encargarse de la limpieza del local antes de cada nueva apertura. \\
\hline Vigilante & 1 & Tercero / Honorarios & Educ. secundaria & Velar por la seguridad de los clientes. \\
\hline
\end{tabular}

Elaboración propia

Los ayudantes apoyan al principal de su área en el cumplimiento de sus objetivos, esto incluye principalmente labores de limpieza y soporte para eficiencia en tiempos de respuesta y mayor control sobre las actividades.

\subsection{Políticas Organizacionales.}

Se fijaron las siguientes políticas organizacionales sobre los cuáles se desarrollarán los planes de recursos humanos dentro de la empresa. Debajo de cada una de estas políticas se explicarán acciones puntuales para cada uno:

a) Generar un buen clima: Se busca que la colaboración entre el equipo de trabajo sea un diferenciador al momento de ofrecer los servicios al cliente. Este objetivo se logrará con las siguientes acciones concretas: 
(i) Brindar retroalimentación constante en aspectos de responsabilidad, cooperación y trabajo en equipo. La comunicación con los colaboradores debe ser fluida y sin restricciones.

(ii) Generar indicadores eficientes de equipo (en su elaboración y ejecución) para establecer objetivos tangibles y exista una motivación constante a la mejora como equipo.

b) Alcanzar altos rendimientos de cada colaborador, lo cual se logrará aplicando las siguientes acciones:

(i) Realizar evaluaciones periódicas y comunicarlas oportunamente para motivar y/o corregir actitudes o rendimientos para asegurar que el desempeño sea el esperado.

(ii) Reconocer a aquellos colaboradores que destaquen en su desempeño. Esto es un amplio rango entre felicitaciones públicas y mayores compensaciones a percibir (bonificaciones, empleado del mes, etc.).

\subsection{Gestión de Talento.}

\subsubsection{Selección y Contratación.}

a) Selección: Para seleccionar al personal, ejecutaremos los siguientes lineamientos:

(i) Búsqueda: Utilizar 3 fuentes de búsqueda de empleo, aprovechando el bajo costo y la eficiencia de los portales web.

(ii) Entrevistas: Se programarán entrevistas con la línea de reporte directo y gerencia general para cada uno de los puestos laborales.

(iii) Referencias: Para la aceptación de un colaborador se deberá obtener, por lo menos una buena referencia para disminuir la posibilidad de un desempeño por debajo de lo esperado.

b) Contratación: Los términos de contratación para este tipo de negocio no son complejos, sobre todo por el número de colaboradores:

(i) Periodo de contrato: Se trabajará con contratos de 3 meses para todo el personal, con el objetivo de evitar sobrecostos y contingencias por despido arbitrario. 
(ii) Cargos de confianza: El gerente general será el representante legal y tendrá cargo de confianza, al igual que el administrador, con el objetivo de excluirlos del pago de horas extras o contingencias de dicho tipo.

\subsubsection{Remuneración y desempeño.}

Las remuneraciones se determinaron de acuerdo al perfil del colaborador, que incluye su profesión u ocupación, años de experiencia, nivel de responsabilidad (ver Tabla 6), y en base a las remuneraciones de mercado para el rubro de restaurantes, el mismo que fueron tomados de la información proporcionada por el experto accionista y encargado de la operación de establecimientos de este rubro. (Ver el Anexo $\mathrm{N}^{\circ} 5$ ).

El régimen de actividad laboral que rige la planilla del negocio es el correspondiente a la actividad privada amparado por el Texto Único Ordenado del D. Leg. 728, Ley de Productividad y Competitividad Laboral - Decreto Supremo $\mathrm{N}^{\circ}$ 003-97-TR. Adicionalmente, es importante indicar que el factor de cargas sociales considerado en la planilla de sueldos de la empresa es de 0.45 , esto se reflejará en los costos de planilla en los flujos financieros en el capítulo 7 .

Como se mencionó en el punto anterior 6.3 b) la administración diseñará y generará indicadores de eficiencia sobre el desempeño del equipo de colaboradores y establecerá objetivos medibles que al ser evaluados su resultado impactará en su remuneración regular, en especial en aquellos que destaquen por encima de los objetivos acordados. Esto sin duda ayudará a mejorar la motivación y el compromiso de dichos colaboradores. 


\subsubsection{Empoderamiento y reconocimiento.}

Debido al tamaño de la empresa y los horizontes temporales, se planea manejar los temas de empoderamiento y reconocimiento mediante la comunicación con la gerencia general. Solo se ofrecerán bonos adicionales de manera deliberada por la gerencia general, en caso se superen ampliamente las proyecciones de venta y margen.

Como observaremos en el capítulo 7, incurrir en gastos fijos adicionales puede impactar negativamente en el VAN económico y por tanto puede afectar la viabilidad total del negocio

\subsubsection{Capacitación, motivación y desarrollo}

a) Capacitación: Se brindarán capacitaciones espontáneas únicamente al puesto de administrador en temas financieros y contables. Esto con el objetivo que pueda revisar adecuadamente lo entregado por el contador externo para velar por su cumplimiento. Planeamos asignar un presupuesto de S/. 1,000 para el primer año con opción a crecimiento en base al rendimiento esperado.

b) Motivación: Se buscará trabajar en la motivación desde el punto de vista de la comunicación y trabajo en equipo. Se buscará ejecutar un presupuesto de S/. 1,500 anuales para integraciones, principalmente en navidad.

c) Desarrollo: Debido a la naturaleza del negocio y los horizontes temporales (explicados en el capítulo 7), no es necesario ejecuta planes complejos de desarrollo y sucesión del personal. Se buscará como política de la empresa, dar prioridad en la oportunidad a personal interno cuando se abra una nueva vacante.

\subsection{Estructura de gastos de recursos humanos}

Luego de lo expuesto en los párrafos anteriores, se detallan los gastos de planilla de la empresa, las remuneraciones fueron validadas contra las diferentes fuentes de mercado laboral a octubre del 2018, tales como Computrabajo.com, 
bumeran.com, entre otras. Asimismo, se considera un importe por el recargo al consumo que también perciben los trabajadores como parte de su remuneración:

Tabla $N^{\circ}$ 7. Detalle de Gastos de Planilla

\begin{tabular}{|c|c|c|c|c|c|}
\hline \multirow[b]{2}{*}{ Gastos de planilla } & \multirow[b]{2}{*}{ Cantidad } & \multicolumn{2}{|c|}{ Empresa } & \multicolumn{2}{|c|}{ Trabajador } \\
\hline & & Sueldo & Full Cost & Recargo al consumo & Total mensual \\
\hline Gerente General & 1 & $7,500.00$ & 10,875 & - & 7,500 \\
\hline Administrador & 1 & $2,700.00$ & 3,915 & 3,113 & 5,813 \\
\hline Cajero & 1 & $1,200.00$ & 1,740 & 800 & 2,000 \\
\hline Jefe de Mozos & 1 & $2,000.00$ & 2,900 & 1,500 & 3,500 \\
\hline Mozos & 3 & $1,000.00$ & 1,450 & 500 & 1,500 \\
\hline Ayudantes (mozo) & -1 & 930.00 & - & - & 930 \\
\hline Jefe de Cocina & 1 & $2,000.00$ & 2,900 & 1,200 & 3,200 \\
\hline Ayudante (cocina) & 1 & 930.00 & - & - & 930 \\
\hline Bartender & 1 & $2,000.00$ & 2,900 & 1,200 & 3,200 \\
\hline Ayudante & 1 & 930.00 & - & - & 930 \\
\hline Comprador/Almacen & 1 & $1,500.00$ & 2,175 & 700 & 2,200 \\
\hline Total & & $25,620.00$ & $31,755.00$ & $10,012.50$ & $35,632.50$ \\
\hline
\end{tabular}

Elaboración propia

Por último se detalla el presupuesto de recursos humanos restante anual para ejecutar en este proyecto:

Tabla $\mathrm{N}^{\circ}$ 8. Otros gastos del personal

\begin{tabular}{|l|r|r|}
\hline Otros gastos & Mensual S/. Anual S/. \\
\hline Valet Parking & 700 & 8,400 \\
\hline Música & 1,000 & 12,000 \\
\hline Limpieza & 800 & 9,600 \\
\hline Vigilante & 800 & 9,600 \\
\hline Anfitriona & 1,000 & 12,000 \\
\hline Contador & 1,500 & 18,000 \\
\hline Capacitación & 83 & 1000 \\
\hline Integración & 125 & 1500 \\
\hline Total & 6,008 & 72,100 \\
\hline
\end{tabular}

Elaboración propia

Como se puede apreciar, se intenta tercerizar una parte considerable de los servicios de la empresa, con el objetivo de ahorrar las cargas sociales del personal, así como posibles contingencias por desvinculación. El objetivo es obtener una estructura apropiada que pueda sustentar la operación de la empresa sin perjudicar el performance financiero del mismo. 


\section{Plan Económico-Financiero.}

\subsection{Supuestos}

A continuación se muestran los principales supuestos para las proyecciones de viabilidad financiera:

a) Horizonte temporal: 4 años con liquidación de activos al final. Esto debido a que luego del periodo en mención, se iniciará un nuevo proceso de inversión; en otras palabras, se renovarán los activos (posiblemente un actualización de software) o se realizará un mantenimiento importante para la continuidad de los equipos surtidores.

b) Ratio de ocupabilidad inicial de 3.5 por mesa (según proyección de ingresos en el Anexo $\mathrm{N}^{\circ}$ 5)

c) Inversión de $3 \%$ de las ventas en gastos de marketing (indicado en la entrevista a expertos en el Anexo $\mathrm{N}^{\circ} 4$ )

d) Tipo de cambio de PEN a USD de 3.3, según proyección del sistema financiero del 31 de agosto del 2018.

e) Tasa libre de riesgo de 4.24\% (2.87\% de rendimiento de bonos del tesoro a 10 años $+1.37 \%$ de riesgo país)

f) Rendimiento de mercado de $11.65 \%$ del índice de consumo de BVL, según el reporte de Septiembre 2018

g) Se mantienen inventarios al cierre por el importe de costos de ventas del mes siguiente

h) Los dividendos se distribuirán en el cuarto año.

\subsection{Presupuesto de inversiones}

A continuación se presenta el presupuesto de inversiones para el horizonte temporal de la inversión (expresados en soles): 
Tabla $\mathrm{N}^{\circ}$ 9: Presupuesto de Inversiones

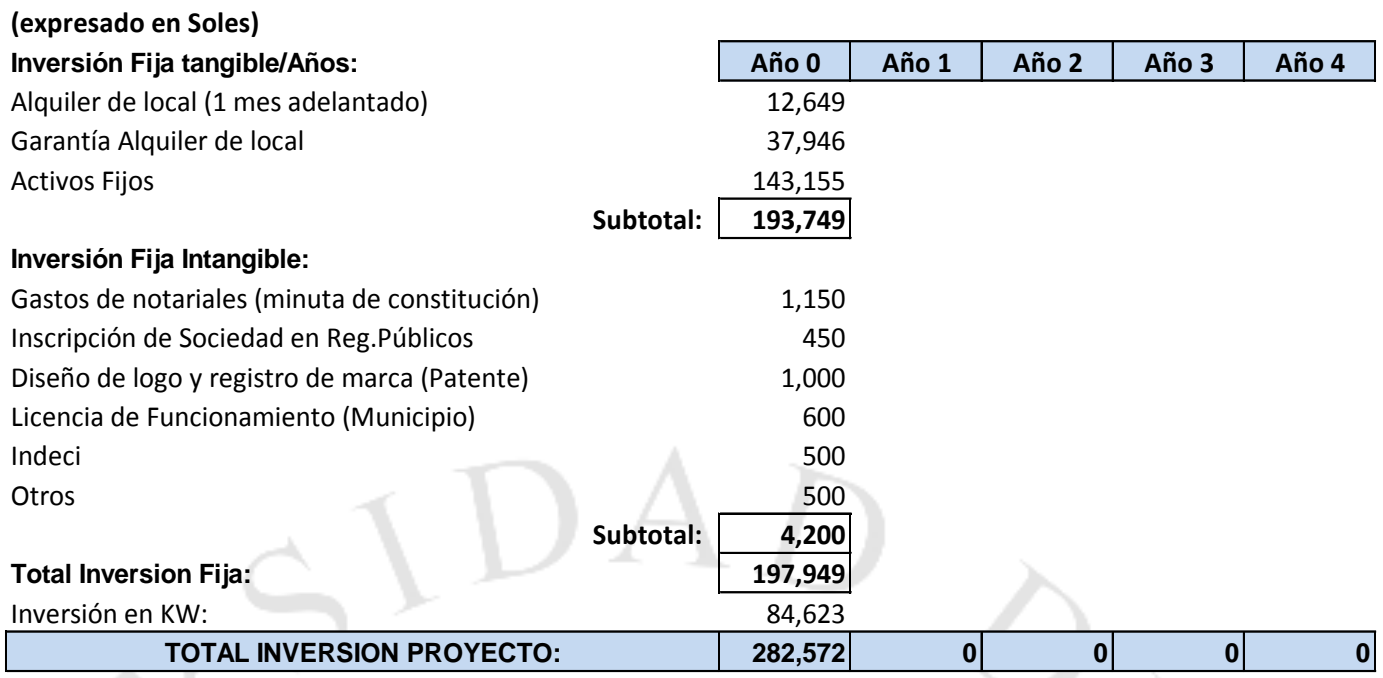

Elaboración propia

El análisis y detalle de los activos fijos e inversión en capital de trabajo se verán en los puntos 7.3 y 7.4, respectivamente. Se incluye la garantía de local (3 meses de renta), un mes adelantado, así como gastos preoperativos de licencias y trámites documentarios para la puesta en marcha del proyecto.

\subsection{Activos fijos y depreciación}

El requerimiento de activos fijos e intangibles fue determinado en el plan de operaciones, el detalle y cálculo de la depreciación se encuentran en el Anexo 6 del presente documento.

La concentración de activos fijos se encuentra en la instalación de los surtidores de autoservicios, el precio por unidad es de 6,500 dólares estadounidenses y se estiman 4 unidades, por lo que representan 60 por ciento de la inversión. El 40 por ciento restante se distribuye en diferentes tipos de inversiones en equipos y mobiliario para el acondicionamiento del local.

En lo referente a activos intangibles, estos se componen básicamente por los gastos en licencias y patentes que ascienden a aproximadamente S/ 4,200. 


\subsection{Capital de trabajo}

De acuerdo a Kesseven Padachi, "el capital de trabajo es capital de comercialización y se encuentra con las fuentes de financiamiento de corto plazo de un negocio, este cambia de forma a lo largo del negocio y debe mantenerse en el tiempo, pues es difícil crecer cuando el flujo de fondos es débil. El ciclo de conversión de efectivo muestra la demora entre en el desembolso de gastos contra la cobranzas por la colocación de bienes, por lo que es una medición de capital de trabajo" (Padachi, 2006).

El capital de trabajo se calcula bajo el método del ciclo de conversión de efectivo, estimamos el monto del costo de ventas y gastos operativos, considerando 15 días de ciclo de conversión de efectivo (S/42,068), puesto que ese será el tiempo de espera entre la puesta en marcha del local y la fecha de apertura; en otras palabras, es el abastecimiento requerido previo a la primera venta. Se calcula sumando los costos de ventas del año $1(\mathrm{~S} / .317,675)$ y los gastos operativos (S/.691,957), dividiéndolos en 360 días para determinar el costo estimado diario y multiplicarlo por 15 para obtener 15 días de ciclo de conversión de efectivo.

También se considera un tercio del importe que debe desembolsarse bajo el concepto de impuesto general a las ventas (S/ 43,593), esto se debe a que en empresas con márgenes altos dicho concepto suele ser elevado, ya que el crédito fiscal generado por facturas de proveedores es considerablemente menor.

El capital de trabajo total es de S/ 85,661 para considerar en el presupuesto de inversiones.

\subsection{Fuentes de financiamiento y amortización.}

Para la puesta en marcha del proyecto, se planea financiar parte de la operación con entidades financieras. De acuerdo al reporte anual de Damodaran (http://pages.stern.nyu.edu/), la industria de restaurantes mantiene un ratio de deuda/patrimonio de $32.21 \%$, por lo que se financiaría un $25 \%$ del total de inversión requerida. Se asume además una tasa de interés anual de 12\% referencial como se muestra en el Anexo 9: Cronograma de amortización, basada en las tasas activas anuales para moneda nacional publicadas por la 
Superintendencia de Banca, Seguros y AFP al 31 de Octubre de 2018 para medianas empresas en "Préstamos a más de 360 días", como se puede ver en la Tabla $\mathrm{N}^{\circ} 10$ presentada a continuación:

Tabla $N^{\circ}$ 10: Tasas de Interés Activas Anuales Promedio del Sistema Bancario

TASA DE INTERES PROMEDIO DEL SISTEMA BANCARIO

Tasas Activas Anuales de las Operaciones en Moneda Nacional Realizadas en los Ûltimos 30 Días Útiles Por Tipo de Crédito al 31110/2018

\begin{tabular}{|c|c|c|c|c|c|c|c|c|c|c|c|c|}
\hline Tasa Anual (\%) & Continenta & Comercio & Crédito & Pichincha & BIF & Scotiabank & Citibank & Interbank & Mibanco & GNB & Santander & Promedio \\
\hline Medianas Empresas & 9.80 & 11.19 & 10.54 & 8.34 & 9.16 & 10.77 & 4.94 & 8.36 & 14.17 & 6.52 & 8.45 & 9.93 \\
\hline Descuentos & 12.30 & 5.50 & 6.48 & 8.49 & 8.59 & 9.28 & - & 7.97 & - & 9.01 & 8.69 & 8.49 \\
\hline Préstamoshasta 30 dias & 9.58 & - & 10.32 & 7.87 & 9.63 & 9.66 & 3.65 & 5.74 & - & 4.71 & 7.24 & 8.96 \\
\hline Préstamos de 31 a 90 dias & 10.58 & 13.73 & 10.45 & 8.03 & 9.85 & 9.84 & 5.04 & 9.10 & - & 6.27 & 6.57 & 9.90 \\
\hline Préstamos de 91 a 180 días & 8.56 & 11.50 & 13.69 & 8.13 & 9.38 & 10.24 & 6.65 & 9.03 & 18.21 & 9.93 & 9.04 & 10.27 \\
\hline Préstamos de 181 a 360 dias & 11.85 & 9.71 & 8.85 & 9.81 & 10.35 & 10.21 & - & 6.50 & 17.03 & 8.00 & 9.50 & 10.40 \\
\hline Préstamos a más de 360 días & 9.36 & - & 11.24 & 9.22 & 7.95 & 12.19 & - & 8.82 & 13.10 & 15.00 & 9.50 & 10.56 \\
\hline Pequeñas Empresas & 14.86 & 10.00 & 15.77 & 20.70 & 12.20 & 17.82 & - & 16.17 & 21.60 & 10.60 & - & 18.54 \\
\hline Descuentos & 20.02 & - & 6.58 & 12.30 & 11.74 & 13.21 & - & 10.46 & - & - & - & 11.38 \\
\hline Préstamos hasta 30 días & 16.10 & - & 8.79 & 43.00 & 15.75 & 13.66 & - & 9.50 & 75.65 & - & - & 10.50 \\
\hline Préstamos de 31 a 90 días & 16.07 & - & 7.37 & 20.59 & 11.49 & 15.04 & - & 16.05 & 28.30 & 12.50 & - & 11.29 \\
\hline Préstamos de 91 a 180 días & 14.98 & - & 22.50 & 18.07 & 11.85 & 15.53 & - & 18.06 & 30.17 & - & - & 21.21 \\
\hline Préstamos de 181 a 360 días & 15.88 & - & 13.92 & 21.20 & 12.18 & 18.67 & - & 18.86 & 24.56 & - & - & 22.70 \\
\hline Préstamos a más de 360 días & 13.79 & 10.00 & 14.89 & 21.08 & 13.63 & 18.26 & - & 16.22 & 20.33 & 10.49 & - & 18.26 \\
\hline Microempresas & 27.26 & - & 23.45 & 32.16 & - & 20.51 & - & 13.90 & 36.49 & 12.50 & - & 33.42 \\
\hline Tarietas de Crédito & 36.08 & - & 25.24 & 45.23 & - & 30.62 & - & - & - & - & - & 26.15 \\
\hline Descuentos & 21.03 & - & 12.75 & 13.05 & - & 18.69 & - & 5.91 & - & - & - & 11.88 \\
\hline Préstamos Revolventes & 32.00 & - & - & - & - & - & - & 16.22 & - & - & - & 16.50 \\
\hline Préstamos a cuota fija hasta 30 días & 21.80 & - & - & 37.82 & - & 9.52 & - & 20.00 & 58.55 & - & - & 13.66 \\
\hline Préstamos acuotafija de 31 a 90 días & 20.74 & - & 6.56 & 33.58 & - & 10.78 & - & 20.00 & 55.78 & - & - & 42.94 \\
\hline Préstamos a cuotafiia de 91 a 180 días & 17.45 & - & 19.80 & 40.00 & - & 13.00 & - & 20.07 & 52.15 & - & - & 44.36 \\
\hline Préstamos a cuota fija de 181 a 360 dias & 18.60 & - & 15.76 & 42.28 & - & 22.58 & - & 25.66 & 43.02 & - & - & 42.81 \\
\hline Préstamos a cuota fiija a más de 360 dias & 13.30 & - & 16.40 & 31.31 & - & 19.74 & - & 13.08 & 29.19 & 12.50 & - & 28.37 \\
\hline
\end{tabular}

Elaboración Propia

Fuente: Superintendencia de Banca, Seguros y AFP - SBS

\subsection{Balances previsionales}

Se presenta el balance general proyectado a 4 años junto con el análisis horizontal de las partidas: 
Tabla $\mathrm{N}^{\circ}$ 11: Balances proyectados

\begin{tabular}{|c|c|c|c|c|c|}
\hline (expresado en Soles) & Año 0 & Año 1 & Año 2 & Año 3 & Año 4 \\
\hline Efectivo & 84,623 & 259,838 & 433,680 & 728,090 & 345,694 \\
\hline Inventarios & - & 23,282 & 27,938 & 30,732 & \\
\hline Otras cuentas por cobrar & 50,594 & 37,946 & 37,946 & 37,946 & \\
\hline Activo Fijo & 147,355 & 103,563 & 73,170 & 42,778 & - \\
\hline Total Activos & 282,572 & 424,628 & 572,734 & 839,545 & 345,694 \\
\hline Cuentas por pagar & & 37,720 & 41,132 & 48,346 & \\
\hline Otras cuentas por pagar & & 14,699 & 15,671 & 17,808 & \\
\hline Cuentas por pagar accionistas & & & & & 345,694 \\
\hline PCDLP & 17,661 & 17,661 & 17,661 & 17,661 & \\
\hline PNCDLP & 52,982 & 35,321 & 17,661 & - & - \\
\hline Total Pasivo & 70,643 & 105,401 & 92,124 & 83,815 & 345,694 \\
\hline Capital Social & 211,929 & 211,929 & 211,929 & 211,929 & \\
\hline Resultados acumuladas & & & 107,298 & 268,682 & \\
\hline Resultados del ejercicio & & 107,298 & 161,383 & 275,120 & \\
\hline Total Patrimonio & 211,929 & 319,227 & 480,610 & 755,730 & 0 \\
\hline Total Pasivo + Patrimonio & 282,572 & 424,628 & 572,734 & 839,545 & 345,694 \\
\hline
\end{tabular}

\begin{tabular}{|c|c|c|c|c|c|c|}
\hline \multicolumn{3}{|c|}{ Analisis Horizontal } & \multicolumn{4}{|c|}{ Analisis Vertical } \\
\hline Aก̃o 2 & Año 3 & Año 4 & Año 1 & Año 2 & Año 3 & Año 4 \\
\hline $67 \%$ & $68 \%$ & $-53 \%$ & $30 \%$ & $61 \%$ & $76 \%$ & $87 \%$ \\
\hline $20 \%$ & $10 \%$ & $-100 \%$ & $0 \%$ & $5 \%$ & $5 \%$ & $4 \%$ \\
\hline $0 \%$ & $0 \%$ & $-100 \%$ & $18 \%$ & $9 \%$ & $7 \%$ & $5 \%$ \\
\hline$-29 \%$ & $-42 \%$ & $-100 \%$ & $52 \%$ & $24 \%$ & $13 \%$ & $5 \%$ \\
\hline $35 \%$ & $47 \%$ & $-59 \%$ & $100 \%$ & $100 \%$ & $100 \%$ & $100 \%$ \\
\hline $9 \%$ & $18 \%$ & $-100 \%$ & $0 \%$ & $9 \%$ & $7 \%$ & $6 \%$ \\
\hline $7 \%$ & $14 \%$ & $-100 \%$ & $0 \%$ & $3 \%$ & $3 \%$ & $2 \%$ \\
\hline $0 \%$ & $0 \%$ & $-100 \%$ & $6 \%$ & $4 \%$ & $3 \%$ & $2 \%$ \\
\hline$-50 \%$ & $-100 \%$ & $0 \%$ & $19 \%$ & $8 \%$ & $3 \%$ & $0 \%$ \\
\hline$-13 \%$ & $-9 \%$ & $312 \%$ & $25 \%$ & $25 \%$ & $16 \%$ & $10 \%$ \\
\hline $0 \%$ & $0 \%$ & $-100 \%$ & $75 \%$ & $50 \%$ & $37 \%$ & $25 \%$ \\
\hline & $150 \%$ & $-100 \%$ & $0 \%$ & $0 \%$ & $19 \%$ & $32 \%$ \\
\hline $50 \%$ & $70 \%$ & $-100 \%$ & $0 \%$ & $25 \%$ & $28 \%$ & $33 \%$ \\
\hline $51 \%$ & $57 \%$ & $-100 \%$ & $75 \%$ & $75 \%$ & $84 \%$ & $90 \%$ \\
\hline $35 \%$ & $47 \%$ & $-59 \%$ & $100 \%$ & $100 \%$ & $100 \%$ & $100 \%$ \\
\hline
\end{tabular}

Elaboración propia

Como principales aspectos en este punto, se puede destacar que el activo más importante durante los 4 años de horizonte temporal es el efectivo, esto se debe principalmente a que el $100 \%$ de las ventas generadas son al contado representando más de la mitad de los recursos económicos de la empresa que aumenta con la generación de utilidades del periodo.

Los inventarios representan un mes de existencias necesarias para la operación de la empresa, las otras cuentas por cobrar están compuestas principalmente por la garantía por el alquiler del local. Por el lado de los pasivos, las cuentas por pagar comerciales representan 30 días de crédito con proveedores y las otras cuentas por pagar se conforman por las cargas sociales a los colaboradores.

Por último, se debe considerar que en el año 4 se considera la posición de cierre de la empresa, por lo que se liquidan los activos y pasivos pendientes, lo que trae como consecuencia que solo quede pendiente el saldo de efectivo y una cuentas por pagar a accionistas. Esto incluye la distribución de dividendos del último periodo.

\subsection{Estado de Resultados proyectado}

Como resumen de los puntos anteriores, presentamos el estado de resultados por los 4 años: 
Tabla $N^{\circ}$ 12: Estado de Resultados Proyectados

\begin{tabular}{|c|c|c|c|c|c|c|c|c|c|c|c|}
\hline \multirow{2}{*}{$\begin{array}{l}\text { ESTADO DE RESULTADOS } \\
\text { (expresado en Soles) }\end{array}$} & & & & & \multicolumn{3}{|c|}{ Analisis Horizontal } & \multicolumn{4}{|c|}{ Analisis Vertical } \\
\hline & Año 1 & Año 2 & Año 3 & Año 4 & Año 2 & Año 3 & Año 4 & Año 1 & Año 2 & Año 3 & Año 4 \\
\hline Ventas & $1,166,059$ & $1,282,665$ & $1,539,198$ & $1,693,118$ & $10 \%$ & $20 \%$ & $10 \%$ & $100 \%$ & $100 \%$ & $100 \%$ & $100 \%$ \\
\hline Costo de Ventas & $-312,451$ & $-343,696$ & $-412,435$ & $-453,678$ & $10 \%$ & $20 \%$ & $10 \%$ & $-27 \%$ & $-27 \%$ & $-27 \%$ & $-27 \%$ \\
\hline Utilidad Bruta & 853,609 & 938,969 & $1,126,763$ & $1,239,440$ & $10 \%$ & $20 \%$ & $10 \%$ & $73 \%$ & $73 \%$ & $73 \%$ & $73 \%$ \\
\hline Gastos Operativos & $-691,177$ & $-705,725$ & $-733,895$ & $-748,171$ & $2 \%$ & $4 \%$ & $2 \%$ & $-59 \%$ & $-55 \%$ & $-48 \%$ & $-44 \%$ \\
\hline Utilidad Operativa & 162,432 & 233,244 & 392,868 & 491,269 & $44 \%$ & $68 \%$ & $25 \%$ & $14 \%$ & $18 \%$ & $26 \%$ & $29 \%$ \\
\hline Otros (Amortiz.Inv. Intang) & $-4,200$ & - & - & - & & & & $0 \%$ & $0 \%$ & $0 \%$ & $0 \%$ \\
\hline Utilidad antes de Intereses e Impuestos & 158,232 & 233,244 & 392,868 & 491,269 & $47 \%$ & $68 \%$ & $25 \%$ & $14 \%$ & $18 \%$ & $26 \%$ & $29 \%$ \\
\hline Gastos Financieros & $-6,036$ & $-4,331$ & $-2,627$ & -923 & $-28 \%$ & $-39 \%$ & $-65 \%$ & $-1 \%$ & $0 \%$ & $0 \%$ & $0 \%$ \\
\hline Utilidad antes de Impuestos & 152,196 & 228,913 & 390,241 & 490,346 & $50 \%$ & $70 \%$ & $26 \%$ & $13 \%$ & $18 \%$ & $25 \%$ & $29 \%$ \\
\hline Impuesto a la Renta & $-44,898$ & $-67,529$ & $-115,121$ & $-144,652$ & $50 \%$ & $70 \%$ & $26 \%$ & $-4 \%$ & $-5 \%$ & $-7 \%$ & $-9 \%$ \\
\hline Participación de los trabajadores & & & & & & & & $0 \%$ & $0 \%$ & $0 \%$ & $0 \%$ \\
\hline Utilidad Neta & 107,298 & 161,383 & 275,120 & 345,694 & $50 \%$ & $70 \%$ & $26 \%$ & $9 \%$ & $13 \%$ & $18 \%$ & $20 \%$ \\
\hline
\end{tabular}

Como se puede apreciar en las cifras proyectadas en el análisis, se estiman tasas de crecimiento de 10 por ciento en el segundo año y 20 por ciento en el tercero, con un ligero aumento proporcional en los gastos operativos (ver detalle en el Anexo 6).

En lo referente al análisis vertical, podemos apreciar que los márgenes brutos ascienden a un 73 por ciento de las ventas, principalmente por las ventas de cervezas y licores. Esto es una característica de este tipo de negocios, puesto que eso permite maximizar la capacidad operativa para lograr cubrir gastos fijos. La utilidad operativa aumenta por las tasas de crecimientos en ventas y con el menor incremento en gastos operativos, llegando hasta 25 por ciento en el último año. Los gastos financieros no representan mayor porcentaje sobre las ventas, puesto que la mayoría están financiados por capital social como se analizará en el punto 7.11 .

\subsection{Proyección de Ventas y Flujo de Tesorería.}

La proyección de Ventas se hizo en base al cálculo de un ticket promedio y a una estacionalidad estimada, basada en la baja que sufre el consumo en los bares restaurantes de Lima - Metropolitana debido a los meses de verano en los cuales los clientes prefieren ir a establecimientos en el sur de la ciudad de Lima (Punta Hermosa, Punta Rocas, San Bartolo y Asia). Asimismo, se ha estimado un incremento en las ventas en los meses de Julio y Diciembre debido al mayor consumo presentado en esos meses por fiestas patrias y festividades de fin de 
año como Navidad y Año Nuevo, meses en los cuales el cliente tienen mayor poder adquisitivo debido a las gratificaciones de sueldo que reciben (ver Anexo $\mathrm{N}^{\circ}$ 5: Cálculo de ticket promedio y Ventas anuales).

A continuación se muestra el estado de flujo de efectivo, como se puede apreciar, los niveles de ingresos por flujos de operación son altos al ser un negocio que materializa sus ingresos en efectivo al contado (sin cuentas por cobrar):

Tabla $\mathrm{N}^{\circ}$ 13: Estado de flujo de efectivo

\begin{tabular}{|c|c|c|c|c|c|}
\hline \multicolumn{6}{|c|}{$\begin{array}{l}\text { ESTADO DE FLUJO DE EFECTIVO } \\
\text { (expresado en Soles) }\end{array}$} \\
\hline 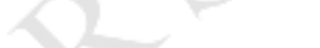 & Año 0 & Año 1 & Año 2 & Año 3 & Año 4 \\
\hline U.Neta & - & 107,298 & 161,383 & 275,120 & 345,694 \\
\hline Depreciación & $x^{2}-$ & 43,792 & 30,392 & 30,392 & 21,389 \\
\hline Inventarios & $y_{2}$ & $-23,282$ & $-4,656$ & $-2,794$ & 30,732 \\
\hline Otras CxC & $-50,594$ & 12,649 & - & - & 37,946 \\
\hline Cuentas por pagar & - & 37,720 & 3,412 & 7,214 & $-48,346$ \\
\hline Otras cuentas por pagar & - & 14,699 & 972 & 2,138 & $-17,808$ \\
\hline Flujo de operación & $-50,594$ & 192,876 & 191,503 & 312,070 & 369,606 \\
\hline Inversión en AF & $-147,355$ & - & - & - & 21,389 \\
\hline Flujo de inversión & $-147,355$ & - & - & - & 21,389 \\
\hline Aportes de capital & 211,929 & & & & $-211,929$ \\
\hline Dividendos & & & & & $-543,801$ \\
\hline Préstamos & 70,643 & $-17,661$ & $-17,661$ & $-17,661$ & $-17,661$ \\
\hline Flujos de financiamiento & 282,572 & $-17,661$ & $-17,661$ & $-17,661$ & $-773,391$ \\
\hline Variación neta & 84,623 & 175,216 & 173,842 & 294,409 & $-382,396$ \\
\hline Efectivo inicial & - & 84,623 & 259,838 & 433,680 & 728,090 \\
\hline Efectivo final & 84,623 & 259,838 & 433,680 & 728,090 & 345,694 \\
\hline
\end{tabular}

Como se puede observar, la variación del efectivo en los 4 años es positiva, esto se debe a que el $100 \%$ de las ventas se realizan al contando, por lo que el riesgo de liquidez se encuentra asociado directamente al riesgo de rentabilidad. En el último año considera la liquidación del negocio, por lo que se puede apreciar el ingreso de efectivo por la garantía, la devolución del capital social y el pago de dividendos de los 3 años anteriores.

Se concluye que de cumplir con los supuestos de la proyección de venta (anexo 6), estado de resultados y balance general (puntos 7.7 y 7.6), la empresa no tendrá complicaciones de liquidez en sus flujos de efectivo. 


\subsection{Análisis de viabilidad y rentabilidad financiera.}

A continuación se muestra el flujo de caja económico, que supone que todo el proyecto se financia con inversión propia:

Tabla $N^{\circ}$ 14: Flujo de caja económico

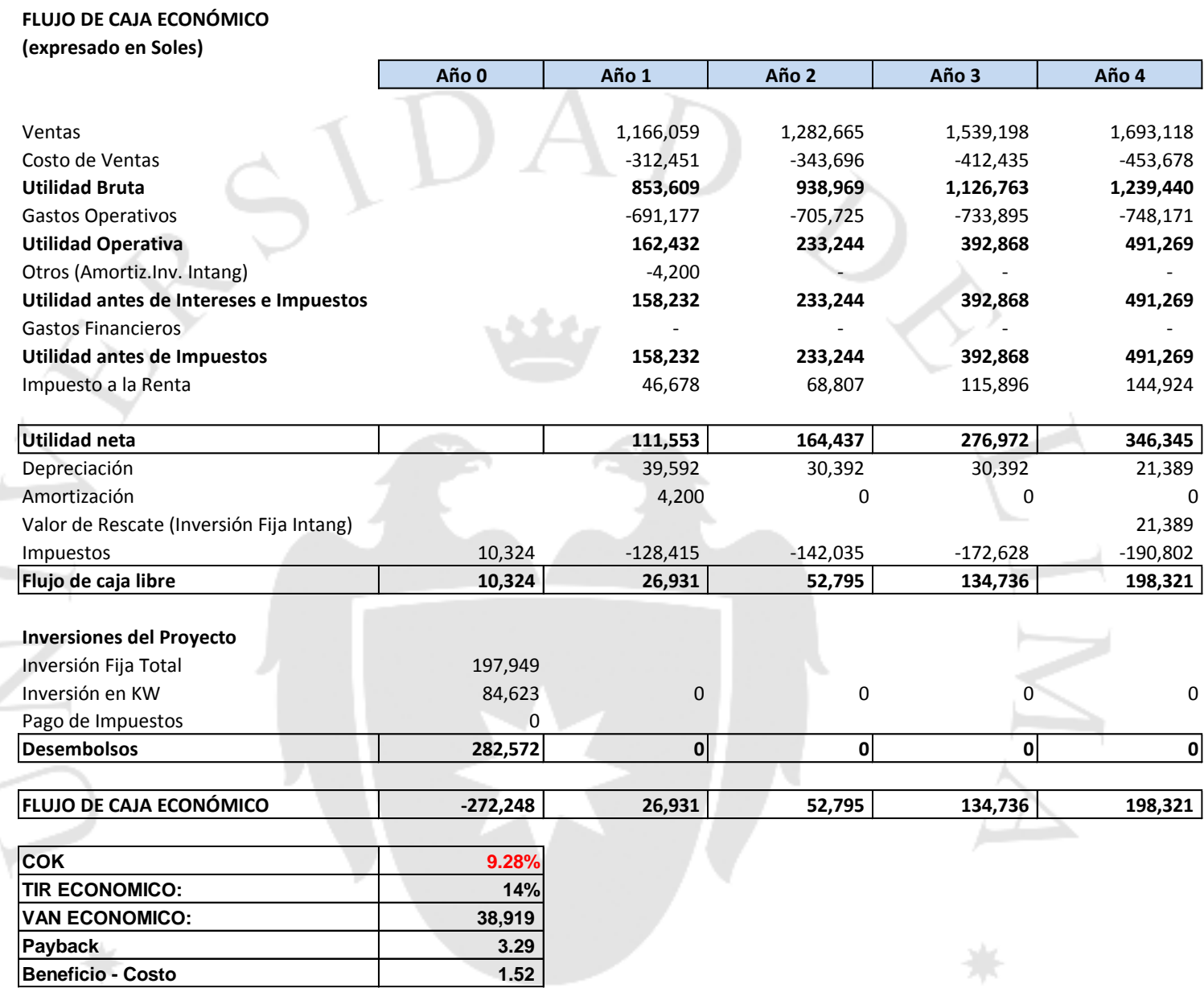

Elaboración propia

Se puede apreciar que los indicadores financieros son positivos, de acuerdo a las reglas de inversión:

- $\quad$ TIR por encima del Costo de Capital

- VAN positivo

- Beneficio/Costo mayor a 1

Si bien la rentabilidad operativa es elevada, el efecto del impuesto general a las ventas elevado en una empresa de servicios, disminuye considerablemente los 
indicadores, debido a que una gran porción del efectivo generado se dirige a la liquidación de dicho concepto.

Se presenta el flujo financiero del proyecto y la nueva evaluación para determinar la viabilidad considerando el monto de financiamiento mostrado en el punto 7.5:

Tabla $\mathrm{N}^{\circ}$ 15: Flujo de caja financiero

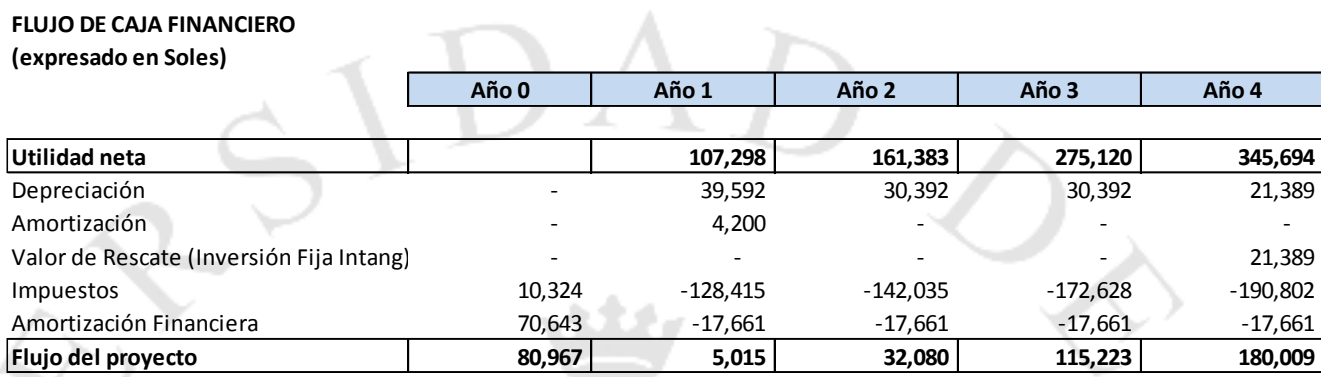

Inversiones del Proyecto

Inversión Fija Total

Inversión en KW

Pago de Impuestos

Desembolsos

148,462

63,467

211,929

115,223

180,009

\section{FLUJO DE CAJA FINANCIERO}

$-130,962$

015

$10.02 \%$

\begin{tabular}{|l|r|}
\hline WACC & $10.02 \%$ \\
\hline TIR FINANCIERO: & $32 \%$ \\
\hline VAN FINANCIERO: & 109,488 \\
\hline Payback & 2.81 \\
\hline Beneficio - Costo & 2.54 \\
\hline
\end{tabular}

Elaboración propia

Como se puede observar los indicadores financieros VAN y TIR se duplican con respecto al flujo de caja económico, esto se debe principalmente a la reducción en la inversión propia por el financiamiento externo. El financiamiento del $25 \%$ de los recursos de la empresa permite reducir los tiempos de recuperación a menos de 3 años. Esto también incluye los gastos por intereses del préstamo bancario.

Es importante recordar que la proporción de financiamiento se determinó en base a los ratios deuda/patrimonio revisados en la industria de restaurantes, descrito en el punto 7.5. 


\subsection{Política de aplicación de resultados}

De acuerdo a lo indicado en los puntos anteriores del Plan económico- financiero, la política de la empresa será distribuir los resultados y devolver la inversión en el año de liquidación, con la finalidad de no descapitalizar la empresa y no enfrentar potenciales riesgos de liquidez y de solvencia.

\subsection{Cálculo de tasas de descuento}

De acuerdo a lo establecido en los supuestos iniciales (ver punto 7.1) y en el detalle del financiamiento (ver punto 7.5), hemos definido el Costo de Capital en base a la metodología CAPM. Posteriormente, se calcula el Weighted Average Cost of Capital (WACC), incluyendo el factor de proporción de la deuda para que sea la tasa de descuento del flujo financiero.

El beta de 0.85 fue estimado en base al reporte anual de Damodaran (http://pages.stern.nyu.edu/) sobre la industria de restaurantes:

Tabla $\mathrm{N}^{\circ}$ 16: Cálculo de tasa de descuento

\begin{tabular}{|c|c|c|c|c|c|}
\hline \multicolumn{2}{|l|}{ CAPM } & \multicolumn{2}{|c|}{ CAPM Leverage } & \multicolumn{2}{|c|}{ WACC } \\
\hline Beta & 0.68 & Beta & 0.85 & $\%$ D & $25 \%$ \\
\hline Rendimiento & $11.65 \%$ & Rendimiento & $11.65 \%$ & $\% \mathrm{E}$ & $75 \%$ \\
\hline Libre de riesgo & $4.24 \%$ & Libre de riesgo & $4.24 \%$ & Interes & 0.12 \\
\hline Total & $9.28 \%$ & Total & $10.54 \%$ & WACC & $10.02 \%$ \\
\hline
\end{tabular}

Elaboración propia

\subsection{Indicadores de rentabilidad representativos}

Se definieron los siguientes indicadores de gestión financiera para realizar controles periódicos y que puedan medir la operación y manejo de la empresa:

a) Margen neto (utilidad neta/ventas): Sirve para medir el rendimiento total de la empresa en todos sus rubros.

b) Rentabilidad sobre patrimonio (utilidad neta/patrimonio): Rendimiento de la inversión propia de los accionistas, es decir cuánto generó el negocio con respecto a la propiedad de los dueños. 
c) Rentabilidad sobre activos (utilidad/actividad): Ayuda a medir el rendimiento del total de recursos de la empresa, sin tomar en cuenta su procedencia (propios o terceros).

d) Rotación de activos (ventas/activos): Muestra la eficiencia y aprovechamiento de los recursos totales de la empresa

e) Periodo promedio de pago (360/rotación de cuentas por pagar): Representa los días promedios de pago a proveedores, sirve para la gestión de la liquidez de la empresa

f) Utilidad neta/Gastos de Marketing: Ratio creado con la finalidad de medir la eficiencia de los gastos de marketing invertidos.

A continuación se muestra la matriz de indicadores en base a lo mostrado en los puntos anteriores:

Tabla $\mathrm{N}^{\circ}$ 17: Indicadores financieros

\begin{tabular}{|c|c|c|c|c|}
\hline Ratios Rentabilidad & Año 1 & Año 2 & Año 3 & Año 4 \\
\hline Margen neto & $9.20 \%$ & $12.58 \%$ & $17.87 \%$ & $20.42 \%$ \\
\hline ROE & $34 \%$ & $34 \%$ & $36 \%$ & n.a \\
\hline ROA & $25 \%$ & $28 \%$ & $33 \%$ & n.a \\
\hline Ratios Gestión & Año 1 & Año 2 & Año 3 & Año 4 \\
\hline Rotación de activos & 2.75 & 2.24 & 1.83 & 4.90 \\
\hline PPP & 43.5 & 43.1 & 42.2 & n.a \\
\hline U.Neta /Gastos Marketing & 3.07 & 4.19 & 5.96 & 6.81 \\
\hline
\end{tabular}

Elaboración propia

Como se puede apreciar, los ratios de rentabilidad suelen mejorar conforme pasan los años, esto se debe a los crecimientos que vienen provenientes de la maduración del negocio y a que no se requieren mayores inversiones ni financiamiento de recursos para operación.

Por otro lado, los ratios de gestión mejoran, salvo por la rotación de activos, esto debido al crecimiento de efectivo que se va generando año a año. 


\subsection{Análisis de riesgos y costos de oportunidad}

El principal riesgo del negocio está asociado al factor ocupabilidad, este indicador determina la rotación de clientes promedio diario por cada mesa, así como el consumo promedio de cada mesa con 2 clientes. Como concepto, el primer riesgo de negocio está asociado al flujo de clientes que entren al local y el segundo a lo que gastan durante su estadía. A continuación se muestra un análisis de sensibilidad de ambas variables para evaluar los efectos en el VAN económico si cada uno de los indicadores incrementa y disminuye en $10 \%$ :

Tabla $\mathrm{N}^{\circ}$ 18: Análisis de sensibilidad

\begin{tabular}{|c|c|c|c|}
\hline Ocupabilidad & $-10 \%$ & Medio & $10 \%$ \\
\hline VAN Económico & $-86,158$ & 38,919 & 239,525 \\
\hline Factor & 2.9988 & 3.332 & 3.6652 \\
\hline Clientes promedio & 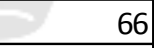 & 73.3 & 85 \\
\hline & & 3.332 & \\
\hline Ticket promedio & $-10 \%$ & Medio & $10 \%$ \\
\hline VAN Económico & $-68,248$ & 38,919 & 146,087 \\
\hline Consumo promedio & 111.51 & 123.9 & 136.29 \\
\hline
\end{tabular}

Elaboración propia

Como se puede observar el primero tiene un mayor impacto en el VAN económico que el segundo; sin embargo, podemos observar que ambos son bastantes sensibles, pues una incremento o disminución de la misma significa una variación 3 y 2 veces el monto del valor actual neto, para el factor de ocupabilidad y el ticket promedio, respectivamente.

Para complementar el análisis, se realizó un análisis de sensibilidad cruzada, esto quiere decir, que se simulará el incremento en unos de los factores y la disminución en el otro y viceversa:

Tabla $N^{\circ}$ 19: Sensibilidad cruzada

\begin{tabular}{|l|r|r|}
\hline Sensibilidad Cruzada & $\mathbf{+ 1 0 \% / - 1 0 \%}$ & $\mathbf{- 1 0 \% / + 1 0 \%}$ \\
\hline VAN Económico & 80,100 & $-23,694$ \\
\hline Factor Ocupabilidad & 3.67 & 2.9988 \\
\hline Consumo promedio & 112 & 136.29 \\
\hline
\end{tabular}

Elaboración propia 
Se observa que una disminución de 10 por ciento en el consumo promedio puede cubrirse satisfactoriamente con un crecimiento de 10 por ciento sobre el factor de ocupabilidad (incluso superando al escenario base), por lo que es válido realizar estrategias relacionadas al precio, siempre y cuando esto signifique mayor flujo al local.

Por otro lado, se aprecia que un aumento en el consumo promedio, reduciendo el flujo de clientes en la misma proporción, no es conveniente, pues el VAN económico se disminuye a niveles por debajo de cero.

Se puede concluir en este análisis que proteger la ocupabilidad es la prioridad para mitigar riesgos de reducción considerable del VAN económico, así como mantener el concepto temático dentro de la operación del bar.

\subsection{Análisis por escenarios y gráficas}

En base a lo visto en el punto anterior definimos 3 escenarios para el realizar el análisis correspondiente. A continuación la descripción de cada uno:

a) Pesimista: Disminución del 10 por ciento del factor de ocupabilidad y el consumo promedio. Se asume un 30 por ciento de probabilidad.

b) Medio: Escenario base sobre el que se calcula la viabilidad financiera. Se propone 50 por ciento de probabilidad.

c) Optimista: Aumento del 10 por ciento de ambos indicadores. Se asume 20 por ciento de probabilidad.

A continuación se muestra el resultado de cada uno, y el cálculo del VAN económico considerando las probabilidades descritas anteriormente: 
Tabla $N^{\circ}$ 21: Análisis de escenarios

\begin{tabular}{|c|c|c|c|}
\hline Indicadores & Pesimista & Medio & Optimista \\
\hline VAN Económico & $-216,596$ & 38,919 & 315,869 \\
\hline Factor Ocupabilidad & 3.00 & 3.33 & 3.67 \\
\hline Consumo promedio & 112 & 124 & 136 \\
\hline Probabilidad & 0.30 & 0.50 & 0.20 \\
\hline VAN Económico & 17,655 & & \\
\hline
\end{tabular}

Elaboración propia

Como se puede apreciar, se asume un punto de vista conservador al asumir que el escenario pesimista tiene mayores probabilidades de suceder con relación al optimista. El VAN económico disminuye con respecto a su escenario medio, pero sigue manteniéndose positivo y por lo tanto, es posible concluir que en lo referido a riesgos y escenarios el proyecto sigue siendo viable financieramente bajo los supuestos planteados.

Para finalizar el análisis de escenarios, se calcularon diferentes escenarios sobre el factor de ocupabilidad y su impacto en el VAN económico desde su punto mínimo hasta el máximo:

Gráfico $\mathrm{N}^{\circ}$ 15: Efecto factor de ocupabilidad

\section{Efecto factor ocupabilidad - VAN Económico}

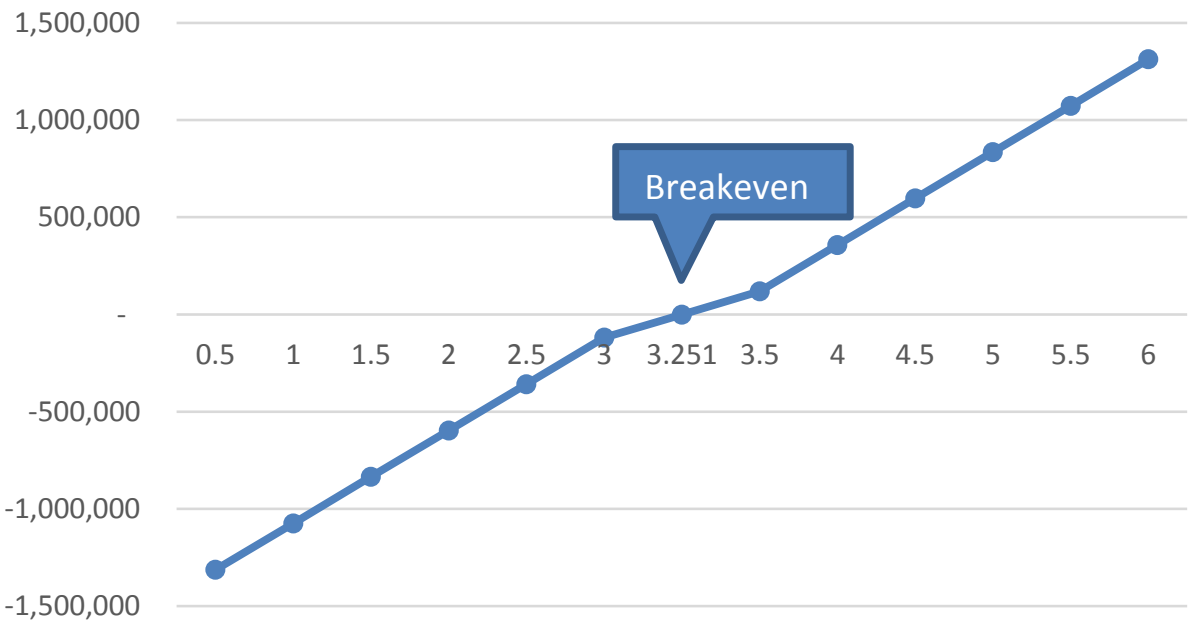

Elaboración propia 
Se puede observar que el punto del escenario medio se encuentra bastante cercano al breakeven point de VAN económico, por lo que puede reconfirmar que las oportunidades de crecimiento están de acuerdo a este indicador

\subsection{Principales riesgos del proyecto (cualitativos)}

Adicionalmente a los riesgos expuestos en el punto 7.13, se identificaron los siguientes riesgos cualitativos, que pueden derivar en posibles contingencias o dificultades en la operación del proyecto:

a) Riesgo tributario: Incumplimiento de normas tributarias que puede derivar en la clausura temporal del local.

b) Riesgo de sistemas: Errores o dificultades en el manejo del software de la empresa que puede traer como consecuencia demoras en la atención de clientes.

c) Riesgo de servicio: El personal no brinda la calidad de servicio esperada y se recibe una gran cantidad de quejas y opiniones negativas del cliente. Impacta directamente en las ventas mensuales

d) Riesgo laboral: Incurrir en alguna contingencia laboral que pueda derivar en multas o juicios impulsados por el Ministerio de Trabajo.

Estos riesgos serán mitigados mediante controles y procedimientos de alerta implementados para un seguimiento periódico.

\subsection{Plan de contingencia y resolución}

En el caso la situación se encuentre en el escenario pesimista descrito en el punto 7.14 y se decida realizar acciones de desinversión, se seguirá el siguiente procedimiento:

1. Solicitar los saldos de garantía por alquiler y resolver los contratos con proveedores y trabajadores.

2. Vender los surtidores al mayor precio de recuperación posible (buscando como punto óptimo 50 por ciento de la inversión en el activo hasta el tercer año y el valor residual para el cuarto año), así como el resto de mobiliario de propiedad de la empresa. 
3. Utilizar los saldos restantes de efectivo para liquidar a los trabajadores en planilla, la administración tributaria y las instituciones financieras, en ese orden de prioridad.

4. Pagar a los proveedores y accionistas con los saldos restantes de efectivo.

La resolución de la empresa se realizará el cuarto año y se efectuará siguiendo los siguientes procedimientos descritos arriba, incluyendo la distribución de los resultados acumulados de los primeros 3 años, y al finalizar el cuarto año los resultados de dicho periodo. Siendo la única transacción del año 5 el pago de las cuentas por pagar a accionistas.

Adicionalmente, se realizó un análisis sobre un plan para asegurar la ocupabilidad en el bar. En este caso, se asume que el factor de ocupabilidad disminuye a 2.5 generando una pérdida neta de S/.48,198, para revertir dicha situación se propone disminuir el consumo promedio en un 30\%, con lo que pasaría de S/.118 a S/. 90 y realizar una inversión adicional en acciones de marketing de S/.30,000 anuales, lo que prácticamente duplica este presupuesto. Conceptualmente, esto incluiría un mayor enfoque en los eventos, incrementar la frecuencia de los mismos, así como aumentar el número de promotores que aseguren la asistencia de los clientes e incurrir en gastos promocionales (ofertas 2x1, inversión en redes sociales, entre otros). Como se puede observar en el siguiente cuadro, los márgenes y sensibilidad sobre la ocupación permiten llegar a un punto de equilibrio en utilidad neta con un factor de ocupabilidad igual de 2.85:

Tabla $\mathrm{N}^{\circ} 22$ : Análisis de ocupabilidad - Resultados

\begin{tabular}{|c|c|c|c|c|}
\hline & Año 1 & $\begin{array}{l}\text { Inversión } \\
\text { adicional }\end{array}$ & Orgánico & $\begin{array}{c}\text { Año } 1 \\
\text { Ajustado }\end{array}$ \\
\hline Ventas & \multicolumn{2}{|l|}{874,894} & \multicolumn{2}{|r|}{997,380} \\
\hline Costo de Ventas & \multicolumn{2}{|l|}{$-234,432$} & \multicolumn{2}{|r|}{$-267,252$} \\
\hline Utilidad Bruta & \multicolumn{2}{|l|}{640,463} & \multicolumn{2}{|r|}{730,127} \\
\hline Gastos Operativos & $-679,531$ & $-30,000$ & $-6,090$ & $-715,620$ \\
\hline Utilidad Operativa & $-39,068$ & & \multicolumn{2}{|r|}{14,507} \\
\hline Otros (Amortiz.Inv. Intang) & $-4,200$ & & \multicolumn{2}{|r|}{$-4,200$} \\
\hline Utilidad antes de Intereses e Impuestos & $-43,268$ & & \multicolumn{2}{|r|}{10,307} \\
\hline Gastos Financieros & $-5,705$ & $-6,000$ & \multicolumn{2}{|r|}{$-11,705$} \\
\hline Utilidad antes de Impuestos & $-48,972$ & & \multicolumn{2}{|r|}{$-1,397$} \\
\hline Impuesto a la Renta & 14,447 & & \multicolumn{2}{|r|}{412} \\
\hline \multicolumn{5}{|l|}{ Participación de los trabajadores } \\
\hline Utilidad Neta & $-34,526$ & & & -985 \\
\hline
\end{tabular}

Elaboración propia 
Si bien esto mantiene un VAN negativo y extiende los periodos de recuperación, esta situación permite la continuidad del negocio.

Luego de la comprobación de los indicadores de gestión financiera y toma de decisiones de inversión, se puede concluir que el proyecto es viable desde el punto de vista financiero. 


\section{CONCLUSIONES}

Luego de lo expuesto en los capítulos anteriores, se concluye lo siguiente:

- La propuesta de un surtidor autoservicio es aceptada por el mercado potencial, enfocándose en comodidad y atención del cliente, pues son los factores relevantes para la elección de un bar.

- La propuesta de valor satisface a un perfil de cliente potencial definido que pertenece a un mercado que es lo suficientemente amplio para desarrollar el negocio dentro del mercado de bares.

- La ventaja competitiva y propuesta de valor es diferente a lo ofrecido por los competidores actualmente.

- La estrategia de marketing está alineada al segmento de mercado objetivo y genera el flujo de venta que sustenta los flujos financieros, por lo que el proyecto es viable desde el punto de vista comercial.

- La capacidad, procesos y recursos propuestos son suficientes para cubrir las proyecciones de venta y para cumplir con la propuesta de valor propuesta, así como el posicionamiento en el mercado.

- Los procesos identificados como necesarios para la operación de la empresa son posibles de ejecutar de forma eficiente, lo cual hace viable este proyecto desde el punto de vista operativo y están alineados con la propuesta de valor y ventaja competitiva.

- Los indicadores financieros y de toma de decisión son positivos en todas sus reglas, en los supuestos del escenario base y también cuando se le incluye la sensibilidad de diferentes variables planteadas desde una perspectiva de riesgo, por lo que el proyecto es viable desde la perspectiva financiera.

Por lo concluido, es posible afirmar que se cumple la hipótesis de factibilidad propuesta relacionada a la implementación de un con autoservicio. 


\section{RECOMENDACIONES}

Las recomendaciones sobre el negocio se plantean sobre un escenario futuro de continuidad para los siguientes años de operación. Se plantean las siguientes consideraciones:

- En caso se superen las expectativas del escenario base o al final del periodo en evaluación, se debería evaluar la apertura de un nuevo local con las mismas características.

- Si la realidad se aproxima al escenario optimista, se debe evaluar la implementación completa del autoservicio en la totalidad del local para generar mayor consumo.

- Se puede revisar la opción de ofrecer el local como alquiler para eventos corporativos como una línea de negocio adicional y disminuir el riesgo del factor de ocupabilidad. 


\section{REFERENCIAS}

Banco Central de Reserva del Perú. (21 de September de 2018).

http://www.bcrp.gob.pel. Obtenido de

http://www.bcrp.gob.pe/docs/Publicaciones/Reporte-

Inflacion/2018/setiembre/reporte-de-inflacion-setiembre-2018-presentacion.pdf

Barletta, F., Pereira, M., Robert, V., \& Yoguel, G. (2013). Argentina: dinámica reciente del sector de software y servicios informáticos. Revista de la CEPAL(110), 137155. Obtenido de http://www.cepal.org/publicaciones/xml/1/50511/RVE110Yoqueletal.pdf

Calvo Perez, J. (2012). La oreja en el piso: Una cultura para el ejercicio del liderazgo. Lima: Santillana.

Chase, R. B. (2014). Administración de Operaciones. Ciudad de México: Mc Graw Hill Education.

Chiavenato, I. (2017). Administración de recursos humanos. En I. Chiavenato, Administración de recursos humanos (pág. 19). NaGraw-Hill Interamericana.

Choy, M., \& Chang, G. (2014). Medidas macroprudenciales aplicadas en el Perú. Lima: Banco Central de Reserva del Perú. Obtenido de http://www.bcrp.gob.pe/docs/Publicaciones/Documentos-deTrabajo/2014/documento-de-trabajo-07-2014.pdf

Damodaran. (s.f.). http://pages.stern.nyu.edu/. Obtenido de http://pages.stern.nyu.edu/ adamodar/New_Home_Page/datafile/Betas.html

Diario Gestion. (7 de Agosto de 2017). Obtenido de https://gestion.pe/economia/: https://gestion.pe/economia/peruanos-gastan-s-100-soles-consumo-cerveza-5anos-141006

Diario Gestión. (10 de Mayo de 2018). CCL: 30\% de bebidas alcohólicas que se consumen en Perú son informales. Obtenido de https://gestion.pe/economia/mercados/ccl-30-bebidas-alcoholicas-consumenperu-son-informales-233381

Drink Command. (s.f.). Recuperado el 21 de Octubre de 2018, de https://www.drinkcommand.com

Drink Command. (s.f.). https://www.drinkcommand.com/. Obtenido de https://www.drinkcommand.com/: https://www.drinkcommand.com/

ebeer. (s.f.). http://www.ebeersystem.com/. Obtenido de http://www.ebeersystem.com/: http://www.ebeersystem.com/

El Comercio. (11 de Octubre de 2018). https://elcomercio.pe/. Obtenido de https://elcomercio.pe/vamos/7-bares-tematicos-geniales-lima: https://elcomercio.pe/vamos/7-bares-tematicos-geniales-lima-noticia446456 ? foto $=1$

García Nieto, J. P. (2013). Consturye tu Web comercial: de la idea al negocio. Madrid: RA-MA.

Google. (18 de Diciembre de 2018). Google. Obtenido de Winning the Zero Moment of Truth: https://books.google.es/books?hl=es\&lr=\&id=V9-

1HWPPNo0C\&oi=fnd\&pg=PT1\&dq=zero+moment+of+truth\&ots=e_Tqtksyc4 \&sig=3G7kPQ5x41x4-

$1 \mathrm{kopGMM} 8 \mathrm{syeU} 3 \mathrm{~s} \# \mathrm{v}=$ onepage $\& \mathrm{q}=\mathrm{zero} \% 20 \mathrm{moment} \% 20 \mathrm{of} \% 20$ truth $\& \mathrm{f}=$ false

INEI. (15 de Octubre de 2018). INEI. Obtenido de www.inei.gob.pe:

https://www.inei.gob.pe/media/MenuRecursivo/boletines/boletin-quincenal18.pdf 
J C, M. (7 de Agosto de 2018). José Bracamonte, 20 años de Sommelier. Obtenido de www.jcmagazine.com/jose-bracamonte-20-anos-de-sommelier/

Kasriel-Alexander, D. (2017). Las 10 principales tendencias globales de consumo para 2017. Londres: Euromonitor International.

Koontz, W. y. (2012). Administración: una perspectiva global y empresarial. (14a).

McGraw Hill. Obtenido de https://ebookcentral.proquest.com

Kotler, P., \& Keller, K. (2012). Dirección de Marketing. México: Pearson Education.

Osterwalder, A. P. (2015). Diseñando la propuesta de valor. Deusto.

Padachi, K. (1 de Enero de 2006). Trends in Working Capital Management and its Impact on Firms' Performance: An Analysis of Mauritian Small Manufacturing Firms. Obtenido de International Review of Business Research Papers: https://www.researchgate.net/publication/238599541_Trends_in_Working_Capi tal_Management_and_its_Impact_on_Firms'_Performance_An_Analysis_of_M auritian_Small_Manufacturing_Firms

Porter, M. (1989). How Competitive Forces Shape Strategy. En D. B. Asch, Readings in Strategic Management (págs. 133-134). Londres: Palgrave.

Ross, S., Westerfield, R., \& Jaffe, J. (2012). Finanzas Corporativas. Ciudad de México: Mc Graw Hill.

RPP. (21 de Setiembre de 2018). https://rpp.pe/cultura/mas-cultura/. Obtenido de https://rpp.pe: https://rpp.pe/cultura/mas-cultura/dia-internacional-de-la-cerveza10-bares-de-lima-para-disfrutar-de-esta-bebida-noticia-1141153

Stephen P. Robbins, T. A. (2009). Comportamiento organizacional. (13a.). Mexico: Pearson Education. Obtenido de https://psiqueunah.files.wordpress.com/2014/09/comportamientoorganizacional-13a-ed-_nodrm.pdf 


\section{ANEXOS}

\section{ANEXO N ${ }^{\circ}$ 1: Cuestionario de Encuesta}

1. Indique su género:

- Hombre

- Mujer

- Otro

2. ¿En qué rango de edad se encuentra?

- $\quad$ Entre 18 y 23 años

- $\quad$ Entre 24 y 30 años

- $\quad$ Entre 30 y 40 años

- $\quad$ Más de 40

3. ¿En qué distrito trabaja?

- Santiago de Surco

- Miraflores

- San Isidro

- La Molina

- Barranco

- San Miguel

4. Indique qué lugares frecuenta normalmente luego del trabajo

- Cine o Teatro

- Ejercicio

- Bar o discoteca

- Restaurantes

- Centro comerciales

- Otros

5. ¿Cuánto gasta a la semana aproximadamente en tiempo de ocio?

- Menos de 100 soles

- Entre 100 y 200 soles

- Entre 200 y 300 soles

- Entre 300 y 400 soles

- Más de 400

6. ¿Cuánto le parece un precio razonable para una botella de cerveza $(350 \mathrm{ml})$ dentro de un local?

- Menos de 8 soles

- Entre 8 y 12 soles

- Entre 12 y 16 soles

- Más de 16 soles

7. ¿Qué tipo de cerveza prefiere?

- Regulares

- Artesanales 
8. ¿Con qué frecuencia visita bares?

- Menos de 1 vez al mes

- Una vez al mes

- Una vez cada 15 días

- Una vez a la semana

- Más de una vez al semana

9. Usualmente, ¿con quién frecuenta resto-bares? Puede marcar más de una opción

- Pareja

- Compañeros del trabajo

- Amigos fuera del trabajo

- Familia

- Otras

10. ¿Qué es lo que destaca más al asistir a un bar? Puede elegir más de una

- Precio

- Conveniencia

- Ambiente

- Comodidad

- Atención

- Variedad de la carta

- Público asistente

- Otros

11. ¿Qué tipo de temática prefiere? Puede marcar más de 1 opción

- Sportsbar

- Stand Up Comedy

- Música en vivo

- Previos para ir a otro lugar

- Charlas de un tema especial

- Otros

12. Por favor indique su posición sobre un nuevo concepto de bar con un Sistema de autoservicio de cerveza, en el cuál usted pagaría por mililitros y no por envase.

- Me gusta mucho

- Me interesa

- Es indiferente

- No me convence

- No me gusta 


\section{ANEXO N ${ }^{\circ}$ 2: Estudio de Mercado Cuantitativo}

A continuación mostramos los resultados de la encuesta, de acuerdo a los lineamientos de la muestra determinada en el capítulo 3. Se obtuvieron 289 cuestionarios completos:

1. Indique su género

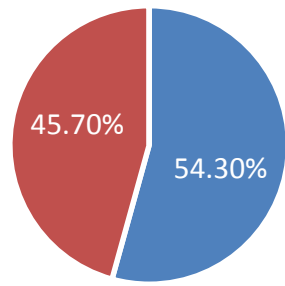

- Hombre - Mujer - Otro

2. Rango de edad

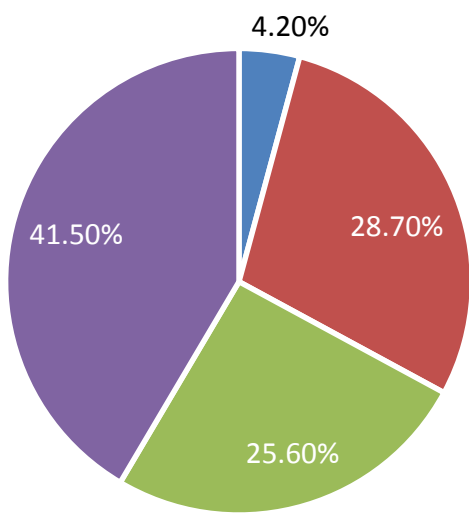

- Entre 18 y 23 años

- Entre 24 y 30 años

- Entre 30 y 40 años

- Más de 40 años

3. Distrito donde trabajan

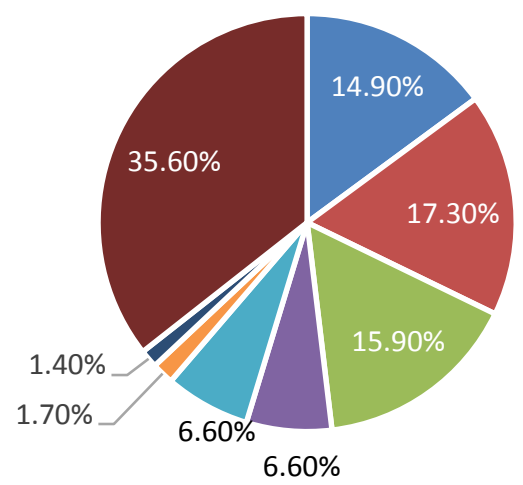

- Santiago de Surco

- Miraflores

- San Isidro

- San Borja

- La Molina

- Barranco

- San Miguel

- Otro 


\section{Lugares Frecuentados (Post Trabajo)}

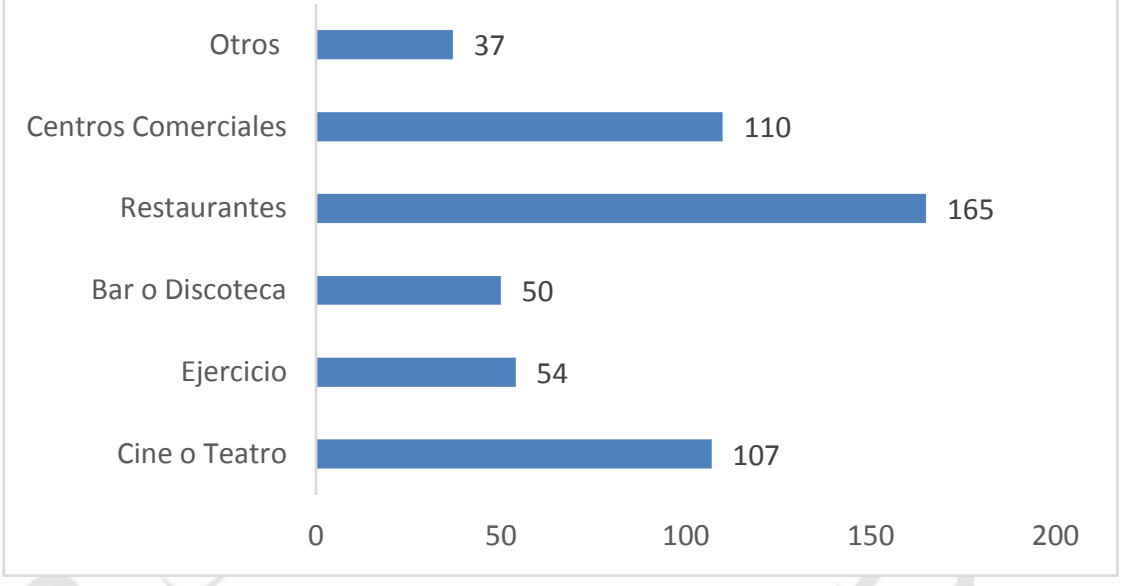

\section{Gasto en tiempo de ocio}

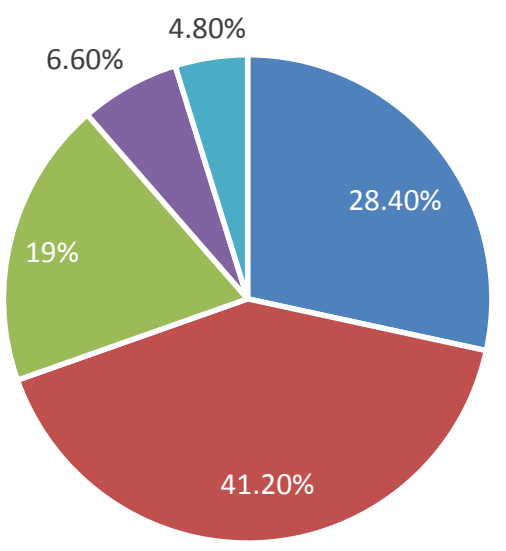

- Menos de 100 soles

- Entre 100 y 200 soles

- Entre 200 y 300 soles

- Entre 300 y 400 soles

- Más de 400 soles

\section{Rangos de precio}

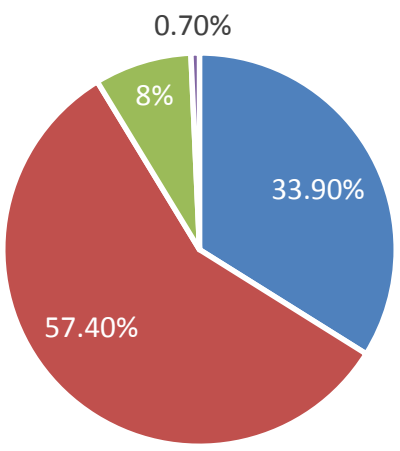

- Menos 8 soles

- Entre 8 y 12 soles

- Entre 12 y 16 soles

- Más 16 soles 


\section{Tipos de cerveza}

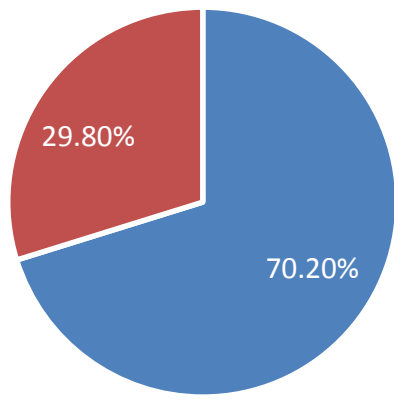

- Regulares Artesanales

\section{Frecuencia de visita a bares}

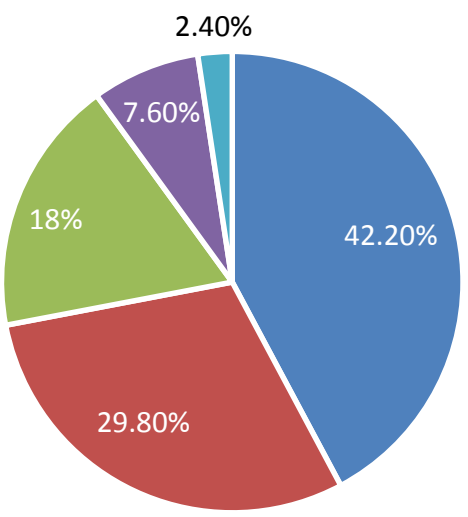

- Menos de 1 vez al mes

- Una vez al mes

- Una vez al cada 15 días

- Una vez a la semana

- Más de una vez a la semana

\section{Acompañantes a restobares}

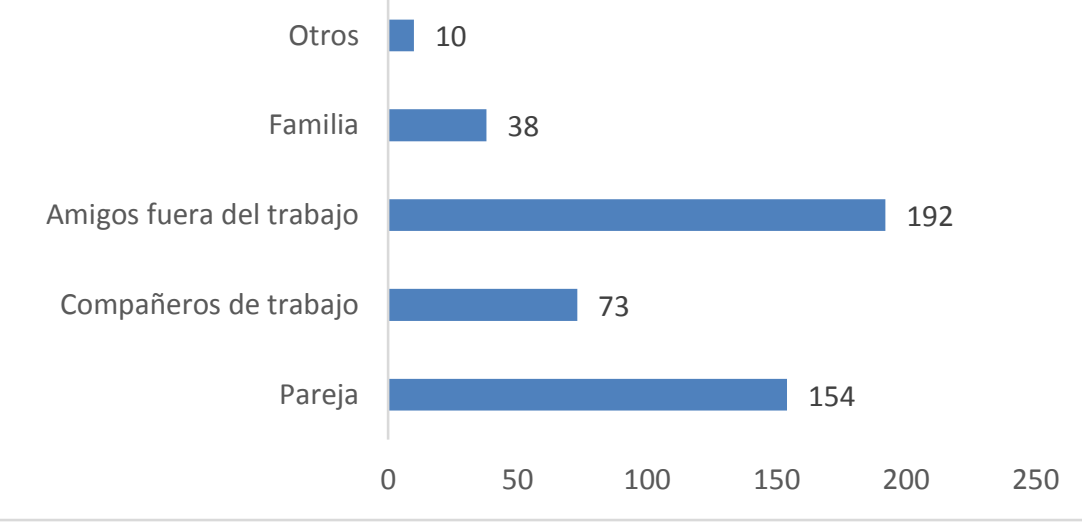




\section{Factores para elección de un bar}

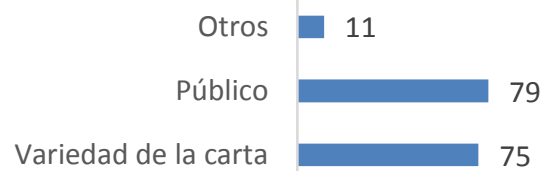

Variedad de la carta

75

Atención

163

Comodidad

Ambiente

Conveniencia

Precio

15

109

$0 \quad 50 \quad 100$

$150 \quad 200$ $250 \quad 300$

\section{Temáticas Preferidas}

tros

12

Charlas

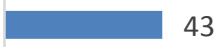

Previos

Música en vivo
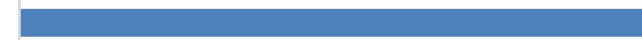

177

Stand up Comedy
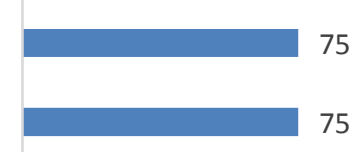

Sportsbar

0

50

100

150

200

\section{Concepto de pago por mililitros}

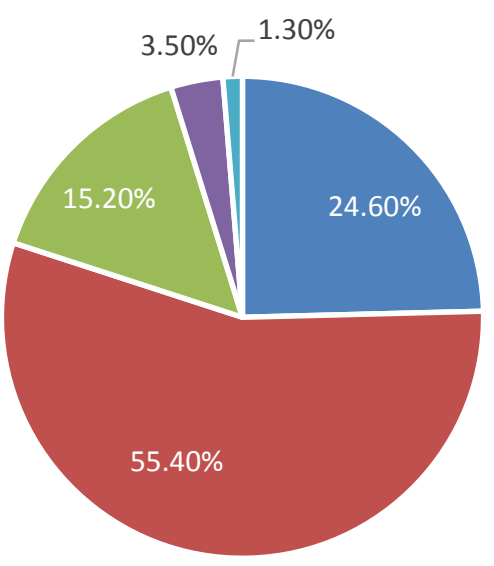

- Me gusta mucho

- Me interesa

- Es indiferente

- No me convence

- No me gusta 


\section{ANEXO N ${ }^{\circ}$ 3: Estudio de Mercado Cualitativo}

Para realizar el estudio cualitativo se eligió la herramienta de observación a un local parecido (posible competidor) para documentar el comportamiento del cliente, así como información clave sobre la operación del negocio:

- $\quad$ Fecha: Martes 7 de Agosto del 2018

- Hora: 10:00 pm

- Lugar: Bar "Entrecopas"

- Ubicación: Centro Comercial El Polo - Santiago de Surco

$\underline{\text { Información sobre los clientes }}$

- $\quad$ Público asistente: Un grupo de 3 amigos, 2 parejas, 2 amigos y una persona sola

- $\quad$ Patrón de consumo: 1 trago por persona y un piqueo por mesa, los pedidos no incrementan lo que deriva en una rotación lenta en pedidos y en clientes. En los fines de semana se recibe un flujo mayor de grupos que piden botellas enteras.

- Se aprecian las largas conversaciones y el ambiente tranquilo en los días de semana, esto se confirmó al momento que una pareja solo pidió bebidas gaseosas, así como la zona de fumadores. En los fines de semana se aprecia la energía para relajarse y el ambiente de fiesta.

- De acuerdo con los trabajadores del local, la preferencia de los clientes va por las cervezas nacionales y tragos simples (p.e chilcanos, pisco sour, vinos) por el lado de bebidas, y el chicharrón de pollo o tequeños por el lado de los piqueos.

\section{$\underline{\text { Información sobre el competidor }}$}

- Carta: Ordenada de las ofertas más especiales a las más simples (amplio), contaba con tragos propios, se caracterizan por su variedad. Bastantes imágenes, no había comida solo piqueos.

- Ambientación: Pantallas que incentivan consumo, auspiciadores, temática de copas y vasos, así como calentadores y luces de fiesta

- Distribución: Aproximadamente 25 mesas de 2 personas, con la flexibilidad para juntarlas, separado en zona interna y externa (fumadores), cuenta con estacionamiento del centro comercial

- Atención: Lunes a Sábado, en los primeros 3 días atienden 2 mozos y 5 en días de alto flujo. Demoras en servir los piqueos, la cocina se encontraba fuera del local, esto ahorra espacio e incomodidades..

- Diferenciadores: Música en vivo de jueves a sábado, ofrecen alquiler de "Sisha" (pipa de agua). 


\section{ANEXO N ${ }^{\circ}$ 4: Estudio de Mercado Cualitativo}

\section{Entrevista a dos expertos en el rubro de Bar Restaurantes.}

Lugar: Restaurant Bar Baco y Vaca.

Fecha: Jueves 27 de Setiembre de 2018.

Entrevistados:

- Sr. Luis Higa - Accionista y Encargado de la Operación de Restaurantes Bar "Baco y Vaca", "Hanzo", "Wasabi”, de Pollerías "Rocky's" y Karaokes "Stragos"

- Sr. José Bracamonte - Sommelier con 20 años de experiencia, considerado uno de los mejores sommelier peruanos en Sudamérica según la Revista JC Magazine. (2018) https://www.jcmagazine.com/jose-bracamonte-20-anos-de-sommelier/. Es asesor de diferentes empresas y tiene hace 4 años el blog "El vino de la semana" en Diario Gestión.

A continuación las preguntas y respuestas de la entrevista:

1. ¿Qué les parece la idea de abrir un bar temático enfocado en tener música en vivo, stand up y en el autoservicio de cerveza con un grifo de chopp en mesa, donde el consumo se mide a través de software?

José Bracamonte: La tendencia actual es la de un bar más tradicional que tecnológico, que cuente con una carta de piqueos corta pero rica, inclusive que se pueda comer con las manos y con servilletas. En cuanto a bebidas alcohólicas tener una vasta variedad de licores y concentrarse en ir incrementando tragos paulatinamente. Para esto último es necesario contar con un barman de prestigio que conozca el negocio, hable por lo menos inglés, influenciador, conocedor de las tendencias en el mercado y que sirva de publicidad para el bar.

En mi opinión y por experiencia creo que un bar con algún tipo de show distrae al cliente y hace que la rotación en el consumo sea lenta.

Luis Higa: Creo que un bar con temática de música en vivo y stand up o algún tipo de show hasta cierto punto es un negocio parecido a un karaoke porque el cliente puede comer y tomar mientras se divierte y es una propuesta que tiene que ser bien enfocada para que no haya poca rotación en el consumo.

\section{2. ¿Cuál es el área mínima requerida para un bar?}

Luis Higa: Para un bar, un mínimo de $150 \mathrm{~m}^{2}$ (mesas y barra) sin contar cocina, baños, almacén, entrada, escenario, otros. Dependiendo de la propuesta que se maneje puede considerarse un área mayor.

José Bracamonte: Lo que he notado es un bar muy grande tampoco es recomendable por más lujoso y llamativo que este sea debido a que el consumidor, 
en especial el local está más acostumbrado a un bar acogedor donde todo este cerca de la barra y en el que se privilegie la interacción con los demás.

3. En su experiencia ¿cuál es la inversión inicial y requerida?, ¿cuáles los niveles de venta y márgenes aproximados en bebidas alcohólicas y comida para un establecimiento de estas características?

Luis Higa: Un bar con música en vivo es un negocio parecido al de un karaoke. Nosotros tenemos 3 locales de Stragos karaoke y la inversión mínima que se consideró para el último local abierto fue de $\$ 100,000$ para equipamiento, mobiliario, menaje, decoración, sin contar la inversión en local.

De los 3 karaokes los niveles de venta mensual promedio del que más vende y el que menos vende es el siguiente:

S/ 220,000 - local de San Borja.

S/ 100,000 - local de Miraflores

La variación de ventas se da por la ubicación de los establecimientos y por los horarios de atención en el de San Borja la atención es de 6:00 pm a 3:00 am y en el de Miraflores es de 6:00 pm a 1:00 pm

Los márgenes en piqueos están entre $50 \%$ y $60 \%$ en promedio. Las bebidas alcohólicas están entre $80 \%$ y $90 \%$ o más, dependiendo si son cocteles o licores clásicos como whisky, vodka, gin, etc. Por ejemplo una botella de whisky marca Johnny Walker de $750 \mathrm{ml}$ cuesta $\mathrm{S} / 92$ y el vaso de whisky de 2 oz cuesta S/ 35, de una botella salen 12 vasos de 2 oz cada uno, saca tu cuenta.

\section{4. ¿Cuál creen que sería una buena ubicación para abrir un bar?}

José Bracamonte: Los lugares predilectos son: Miraflores y San Isidro. Sin embargo creo que San Borja y Surco sería una buena opción. Creo que debería tener estacionamiento propio o cercano al establecimiento. Un elemento clave a considerar es que debe estar en una zona donde estén ubicados otros bares por ejemplo como en Calle Manuel Bonilla en Miraflores, porque la oferta de varias propuestas es buena para el cliente y si tienes un buen elemento diferenciador será fácil identificar tu bar.

Luis Higa: También creo que algunas zonas en distritos como: Av Aviación en San Borja y Chacarilla en Santiago de Surco son buenas para abrir un bar, calles y avenidas cercanas a la avenida Aviación. Y definitivamente si se cuenta con el capital suficiente se puede considerar Miraflores, San Isidro, Barranco.

\section{5. ¿Cuáles son las mermas propias de este negocio y cómo las tratan?}

José Bracamonte: en el proceso de "mise en place" para cocina y barra, que tiene que ver con la preparación y disposición de los ingredientes y utensilios necesarios para llevar a cabo una receta de cocina y en cocteles respectivamente, quedan cascaras de frutas y verduras que son utilizadas en la presentación de 
platos y cocteles, por ejemplo: la cáscara de naranja y limones son deshidratadas y utilizadas en la decoración de copas en cocteles.

Luis Higa: En alimentos las mermas son mínimas, casi todo se utiliza dado que en el proceso de preparación de los ingredientes de platos de la carta parten de una compra planificada y buscando eficiencias. En licores y cocteles la merma es cero.

\section{6. ¿Tiene una política de responsabilidad social y de respeto al medioambiente,} como tratamiento de residuos orgánicos, no orgánicos?

Luis Higa: A nivel de responsabilidad social no se hace mucho. Sin embargo se apoya se hacen actividades para los trabajadores y sus familiares en época de Navidad. Por el lado del tratamiento de residuos, estos se separan para la entrega a los camiones recolectores.

José Bracamonte: Una acción concreta en este giro de negocio es que desde hace 2 años no se están poniendo en los cocteles o bebidas no alcohólicas cañitas de plástico y se han reemplazado por cañitas hechas de fibra de caña de azúcar, de acero inoxidable y de papel encerado.

\section{7. ¿Cuál es la tendencia que ven en bar restaurantes?}

José Bracamonte: Desde hace algún tiempo la tendencia en el Perú es tener una propuesta que incluya productos (alimentos y bebidas), decoración, aspectos culturales resaltantes de las regiones del país. Tenemos bares como: "La emolientería" que confirma esta tendencia. Actualmente, estoy asesorando a un grupo corporativo que está planeando abrir una cadena de bares en una región del país (no especifica) que resalta su región de procedencia.

\section{Conclusiones de la entrevista:}

- Gestionar nuestra oferta de bar temático enfocado en música en vivo, stand up shows, de tal forma que no impacte el consumo esperado del negocio. Una manera de hacerlo es ir poco a poco introduciendo la música en vivo, alternando en una frecuencia quincenal con stand up show para ir viendo el comportamiento y las preferencias del cliente.

- Dimensiones del bar no debe ser menor a $150 \mathrm{~m}^{2}$.

- Ubicación del negocio: Se confirma los distritos y zonas escogidos para abrir el negocio.

- Considerar las cifras proporcionadas por Luis Higa propietario de Stragos Karaoke en cuanto a inversión inicial, niveles de venta y márgenes en piqueos y bebidas alcohólicas, planillas de sueldos, debido a que es un negocio vigente y de un rubro de negocios que ofrece productos y servicios similares a nuestra propuesta: bar, música en vivo, piqueos. 


\section{ANEXO N ${ }^{\circ}$ 5: Estudio de Mercado Cualitativo}

\section{Entrevista a profundidad a potenciales clientes del bar autoservicio.}

Se entrevistó a varias personas de diferentes edades, ocupaciones y sexo, quienes tienen ingresos propios regulares y se les hizo las preguntas indicadas a continuación:

1. ¿Estaría interesado en frecuentar un bar donde se ofrece autoservicio de cerveza (chopp) directamente en mesa a través de un sistema de consumo por mililitros?

2. Le gustaría que el bar ofreciera como complemento actividades temáticas como: música en vivo, stand up comedy, catas?

3. De interesarle la propuesta de bar ¿Cuántas veces estaría dispuesto a asistir?

4. ¿Qué cantidad de dinero estaría dispuesto a destinar en una asistencia al bar propuesto?

5. ¿Con quienes asistiría al bar? Especifique.

Estas preguntas tienen por finalidad obtener mayor información real detallada sobre las preferencias de potenciales clientes del bar propuesto, saber si les parece una buena idea e innovadora, así como si estarían interesados en asistir a un bar de las características propuestas de autoservicio y de elementos temáticos, la frecuencia con que asisten a bares y con quienes lo hacen.

Entrevistados:

- Clifton Casas - Gerente de TI, 52 años.

Opina que le parece una excelente idea, principalmente porque es consumidor habitual de cerveza y frecuenta bares con sus amigos una vez al mes y el formato de música en vivo y stand up comedy le parece acertado.

Resaltó que debe ser un bar orientado a un segmento A y B y para edades a partir de los 30 a 35 años, sino el hecho de tener un sistema de chopp en mesa significaría tener gente muy joven que ve el establecimiento como un bar cervecero, con el riesgo que no sepan comportarse adecuadamente, lo cual puede encasillarlo en un lugar inseguro. Suele destinar un promedio de 200 soles en una visita a un bar.

- Katya Villalobos - Administradora hotelera, 39 años.

Cree que en promedio asistiría al bar 1 vez al mes y gasta un promedio de 100 soles en cada salida. En la actualidad esta frecuencia de concurrencia a un bar es mínimo debido a que se encuentra en búsqueda de trabajo. No le gusta mucho la cerveza, pero suele pedir cocteles clásicos por lo que la propuesta de bar clásico en coctelería y piqueos le parece importante.

La idea de autoservicio de cerveza chopp en mesa le parece una buena idea, que puede "pegar" porque refiere que hay una tendencia a consumir cervezas artesanales en chopp, que se puede trasladar a este nuevo concepto. El elemento que le atrae es el de show en vivo. Remarcó su preferencia en este elemento debido a que ella frecuenta con su pareja y amigos un bar en Miraflores, en la Av Manuel Bonilla llamado "La Tarima", donde hay show en vivo. Cree que si esta propuesta está dirigida a un segmento A y B con clientes de 40 a 45 en promedio de edad será acogida. 
- Luis Casanova - Contador público y emprendedor, 58 años.

La idea de autoservicio de cerveza le parece interesante e innovadora, especialmente que este relacionado a un software que contabilice el consumo y controle el inventario de cerveza. Estaría dispuesto a visitar el bar probablemente una vez cada 2 o 3 meses y lo haría con amigos y colegas de trabajo. Le gusta la cerveza pero en la actualidad por un tema de salud consume principalmente whisky. Destinaría 200 soles en promedio en una visita al bar.

La propuesta de show es lo que más le anima, en especial la de música en vivo y por ese motivo podría estar dispuesto a frecuentar más el bar.

- Hugo LLap - Ingeniero químico, 46 años.

No es consumidor habitual de alcohol. Sin embargo, le parece una muy buena idea la propuesta de tener un bar con temática relacionada a shows en vivo, ya sea de música o stand up comedy. Le parece que es un formato al que si frecuentaría con amigos como usualmente solía hacerlo hace algún tiempo que asistía a shows en Miraflores como "Jazz Zone".

Podría destinar entre 100 y 150 soles en promedio en una visita al bar on una frecuencia de una vez cada 3 meses, dado que prefiere visitar con mayor frecuencia restaurantes en el lapso de un mes.

- Sofía Ormeño - Arquitecta de interiores y emprendedora, 40 años.

No le gusta la cerveza, pero frecuenta bares 2 veces al mes y estaría dispuesta a visitar el bar propuesto con la misma frecuencia. Gasta 200 soles en promedio $\mathrm{n}$ cada visita a un bar. Visita bares con amigos que si le gustan la cerveza ero que prefieren el whisky, gin, vodka y pisco.

Lo que le atrae del bar es la propuesta de shows en vivo, el ambiente y la coctelería. Opina que un bar de estas características bien ubicado daría resultado básicamente por la variedad de elementos propuestos.

- Liliana Murga - Gerente Administrativo y empresaria, 50 años.

Frecuenta bares 1 vez al mes y lo hace con amigos, gasta un promedio de S/ 100 soles, que en cada salida. Prefiere el vino y la cerveza, ésta última en especial en verano.

Al ser consultada sobre la propuesta de bar autoservicio, con elementos temáticos le parece una idea "super" porque considera que la gente es "chelera". Puso como ejemplo bares que ofrecen cerveza regular y artesanal en Miraflores y Barranco, los cuales son muy concurridos en su opinión. Por esta razón considera que una oferta de un sistema de chopp directamente en mesa como autoservicio cree que tendrá aceptación, además porque los shows en vivo son muy valorados por las personas de un rango amplio de edades.

Comentó también que prefiere que los clientes del bar estén entre los 35 y 50 años de edad porque son personas que se mantienen y gastan un monto importante de dinero. También indicó que con respecto a la ubicación del bar le parece que debería ser San Isidro o Chacarilla. 


\section{Conclusiones de las entrevistas a profundidad:}

De las respuestas dadas por las 6 personas entrevistadas se puede concluir lo siguiente:

- $\quad 100 \%$ de los entrevistados mostraron abiertamente su preferencia por shows en vivo, en especial la música en vivo.

- 67\%, es decir 4 de 6 entrevistados creen que la idea de autoservicio es novedosa y que puede "pegar".

- El promedio de consumo aproximado por visita al bar con una frecuencia de $1 \mathrm{vez}$ al mes por cada potencial cliente es de S/ 161.00.

- $\quad$ El rango de edades de los entrevistados es de 39 a 58 años.

- El 83\%, es decir 5 de 6 cuentan con ingresos propios regulares.

- $100 \%$ de entrevistados visitan bares con amigos y pareja. 
ANEXO N ${ }^{\circ}$ 6: Cálculo de Ticket Promedio y de Ventas anuales.

Cálculo de la Demanda

Tiempo de estadía: 1 hora

\begin{tabular}{|l|r|r|r|}
\hline \multicolumn{1}{|c|}{ Mesa 2 personas } & \multicolumn{1}{c|}{ P.Unit } & \multicolumn{1}{c|}{ Cant } & \multicolumn{1}{c|}{ P.Total } \\
\hline Piqueo & 30.00 & 1.00 & 30.00 \\
1.4 litros de cerveza & 12.00 & 6.00 & 72.00 \\
Agua & 8.00 & 2.00 & 16.00 \\
\hline \multicolumn{2}{|r}{} \\
\cline { 1 - 2 }
\end{tabular}

\begin{tabular}{|r|r|}
\hline Comida & Bebida \\
\hline 30.00 & \\
\hline & \\
\hline & \\
\hline & \\
\hline & \\
\hline 46.00 & \\
\hline
\end{tabular}

\begin{tabular}{|l|r|r|r|r|}
\hline Capacidad en mesas (máx capacidad 4) & 11 \\
Factor ocupabilidad & 3.5 & \multicolumn{1}{|l|}{$1,298.00$} & 10 mesas + barra \\
Semanal & 6 & $4,543.00$ \\
$27,258.00$ & \\
Mensual & 24 & $109,032.00$ \\
\hline
\end{tabular}

Marginal

\begin{tabular}{|c|c|c|c|}
\hline \hline Mesa 2 personas & P.Unit & Cant & P.Total \\
\hline Trago con & \multicolumn{3}{|c|}{30}
\end{tabular}

60.00

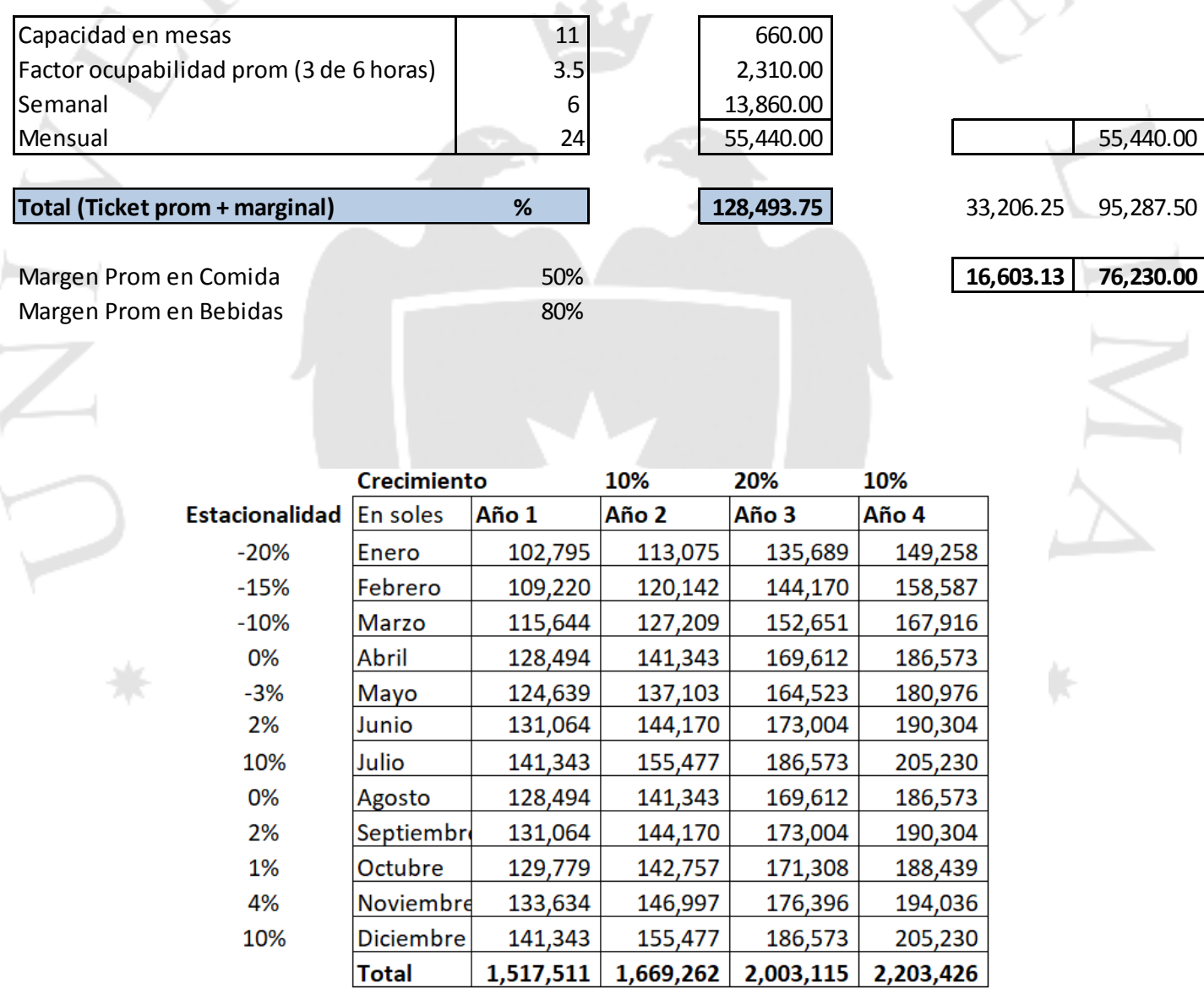

Estacionalidad: Meses de Ene a Mar negativos debido a la tendencia de consumo en bares del sur de la ciudad y Jul y Dic debido a Fiestas Patrias y Festividades de fin de año 
ANEXO $\mathbf{N}^{\circ}$ 7: Presupuesto de inversiones y gastos

\section{Presupuesto de gastos operativos}

\section{GASTOS DE OPERACIÓIN \\ (expresado en Soles)}

$\%$ inflación

tipo de cambio

Planillas

Terceros

Alquiler local

Gastos Generales

Gastos de Administración

Gastos de Marketing

Depreciación

Otros

TOTAL GASTOS DE OPERACIÓN

\begin{tabular}{|c|c|c|c|c|}
\hline Año 1 & Año 2 & Año 3 & Año 4 & Total \\
\hline & $4.0 \%$ & $3.80 \%$ & $3.50 \%$ & \\
\hline 3.329 & 3.35 & 3.35 & 3.35 & \\
\hline 381,060 & 396,302 & 411,362 & 425,760 & $1,614,484$ \\
\hline 72,100 & 74,984 & 77,833 & 80,558 & 305,475 \\
\hline 151,782 & 152,740 & 152,740 & 152,740 & 610,002 \\
\hline 33,665 & 37,032 & 44,438 & 48,882 & 164,017 \\
\hline 604,942 & 624,026 & 641,935 & 659,057 & $2,529,961$ \\
\hline
\end{tabular}

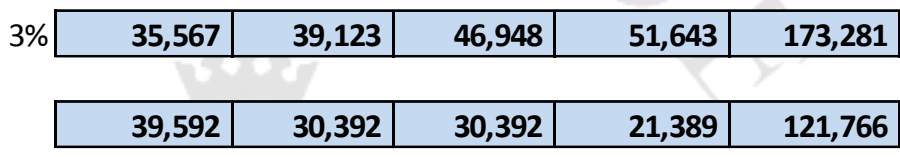

\begin{tabular}{|r|r|r|r|r|}
\hline 11,856 & 13,041 & 15,649 & 17,214 & 57,760 \\
\hline
\end{tabular}

\section{Inversión en Activo Fijo}

\begin{tabular}{|c|c|c|c|c|c|c|c|c|c|c|}
\hline Equipo & C.Unit & Cant. & \begin{tabular}{|c|} 
Costo \\
Equipamiento \\
PEN \\
\end{tabular} & $\begin{array}{l}\text { Vida útil } \\
\text { (meses) }\end{array}$ & $\begin{array}{c}\text { Amortización } \\
\text { Mensual } \\
\text { PEN }\end{array}$ & Año 1 & Año 2 & Año 3 & Año 4 & Liq \\
\hline Chopp Autoservicio & 21,450 & 4 & 85,800 & 60 & $1,430.00$ & 17,160 & 17,160 & 17,160 & 17,160 & 17,160 \\
\hline Mesa con 4 sillas & 600 & 12 & 7,200 & 36 & 200.00 & 2,400 & 2,400 & 2,400 & & - \\
\hline Barra & 7,000 & 1 & 7,000 & 36 & 194.44 & 2,333 & 2,333 & 2,333 & & - \\
\hline Copas (set de 6) & 40 & 200 & 8,000 & 12 & 666.67 & 8,000 & & & & - \\
\hline Cubiertos (jgo 12 pers) & 350 & 3 & 1,050 & 36 & 29.17 & 350 & 350 & 350 & & - \\
\hline Platos, tazas y vasos (jgo 12 pers) & 400 & 3 & 1,200 & 12 & 100.00 & 1,200 & & & & - \\
\hline Utensilios de cocina & 3,000 & 1 & 3,000 & 36 & 83.33 & 1,000 & 1,000 & 1,000 & & - \\
\hline Freidora & 1,500 & 1 & 1,500 & 36 & 41.67 & 500 & 500 & 500 & & - \\
\hline Congeladora cocina & 4,000 & 1 & 4,000 & 60 & 66.67 & 800 & 800 & 800 & 800 & 800 \\
\hline Congeladora bar & 2,000 & 2 & 4,000 & 60 & 66.67 & 800 & 800 & 800 & 800 & 800 \\
\hline Caja Registradora & 2,145 & 1 & 2,145 & 60 & 35.75 & 429 & 429 & 429 & 429 & 429 \\
\hline Computadoras 2 & 3,630 & 2 & 7,260 & 36 & 201.67 & 2,420 & 2,420 & 2,420 & & - \\
\hline Equipo de sonido $\&$ audio (sistema Bose) & 8,000 & 1 & 8,000 & 60 & 133.33 & 1,600 & 1,600 & 1,600 & 1,600 & 1,600 \\
\hline Pantalla led & 1,500 & 2 & 3,000 & 60 & 50.00 & 600 & 600 & 600 & 600 & 600 \\
\hline & 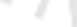 & & 143,155 & & 3,299 & 39,592 & 30,392 & 30,392 & 21,389 & 21,389 \\
\hline
\end{tabular}


ANEXO N ${ }^{\circ}$ 8: Presupuesto de costos

\begin{tabular}{|c|c|c|c|c|c|c|c|c|c|c|c|c|c|c|}
\hline & & ene & feb & mar & abr & may & jun & jul & ago & sep & oct & nov & dic & Total \\
\hline VENTAS año 1 & & 80,309 & 85,328 & 90,347 & 100,386 & 97,374 & 102,393 & 110,424 & 100,386 & 102,393 & 101,390 & 104,401 & 110,424 & $1,478,095$ \\
\hline Cerveza & $5 \%$ & $4,344.71$ & 4,616 & 4,888 & 5,431 & 5,268 & 5,540 & 5,974 & 5,431 & 5,540 & 5,485 & 5,648 & 5,974 & 64,139 \\
\hline Whisky & $4 \%$ & $3,460.63$ & 3,677 & 3,893 & 4,326 & 4,196 & 4,412 & 4,758 & 4,326 & 4,412 & 4,369 & 4,499 & 4,758 & 51,087 \\
\hline Pisco & $3 \%$ & $2,082.65$ & 2,213 & 2,343 & 2,603 & 2,525 & 2,655 & 2,864 & 2,603 & 2,655 & 2,629 & 2,707 & 2,864 & 30,745 \\
\hline Licores y cremas & $5 \%$ & $4,263.75$ & 4,530 & 4,797 & 5,330 & 5,170 & 5,436 & 5,863 & 5,330 & 5,436 & 5,383 & 5,543 & 5,863 & 62,944 \\
\hline Bebidas sin alcohol & $2 \%$ & $1,888.89$ & 2,007 & 2,125 & 2,361 & 2,290 & 2,408 & 2,597 & 2,361 & 2,408 & 2,385 & 2,456 & 2,597 & 27,885 \\
\hline Insumos de cocktelería & $1 \%$ & 905.25 & 962 & 1,018 & 1,132 & 1,098 & 1,154 & 1,245 & 1,132 & 1,154 & 1,143 & 1,177 & 1,245 & 13,364 \\
\hline Insumos de Cocina & $5 \%$ & 3,704 & 3,936 & 4,167 & 4,631 & 4,492 & 4,723 & 5,094 & 4,631 & 4,723 & 4,677 & 4,816 & 5,094 & 54,687 \\
\hline Hielo & $0 \%$ & 204 & 217 & 229 & 255 & 247 & 260 & 280 & 255 & 260 & 257 & 265 & 280 & 3,008 \\
\hline Cigarros & $0 \%$ & 278 & 296 & 313 & 348 & 337 & 355 & 383 & 348 & 355 & 351 & 362 & 383 & 4,107 \\
\hline Utensilios de bar & $0 \%$ & 141 & 150 & 159 & 176 & 171 & 180 & 194 & 176 & 180 & 178 & 183 & 194 & 2,083 \\
\hline Cristalería, menaje & $0 \%$ & 122 & 130 & 137 & 153 & 148 & 156 & 168 & 153 & 156 & 154 & 159 & 168 & 1,802 \\
\hline Movilidad de Compras & $0 \%$ & 124 & 131 & 139 & 154 & 150 & 158 & 170 & 154 & 158 & 156 & 161 & 170 & 1,824 \\
\hline COSTO DE VENTAS AÑO 1 & & 21,519 & 22,864 & 24,209 & 26,899 & 26,092 & 27,437 & 29,589 & 26,899 & 27,437 & 27,168 & 27,975 & 29,589 & 317,675 \\
\hline VENTAS año 2 - incremento 1 & & 88,339 & 93,861 & 99,382 & 110,424 & 107,112 & 112,633 & 121,467 & 110,424 & 112,633 & 111,529 & 114,841 & 121,467 & $1,304,111$ \\
\hline Cerveza & $5 \%$ & 4,779 & 5,078 & 5,377 & 5,974 & 5,795 & 6,093 & 6,571 & 5,974 & 6,093 & 6,034 & 6,213 & 6,571 & 70,553 \\
\hline Whisky & $4 \%$ & 3,807 & 4,045 & 4,283 & 4,758 & 4,616 & 4,854 & 5,234 & 4,758 & 4,854 & 4,806 & 4,949 & 5,234 & 56,196 \\
\hline Pisco & $3 \%$ & 2,291 & 2,434 & 2,577 & 2,864 & 2,778 & 2,921 & 3,150 & 2,864 & 2,921 & 2,892 & 2,978 & 3,150 & 33,820 \\
\hline Licores y cremas & $5 \%$ & 4,690 & 4,983 & 5,276 & 5,863 & 5,687 & 5,980 & 6,449 & 5,863 & 5,980 & 5,921 & 6,097 & 6,449 & 69,238 \\
\hline Bebidas sin alcohol & $2 \%$ & 2,078 & 2,208 & 2,337 & 2,597 & 2,519 & 2,649 & 2,857 & 2,597 & 2,649 & 2,623 & 2,701 & 2,857 & 30,673 \\
\hline Insumos de cocktelería & $1 \%$ & 996 & 1,058 & 1,120 & 1,245 & 1,207 & 1,270 & 1,369 & 1,245 & 1,270 & 1,257 & 1,295 & 1,369 & 14,700 \\
\hline Insumos de Cocina & $5 \%$ & 4,075 & 4,330 & 4,584 & 5,094 & 4,941 & 5,195 & 5,603 & 5,094 & 5,195 & 5,145 & 5,297 & 5,603 & 60,155 \\
\hline Hielo & $0 \%$ & 224 & 238 & 252 & 280 & 272 & 286 & 308 & 280 & 286 & 283 & 291 & 308 & 3,309 \\
\hline Cigarros & $0 \%$ & 306 & 325 & 344 & 383 & 371 & 390 & 421 & 383 & 390 & 386 & 398 & 421 & 4,518 \\
\hline Utensilios de bar & $0 \%$ & 155 & 165 & 175 & 194 & 188 & 198 & 213 & 194 & 198 & 196 & 202 & 213 & 2,292 \\
\hline Cristalería, menaje & $0 \%$ & 134 & 143 & 151 & 168 & 163 & 171 & 185 & 168 & 171 & 169 & 175 & 185 & 1,982 \\
\hline Movilidad de Compras & $0 \%$ & 136 & 144 & 153 & 170 & 165 & 173 & 187 & 170 & 173 & 172 & 177 & 187 & 2,007 \\
\hline COSTO DE VENTAS AÑO 2 & & 23,671 & 25,150 & 26,630 & 29,589 & 28,701 & 30,180 & 32,548 & 29,589 & 30,180 & 29,885 & 30,772 & 32,548 & 349,442 \\
\hline VENTAS año 3 - incremento 2 & & 106,007 & 112,633 & 119,258 & 132,509 & 128,534 & 135,159 & 145,760 & 132,509 & 135,159 & 133,834 & 137,810 & 145,760 & $1,564,933$ \\
\hline Cerveza & $5 \%$ & 5,735 & 6,093 & 6,452 & 7,169 & 6,954 & 7,312 & 7,886 & 7,169 & 7,312 & 7,240 & 7,456 & 7,886 & 84,663 \\
\hline Whisky & $4 \%$ & 4,568 & 4,854 & 5,139 & 5,710 & 5,539 & 5,824 & 6,281 & 5,710 & 5,824 & 5,767 & 5,938 & 6,281 & 67,435 \\
\hline Pisco & $3 \%$ & 2,749 & 2,921 & 3,093 & 3,436 & 3,333 & 3,505 & 3,780 & 3,436 & 3,505 & 3,471 & 3,574 & 3,780 & 40,584 \\
\hline Licores y cremas & $5 \%$ & 5,628 & 5,980 & 6,332 & 7,035 & 6,824 & 7,176 & 7,739 & 7,035 & 7,176 & 7,106 & 7,317 & 7,739 & 83,086 \\
\hline Bebidas sin alcohol & $2 \%$ & 2,493 & 2,649 & 2,805 & 3,117 & 3,023 & 3,179 & 3,428 & 3,117 & 3,179 & 3,148 & 3,241 & 3,428 & 36,808 \\
\hline Insumos de cocktelería & $1 \%$ & 1,195 & 1,270 & 1,344 & 1,494 & 1,449 & 1,524 & 1,643 & 1,494 & 1,524 & 1,509 & 1,553 & 1,643 & 17,640 \\
\hline Insumos de Cocina & $5 \%$ & 4,890 & 5,195 & 5,501 & 6,112 & 5,929 & 6,235 & 6,724 & 6,112 & 6,235 & 6,173 & 6,357 & 6,724 & 72,186 \\
\hline Hielo & $0 \%$ & 269 & 286 & 303 & 336 & 326 & 343 & 370 & 336 & 343 & 340 & 350 & 370 & 3,971 \\
\hline Cigarros & $0 \%$ & 367 & 390 & 413 & 459 & 445 & 468 & 505 & 459 & 468 & 464 & 477 & 505 & 5,421 \\
\hline Utensilios de bar & $0 \%$ & 186 & 198 & 210 & 233 & 226 & 237 & 256 & 233 & 237 & 235 & 242 & 256 & 2,750 \\
\hline Cristalería, menaje & $0 \%$ & 161 & 171 & 181 & 201 & 195 & 205 & 221 & 201 & 205 & 203 & 209 & 221 & 2,378 \\
\hline Movilidad de Compras & $0 \%$ & 163 & 173 & 184 & 204 & 198 & 208 & 224 & 204 & 208 & 206 & 212 & 224 & 2,408 \\
\hline COSTO DE VENTAS AÑO 3 & & 28,405 & 30,180 & 31,956 & 35,506 & 34,441 & 36,217 & 39,057 & 35,506 & 36,217 & 35,861 & 36,927 & 39,057 & 419,331 \\
\hline VENTAS año 4 - incemento 10 & & 116,608 & 123,896 & 131,184 & 145,760 & 141,387 & 148,675 & 160,336 & 145,760 & 148,675 & 147,218 & 151,591 & 160,336 & $1,721,427$ \\
\hline Cerveza & $5 \%$ & 6,309 & 6,703 & 7,097 & 7,886 & 7,649 & 8,043 & 8,674 & 7,886 & 8,043 & 7,964 & 8,201 & 8,674 & 93,129 \\
\hline Whisky & $4 \%$ & 5,025 & 5,339 & 5,653 & 6,281 & 6,093 & 6,407 & 6,909 & 6,281 & 6,407 & 6,344 & 6,532 & 6,909 & 74,179 \\
\hline Pisco & $3 \%$ & 3,024 & 3,213 & 3,402 & 3,780 & 3,667 & 3,856 & 4,158 & 3,780 & 3,856 & 3,818 & 3,931 & 4,158 & 44,642 \\
\hline Licores y cremas & $5 \%$ & 6,191 & 6,578 & 6,965 & 7,739 & 7,507 & 7,893 & 8,513 & 7,739 & 7,893 & 7,816 & 8,048 & 8,513 & 91,394 \\
\hline Bebidas sin alcohol & $2 \%$ & 2,743 & 2,914 & 3,085 & 3,428 & 3,325 & 3,497 & 3,771 & 3,428 & 3,497 & 3,463 & 3,565 & 3,771 & 40,489 \\
\hline Insumos de cocktelería & $1 \%$ & 1,314 & 1,397 & 1,479 & 1,643 & 1,594 & 1,676 & 1,807 & 1,643 & 1,676 & 1,659 & 1,709 & 1,807 & 19,404 \\
\hline Insumos de Cocina & $5 \%$ & 5,379 & 5,715 & 6,051 & 6,724 & 6,522 & 6,858 & 7,396 & 6,724 & 6,858 & 6,791 & 6,992 & 7,396 & 79,405 \\
\hline Hielo & $0 \%$ & 295.91 & 314.40 & 332.89 & 369.88 & 358.79 & 377.28 & 406.87 & 369.88 & 377.28 & 373.58 & 384.68 & 406.87 & 4,368 \\
\hline Cigarros & $0 \%$ & 403.95 & 429.20 & 454.45 & 504.94 & 489.79 & 515.04 & 555.44 & 504.94 & 515.04 & 509.99 & 525.14 & 555.44 & 5,963 \\
\hline Utensilios de bar & $0 \%$ & 204.90 & 217.70 & 230.51 & 256.12 & 248.44 & 261.24 & 281.73 & 256.12 & 261.24 & 258.68 & 266.37 & 281.73 & 3,025 \\
\hline Cristalería, menaje & $0 \%$ & 177.20 & 188.27 & 199.35 & 221.50 & 214.85 & 225.93 & 243.64 & 221.50 & 225.93 & 223.71 & 230.36 & 243.64 & 2,616 \\
\hline Movilidad de Compras & $0 \%$ & 179.45 & 190.66 & 201.88 & 224.31 & 217.58 & 228.79 & 246.74 & 224.31 & 228.79 & 226.55 & 233.28 & 246.74 & 2,649 \\
\hline COSTO DE VENTAS AÑO 4 & & 31,246 & 33,198 & 35,151 & 39,057 & 37,885 & 39,838 & 42,963 & 39,057 & 39,838 & 39,448 & 40,619 & \begin{tabular}{|c|}
42,963 \\
\end{tabular} & 461,264 \\
\hline
\end{tabular}


ANEXO $N^{\circ}$ 9: Cronograma de amortización

\begin{tabular}{|c|c|c|c|c|c|}
\hline Nro Cuota & Principal & Interes & Amortizacion & Cuota & Saldo \\
\hline 0 & & & & & 70,903 \\
\hline 1 & 70,903 & 673 & 1,477 & 2,150 & 69,425 \\
\hline 2 & 69,425 & 659 & 1,477 & 2,136 & 67,948 \\
\hline 3 & 67,948 & 645 & 1,477 & 2,122 & 66,471 \\
\hline 4 & 66,471 & 631 & 1,477 & 2,108 & 64,994 \\
\hline 5 & 64,994 & 617 & 1,477 & 2,094 & 63,517 \\
\hline 6 & 63,517 & 603 & 1,477 & 2,080 & 62,040 \\
\hline 7 & 62,040 & 589 & 1,477 & 2,066 & 60,563 \\
\hline 8 & 60,563 & 575 & 1,477 & 2,052 & 59,085 \\
\hline 9 & 59,085 & 561 & 1,477 & 2,038 & 57,608 \\
\hline 10 & 57,608 & 547 & 1,477 & 2,024 & 56,131 \\
\hline 11 & 56,131 & 533 & 1,477 & 2,010 & 54,654 \\
\hline 12 & 54,654 & 519 & 1,477 & 1,996 & 53,177 \\
\hline 13 & 53,177 & 505 & 1,477 & 1,982 & 51,700 \\
\hline 14 & 51,700 & 491 & 1,477 & 1,968 & 50,223 \\
\hline 15 & 50,223 & 477 & 1,477 & 1,954 & 48,745 \\
\hline 16 & 48,745 & 463 & 1,477 & 1,940 & 47,268 \\
\hline 17 & 47,268 & 449 & 1,477 & 1,926 & 45,791 \\
\hline 18 & 45,791 & 435 & 1,477 & 1,912 & 44,314 \\
\hline 19 & 44,314 & 420 & 1,477 & 1,898 & 42,837 \\
\hline 20 & 42,837 & 406 & 1,477 & 1,884 & 41,360 \\
\hline 21 & 41,360 & 392 & 1,477 & 1,870 & 39,883 \\
\hline 22 & 39,883 & 378 & 1,477 & 1,856 & 38,406 \\
\hline 23 & 38,406 & 364 & 1,477 & 1,842 & 36,928 \\
\hline 24 & 36,928 & 350 & 1,477 & 1,828 & 35,451 \\
\hline 25 & 35,451 & 336 & 1,477 & 1,814 & 33,974 \\
\hline 26 & 33,974 & 322 & 1,477 & 1,800 & 32,497 \\
\hline 27 & 32,497 & 308 & 1,477 & 1,785 & 31,020 \\
\hline 28 & 31,020 & 294 & 1,477 & 1,771 & 29,543 \\
\hline 29 & 29,543 & 280 & 1,477 & 1,757 & 28,066 \\
\hline 30 & 28,066 & 266 & 1,477 & 1,743 & 26,588 \\
\hline 31 & 26,588 & 252 & 1,477 & 1,729 & 25,111 \\
\hline 32 & 25,111 & 238 & 1,477 & 1,715 & 23,634 \\
\hline 33 & 23,634 & 224 & 1,477 & 1,701 & 22,157 \\
\hline 34 & 22,157 & 210 & 1,477 & 1,687 & 20,680 \\
\hline 35 & 20,680 & 196 & 1,477 & 1,673 & 19,203 \\
\hline 36 & 19,203 & 182 & 1,477 & 1,659 & 17,726 \\
\hline 37 & 17,726 & 168 & 1,477 & 1,645 & 16,248 \\
\hline 38 & 16,248 & 154 & 1,477 & 1,631 & 14,771 \\
\hline 39 & 14,771 & 140 & 1,477 & 1,617 & 13,294 \\
\hline 40 & 13,294 & 126 & 1,477 & 1,603 & 11,817 \\
\hline 41 & 11,817 & 112 & 1,477 & 1,589 & 10,340 \\
\hline 42 & 10,340 & 98 & 1,477 & 1,575 & 8,863 \\
\hline 43 & 8,863 & 84 & 1,477 & 1,561 & 7,386 \\
\hline 44 & 7,386 & 70 & 1,477 & 1,547 & 5,909 \\
\hline 45 & 5,909 & 56 & 1,477 & 1,533 & 4,431 \\
\hline 46 & 4,431 & 42 & 1,477 & 1,519 & 2,954 \\
\hline 47 & 2,954 & 28 & 1,477 & 1,505 & 1,477 \\
\hline 48 & 1,477 & 14 & 1,477 & 1,491 & -0 \\
\hline
\end{tabular}

